Max-Planck-Institut für demografische Forschung

Max Planck Institute for Demographic Research

Konrad-Zuse-Strasse 1 - D-18057 Rostock = Germany = Tel +49 (0) 3812081 - 0 - Fax +49 (0) 3812081 - 202 - www.demogr.mpg.de

MPIDR Working Paper WP 2019-023 I November 2019

\title{
New opportunities for comparative male fertility research: Insights from a new data resource based on high-quali- ty birth registers
}

Christian Dudel I dudel@demogr.mpg.de

Sebastian Klüsener I sebastian.kluesener@bib.bund.de

This working paper has been approved for release by: Peter Eibich (eibich@demogr.mpg.de), Deputy Head of the Research Group: Labor Demography.

(C) Copyright is held by the authors.

Working papers of the Max Planck Institute for Demographic Research receive only limited review. Views or opinions expressed in working papers are attributable to the authors and do not necessarily reflect those of the Institute. 


\title{
New opportunities for comparative male fertility research: Insights from a new data resource based on high-quality birth registers
}

\author{
${\text { Christian } \text { Dudel }^{* 1} \text { and Sebastian Klüsener }}^{\dagger 1,2,3}$ \\ ${ }^{1}$ Max Planck Institute for Demographic Research \\ ${ }^{2}$ Federal Institute for Population Research \\ ${ }^{3}$ Vytautas Magnus University
}

\begin{abstract}
Obtaining cross-country comparative perspectives on male fertility has long been difficult, as male fertility is usually less well registered than female fertility. This paper presents analyses based on a new male fertility database providing data on more than 330 million live births. This new resource, made available in the Human Fertility Collection, allows for the first time a comparative perspective on male fertility in high-income countries using high-quality birth register data. Contrasting male and female fertility trends across 17 countries, we show that trends in disparities between male and female period fertility rates are driven to a large degree by the interplay of parental age and cohort size differences. For parental age differences at childbirth, we observe a tendency toward smaller disparities, except in Eastern Europe. This observation fits with expectations based on gender theories. However, variation across countries also seems to be driven by factors other than gender equality.
\end{abstract}

\footnotetext{
*Corresponding author; address: Max Planck Institute for Demographic Research, Konrad-Zuse-Str. 1, 18057 Rostock, Germany; email: dudel@ demogr.mpg.de; phone: +49 3812081221

†Email: sebastian.kluesener@bib.bund.de
} 


\section{Toward a comparative assessment of male fertility with birth register data}

While the analysis of female fertility is one of the core topics of demography, fertility among men has received considerably less attention (Coleman 2000). The limited amount of comparative research on male fertility is also remarkable considering the increasing involvement of men in fertility decisions and parenting (Lappegård et al. 2011). A fact that may be surprising to some, but which has long been known in demography (Karmel 1947; Schoen 1985), is that the fertility of males and females sometimes differs significantly in the same population. This pattern has been observed in both high-income and low-income countries by the few existing papers that have compared male and female fertility. For instance, Schoumaker (2019) estimated that in several African countries the total fertility rate of males is up to $50 \%$ higher than the total fertility rate of females. Substantial differences between males and females have also been recorded in the mean age at childbirth. It has, for instance, been shown that in Germany males are on average 3-4 years older than females at childbirth (Dudel and Klüsener 2016). Moreover, according to estimates by Schoumaker (2017), fathers in Mali and Niger are on average up to 12 years older than mothers.

Why male and female fertility can differ substantially with respect to quantum and timing is not yet well understood. Several mechanisms have been proposed to explain differences in fertility levels, including the ratio of males to females of reproductive age (Dudel and Klüsener 2016; Keilman et al. 2014), and gender differences in the timing of births (Schoumaker 2019, 2017). But the impact of each of these and other potential mechanisms on the quantum of male and female fertility has not been thoroughly studied, and the extent of their respective contributions to fertility differentials remains unknown. The question of how the paternal age and the maternal age at childbirth develop jointly over time has also received scant attention. Moreover, there is almost no research on the question of whether men postpone fertility to the same extent as women (for an exception, see Nordfalk et al. 2015), and little is known about trends in parental age differences (for an exception, see Kolk 2015). Parental age differences have been linked to social norms and biological factors (e.g., Presser 1975, Trivers 1972), and it has also been suggested that age differences between parents might be an indicator of shifts in gender relations (Safilios-Rothschild 1972, cited by Presser 1975, Bozon 1991, Kolk 2015). Independent of age differences, the paternal age at childbirth has been shown to be an important predictor of the health outcomes of the offspring (Kong 2012, Khandwala et al. 2017, Paavilainen et al. 2016).

Several potential explanations for the limited research on male fertility have been offered, including a lack of data and data quality issues (Poston et al. 2006). For instance, survey data on the fertility of males is generally considered to be less reliable, as males are prone to underreport their number of children (e.g., Rendall et al. 1999, Vere 2008). However, in recent years, several studies assessing male fertility based on birth register data have been published (Jalovaara et al. 2018, Bagavos and Tragaki 2017, Dudel and Klüsener 2016, UN Department of Economic and Social Affairs 2015, Nordfalk et al. 2015, Nisén et al. 2014, Carmichael 2013, Lappegård et al. 2011, Zhang 2011) that focused on single countries or on comparisons of countries. The comparative studies were, 
however, often limited to a cross-sectional perspective. Moreover, even though register data are usually of higher quality than survey data, they are still not free of problems. A key challenge that frequently arises when researching male fertility using register data is that in many countries, information on the age of the father is missing for a non-negligible share of births (Dudel and Klüsener 2018).

With this paper, we provide for the first time a comparative dataset on male fertility trends for a large number of high-income countries based on birth registration data that are of high quality. Our male fertility dataset covers 17 high-income countries in North America, Europe, Asia, and Oceania (more details are available in the data section). ${ }^{1}$ In total, the dataset contains information on more than 330 million live births. For all countries, we use birth register data, and apply a consistent and thoroughly tested set of methods to deal with data issues. These methods include a recently developed approach for imputing missing information on the age of the father (Dudel and Klüsener 2018). We make the age-specific fertility rates (ASFRs) underlying our analyses freely available online through the Human Fertility Collection (2019; http://www . fertilitydata.org), which accompanies the Human Fertility Database (2019). Additional materials allowing to reproduce the findings of this paper are available through the Open Science Framework: https://osf .io/f26de/.

Exploring the potential of this rich database, we add to the literature by studying two questions regarding male-female differentials in the quantum and the tempo of fertility, using two outcomes that have also been employed in earlier studies. First, we analyze the ratio of the male total fertility rate (TFR) to the female TFR in order to determine to what extent male and female fertility levels differ. We also investigate the potential mechanisms behind these differences. Our analyses suggest that the degree to which male TFRs deviate from female TFRs seems to be driven by the interplay of differences between maternal and paternal ages at childbirth, combined with variation in cohort sizes. Second, we shed light on trends in parental age differences in a comparative perspective, and examine whether men postpone fertility to the same extent as women. We find that in recent years, fertility postponement has generally been more pronounced among women than among men, which has resulted in the age differences between fathers and mothers becoming smaller. This finding generally fits with gender theories about the shifting roles of women in the gender revolution (Goldscheider et al. 2015, Klesment and Van Bavel 2017). The only exception to this pattern is observed in Eastern Europe, where processes of societal restoration (Fodor and Balogh 2010) have been accompanied by increases in age differences. Variation of age differences across countries and cultures, in contrast to trends over time, does not match expectations based on gender theories, though.

Before presenting our results, we first review the explanations and the mechanisms driving differences in the quantum and the timing of male and female fertility. We then provide an overview of our new database and its sources, and of the methods we used for preparing the data. In the outlook section, we discuss the substantial analytical potential our new male fertility database offers.

\footnotetext{
${ }^{1}$ For Germany, we provide outcomes for total Germany as well as results for the formerly divided eastern and western parts of the country.
} 


\section{Differences in quantum of male and female fertility}

The fertility levels of males and females, as measured by the total fertility rate (TFR) or cohort fertility rate (CFR), can differ substantially, and male fertility can be both lower and higher than female fertility. Zhang (2011) found that in the majority of 43 countries across the globe, levels of male fertility were lower than levels of female fertility; but also that when levels of fertility were high, male fertility tended to be relatively high. The latter finding is consistent with the results of Schoumaker $(2019,2017)$. From a demographic perspective, such disparities can be driven by three main factors: first, differences in the population sizes of males and females, i.e., in the sex ratio, which can affect both TFR and CFR differences; second, age differences between mothers and fathers in interplay with variation in cohort sizes (affecting the TFR and the CFR); and, third, gender differences in tempo effects, which can impact gender differences in the TFR, but not in the CFR.

Differences in the sex ratio of females and males of reproductive age can occur as a result of different processes. One potential contributor to these differences is the sex ratio at birth. For many populations, the sex ratio at birth in non-crisis situations is at around 105 males per 100 females (Markle 1974; Lazarus 2002). ${ }^{2}$ To see how this can affect fertility levels, consider a simple hypothetical scenario that ignores mortality, and in which there is only one cohort of males and females having children with partners of the same cohort. As the number of births would be the same for males and females, the numerator of the average number of children would also be the same. But the denominators would differ because of the sex ratio at birth, and the average number of children among males would be lower by a factor of 100/105.

Two other factors shaping sex ratios are differential mortality and sex-selective migration patterns. Low male-to-female sex ratios in the general population due to male survival disadvantages can occur as the result of wars (Dinkel and Milenovic 1993) or a higher tendency among males to engage in health adverse behavior. An extreme example of the latter factor is the high premature male mortality in Eastern Europe due to alcohol consumption (Leon et al. 2009; Grigoriev et al. 2015). As migration patterns are often sex-selective, they can also affect sex ratios. In eastern Germany, for example, women were more likely than men to leave the region for a period of time following German reunification, which resulted in high male-to-female sex ratios in the population of reproductive age (Kröhnert and Vollmer 2012). By contrast, international migration has long been male-dominated, although tendencies toward a feminization of migration have been observed in recent decades (Lutz 2010).

Age differences between mothers and fathers can affect male-female differences in fertility when there is variation in cohort sizes (Schoen 1985). Generally, the reproductive age range of men is longer than that of women (Dudel and Klüsener 2016); and fathers are, on average, older than mothers (e.g., Kenrick and Keefe 1992). If mothers and fathers come from different birth cohorts and there is variation in cohort size, the denominators of

\footnotetext{
${ }^{2}$ In some populations with a strong son preference, such as India or South Korea, we have witnessed much higher sex ratios at birth in recent decades, which were achieved through modern reproductive technologies and sex-selective abortions (see, e.g., Kashyap 2017). However, the populations covered in our study did not experience strong deviations from the typical sex ratio at birth for the observed cohorts (e.g., Mathews and Hamilton 2005 for the U.S.), with the exception of the Taiwanese population in certain years (Human Mortality Database 2019).
} 
male and female fertility rates will differ. ${ }^{3}$ For instance, Schoumaker (2017) has shown that the rapid expansion of African populations can lead to male TFR levels increasing more than female TFR levels, as fathers tend to come from the older and smaller cohorts (see also Field 2016). A related pattern with potential implications for male/female differences in fertility outcomes is the transition from the baby boomer to the baby bust generation, which many high-income countries experienced in the mid-20th century. Such a population trend might cause male fertility to decrease relative to female fertility, as fathers are more likely to belong to the older, bigger cohorts.

Tempo effects might also contribute to gender differences in fertility, at least for periodbased measures like the TFR. Period measures are affected not only by changes in the quantum of births, but also by changes in the timing of births (tempo effects), as has been extensively demonstrated for females in the context of fertility postponement and delayed childbearing (e.g., Kohler et al. 2002; see the next section for a more detailed discussion). If these tempo effects differ between males and females, then period-based measures of fertility levels will differ accordingly. To what extent this dynamic drives fertility differentials between males and females has, however, rarely been studied. We are aware of one only one previous paper on this topic: namely, the aforementioned study by Nordfalk et al. (2015). Using Danish data and the method developed by Bongaarts and Feeney (1998) to control for fertility postponement, they found for the 1980-2010 period that fertility postponement reduced the male TFR as well as the female TFR. But as men had lower levels of fertility postponement than women, the downward-depressing effects were 0.1 TFR points lower among males than among females.

\section{Differences in the timing of male and female fertility}

\section{Why are fathers older on average? Social status, biological perspec- tives, and limiting factors}

Within human populations, fathers are, on average, older than mothers. This pattern seems to hold across time and space (Kenrick and Keefe 1992; Schoumaker 2017, 2019). For instance, in high-income countries, males are, on average, two to four years older at childbirth than their female partners (Kolk 2015, Dudel and Klüsener 2016). Intertwined social and biological perspectives have been offered to explain why fathers tend to be older than mothers.

From a social status perspective, it can be argued that women have, at least historically, had fewer opportunities than men to acquire social status, be it through education or work (Presser 1975). Thus, it was common for a woman to secure her social status through a partnership with a man (Blake 1974, cited by Presser 1975). A related point is that a man

\footnotetext{
${ }^{3}$ As a simple example of the effect of cohort size, consider a hypothetical scenario in which only men belong to a cohort born in year $C$. These men only have children with women of a younger cohort born in year $C+z$. Let $B$ denote the total number of children they have. $N$ is the size of the cohort of men, and $N^{\prime}$ is the size of the cohort of women. The crude birth rate is $B / N$ for men and is $B / N^{\prime}$ for women. The ratio of these rates is $N^{\prime} / N$; i.e., the size of the cohort of women relative to the size of the cohort of men. If there are more women than men, the ratio of the birth rates will be larger than one; which means that male fertility, as measured through the crude birth rate, is higher than female fertility.
} 
who is older than his female partner is likely to be at an advantage compared to men who are the same age as the woman, as an older man is likely to be more established in his life, which reduces the couples uncertainty about their future social status trajectory (Presser 1975). This dynamic has probably contributed to the emergence of a pattern in which a woman is less likely to partner with a younger man (Bozan 1991). Moreover, especially in societies with a strong patriarchal orientation, social norms regarding male and female reproductive behavior have been instrumented to stabilize existing sex- and age-related social inequalities (see, e.g., Szołtysek et al. 2017).

In addition to social mechanisms, biological mechanisms have been discussed as potential explanations for the age gap between fathers and mothers. Proponents of the evolutionary perspective of parental investment (Trivers 1972) have argued that both females and males have to be selective in their partner choices, as among humans, it is usually necessary for both partners to invest heavily in their offspring (Kenrick and Keefe 1992). However, while the investments of females are high in terms of bodily resources (pregnancy and lactation), the investments of males are more indirect (providing resources such as food or security). Based on this perspective of differential investments, it has been argued that when choosing a partner, females are more focused on whether the male is able to provide indirect resources, while males are more focused on whether the female is healthy and has reproductive potential (Kenrick and Keefe 1992). Among men, social status and, thus, the ability to provide resources generally increases with age, which tends to put older males at an advantage. Among women, on the other hand, biological fitness tends to decrease with age, which tends to put younger females at an advantage.

However, from a theoretical point of view, it is also possible to identify mechanisms that could lead to partners having more similar ages. It has been shown that the relationships of partners with shared characteristics tend to be of higher quality (e.g., Gaunt 2006). Age homogamy not only increases the likelihood of having similar attitudes, it decreases the likelihood of unequal power relations emerging (see Dribe and Stanfors 2017). Thus, under conditions in which there are no strong factors favoring age heterogamy in couples, many individuals might prefer to partner with a person of a similar age, as doing so may increase the quality and the durability of the relationship. Moreover, having a stable relationship could, in turn, have implications for the couples ability to support the development of their potential offspring (see also Kenrick and Keefe 1992).

\section{The gender revolution, fertility postponement, and changes in age dif- ferences}

While fathers are, on average, older than mothers, there has been considerable heterogeneity in these age differences across time and space. Historical research on the age at marriage has shown for a number of European countries that age differences within couples were larger in the 19th and the early 20th century than they were in recent years (Presser 1975, van Poppel et. al. 2001). ${ }^{4}$ Several partly related factors might have caused age differences to decline in high-income countries. These include the establishment of the modern

\footnotetext{
${ }^{4}$ However, even earlier evidence of rather small age differences for France for the 18th century suggest that these large differences were not necessarily long-standing patterns (Bozon 1991).
} 
welfare state, the gender revolution (Goldscheider et al. 2015), and differential levels of postponement of fertility.

The rise of the modern welfare state has likely contributed to the decrease in the relevance of a set of factors that would otherwise tend to encourage greater age differences within couples. Having access to welfare state benefits can make a woman less dependent on her male partner as a provider of support (Esping-Andersen 1999; McLaughlin and Glenndinning 1994). Moreover, modern health care systems and reproductive technologies have led to a decrease in the relevance of natural fecundity over the life course for successful reproduction even though assisted attempts to have a child do not always result in a birth (Gameiro and Finnigan 2017; Leridon 2004). Under these circumstances, age heterogamy might be less advantageous, which could lead to a reduction in the age differences between partners.

The gender revolution has substantially increased womens opportunities to obtain social status through their own education and work (Goldscheider et al. 2015). Meanwhile, female enrollment in higher education has risen considerably, surpassing that of men in many countries (Grow et al. 2017). This trend toward gender equality might affect age differences in two ways. First, tertiary education extends well into early adulthood and the ages at which family formation typically occurs, while also bringing together individuals in a rather limited age range, which could lead to increased homogamy (Kolk 2015). Second, as it becomes increasingly difficult for a woman to find a partner with similar or higher educational attainment, she may be willing to marry a man with a lower educational level (Esteve et al. 2016; Klesment and Van Bavel 2017). If women are accepting male partners with lower educational attainment, these men might also be younger than potential partners with similar or higher educational attainment.

Differential patterns of postponement of fertility to older ages is a mechanism that could affect differences in the mean paternal and maternal ages at childbirth. If, for instance, postponement was more pronounced among females than among males, the mean age at childbirth would increase faster for females than for males. While fertility postponement among females has received considerable attention in the demographic literature (Kohler et al. 2002; Sobotka 2004, Fox et al. 2018), this has not been the case for males (Nordfalk et al. 2015). A potential mechanism for gender differences in postponement could be increased educational hypergamy, as described above. If women who are highly educated tend to postpone childbirth and have children with partners who have similar or lower educational levels and are of similar ages, postponement among women would not necessarily translate into a similar degree of postponement among males.

Despite these factors favoring age homogamy, women and especially mothers are still subject to gender discrimination, which can limit their career opportunities and compensation (e.g., Budig and England 2001). This discrimination might incentivize women to seek out somewhat older partners, particularly if they plan to have children. Nevertheless, as age-homogamous couples tend to have relationships of higher quality (Gaunt 2006), a woman might prefer to marry a man who is not substantially older. 
Table 1: List of countries and years covered, the cumulative number of births covered for each country, and the smallest and the largest annual proportion of births with missing paternal age. For the French birth register data, missing paternal ages were imputed by the French Statistical office; thus, the raw data we used did not show any missing values.

\begin{tabular}{lrrrr}
\hline \hline Country & Years & \# births & Min. \% missing & Max. \% missing \\
\hline Australia & $1975-2014$ & $15,802,285$ & $<1$ & $<1$ \\
Canada & $1974-2016$ & $10,312,460$ & 4 & 1 \\
Denmark & $1986-2015$ & $1,899,172$ & 10 & 47 \\
England and Wales & $1982-2016$ & $23,345,243$ & 5 & 8 \\
Estonia & $1989-2014$ & 391,541 & 5 & 17 \\
Finland & $1987-2015$ & $1,741,444$ & 1 & 4 \\
France & $1998-2013$ & $12,507,805$ & - & - \\
Germany & $1991-2013$ & $20,905,142$ & 7 & 22 \\
Hungary & $1970-2014$ & $5,531,052$ & 2 & 14 \\
Italy & $1999-2014$ & $8,743,545$ & 5 & 11 \\
Japan & $2009-2014$ & $6,262,714$ & 2 & 2 \\
Poland & $1986-2014$ & $12,735,720$ & 3 & 5 \\
Portugal & $1980-2015$ & $4,128,924$ & 2 & 5 \\
Spain & $1975-2014$ & $18,572,616$ & 1 & 3 \\
Sweden & $1968-2015$ & $5,010,338$ & $<1$ & 5 \\
Taiwan & $1998-2014$ & $3,820,183$ & $<1$ & 23 \\
USA & $1969-2015$ & $179,487,897$ & 8 & 1 \\
\hline \hline
\end{tabular}

\section{The new database on male fertility}

\section{Data}

To investigate how and why male and female fertility differ, we created a large, novel database on male fertility. We make the database available as part of the Human Fertility Collection. In this database, we provide annual age-specific fertility rates (ASFRs) for men based on counts of live births for the following 17 countries and years: Australia, 19752014; Canada, 1974-2011; Denmark, 1986-2015; England and Wales, 1982-2016; Estonia, 1989-2014; Finland, 1987-2015; France, 1998-2013; eastern, western, and total Germany, 1991-2013; Hungary, 1970-2014; Italy, 1999-2014; Japan, 2009-2016; Poland, 1986-2014; Portugal, 1980-2015; Spain, 1975-2014; Sweden, 1968-2015; Taiwan 1998-2014; and the United States, 1969-2015. An overview of the data is provided in Table 1. It shows for each country the years covered, the total number of births on which the ASFRs are based, and the smallest and the largest annual proportion of births with unknown age of the father (see below for a discussion). For a complete description of the data and the underlying methods, see Dudel and Klüsener (2019).

The data were obtained from the national statistical offices, and the U.S. data were provided by the National Bureau of Economic Research. All of the birth counts were derived from birth registers and were based on complete enumeration, except for the U.S. 
for the years from 1969 to $1984 .{ }^{5}$ Population exposure data was taken from the Human Mortality Database (2019). The raw data for western, eastern, and total Germany were obtained from data collected by Dudel and Klüsener (2016), with some minor modifications (see below).

For all countries, we provide data by single-year ages for the age range of 15 to 59 years. We chose 59 as the highest age, as fathers aged 59 or older are rare. The highest proportion of fathers aged 59+ across all of our countries and years was $0.2 \%$ in Italy in 1999, and the proportion was considerably lower for most other countries and years. Generally, it can be observed that the age-specific fertility rates of men quickly decline to very low levels above age 45, at least in high-income countries (see also Nisén 2014, Nordfalk et al. 2015). Thus, while a share of male fertility occurs at higher ages, it appears that male fertility is mostly concentrated over an age range of roughly 25 years (age 20 to age 45) despite claims to the contrary sometimes made in the literature (see Poston et al. 2006 for a discussion). This observation can be explained by decreasing male fecundity and the declining fecundity of the female partner (who is, on average, two to four years younger than her male partner), as well as age norms regarding childbearing (Billari et al. 2011).

For Italy and Japan, not all live births are included in the raw data obtained from official sources. In Italy, births are recorded at the municipality level. The municipalities can register each birth using a long or a short form. Only the long form includes the age of the father. The data we analyze only cover births recorded with the long form, which is used in most municipalities. The short form is usually employed by smaller municipalities. Over time, however, the proportion of municipalities that register births using the short form seems to have decreased. This can be assessed through comparison with the Human Fertility Database (HFD) that covers all births regardless of whether the long or the short form is used. In our data, by contrast, between 6,126 and 22,805 births, or 1-4\% of births, are missing, depending on the year. For Japan, the data we have access to cover marital births only. However, as the proportion of non-marital births is rather low in Japan, the difference between our data and the HFD data amounts to around 23,000 births, or about $2 \%$ of births per year. To deal with these coverage issues, we assume that the birth counts by maternal age recorded in the HFD are correct, and add the missing births by maternal age to our raw data.

\section{Methods for data preparation}

As Dudel and Klüsener (2018) pointed out, one of the biggest challenges researchers face when studying male fertility are missing values for the age of the father, as in many datasets, the paternal age is not recorded for a sizable number of births. For the countries and the years we study, the proportion of missing values ranges from below $1 \%$ (e.g., Sweden, 2002) to $47 \%$ (Denmark, 1994). For some countries, the proportion also varies considerably over time. For instance, in Germany, the highest proportion of missing values

\footnotetext{
${ }^{5}$ Most registers cover births among the resident population. For this reason, some births to fathers might be missing when the mother is living abroad, especially if the child is born abroad. However, the number of such births is very small, and they are likely to be offset to some extent by births to mothers when the father is living abroad.
} 
was recorded in 1999, at 22\%; but the proportion had decreased to $7 \%$ by 2013 . An overview of the proportion of births with missing age of the father by country is given in Table 1.

Missing values might be due to the mother not knowing the father, or not wanting to provide information on the father. Depending on the country and the year, other factors may also play an important role. For instance, in Germany until 1999, the paternal age was recorded for marital births only, and not for non-marital births (Dudel and Klüsener 2016). Conversely, in Sweden, the proportion of missing values has generally been very low, at around 1\%; but was around 5\% in 1998. This pattern can be explained by procedural changes in Sweden that led to the statistics for 1998 being derived from the birth register very early in 1999. At that time, paternal ages were still missing for a considerable share of non-marital births, as there is a fixed period after the initial registration during which the mother can add missing required information on the father (Statistics Sweden, personal correspondence, February 16, 2018). Among the factors that might lead to missing information on the father are fertility within same-sex couples and fatherless reproduction due to assisted reproductive technologies. However, as the number of such births is currently relatively low, we assume for our calculations that all births have a mother and a father. 6

One approach for dealing with the missing values is to impute them using what we call an unconditional approach. This approach which is, for example, being used by the Demographic Yearbook of the United Nations (UN Department of Economic and Social Affairs 2015) assumes that the unobserved paternal ages have the same age distribution as the observed paternal ages. However, this approach is likely to derive paternal ages for the missing values that are too high, as it does not take into account research findings indicating that paternal ages are particularly likely to be missing for young mothers (Dudel and Klüsener 2018).

In this paper, we use the conditional imputation approach, which is generally superior to the unconditional approach, as demonstrated by Dudel and Klüsener (2018). It imputes the missing paternal ages conditional on the age of the mother. The intuition underlying this approach is that the age of the mother is an excellent predictor of the paternal age, and thus should be included when imputing the paternal age. Here, we explain this approach using a simple case in which the maternal age is recorded for all births, while the paternal age is missing for some births, in the birth register data of a given country and year. For each maternal age (e.g., 30) this approach starts from the number of births for which the age of the father is missing. To impute the paternal ages for these births, the conditional age distributions of fathers, assuming that the mother is aged 30, are calculated. The births to mothers aged 30 and the missing paternal ages are then assigned paternal ages according to this distribution. If, for example, there are 1,000 births with a maternal age of 30 and a missing paternal age, and $10 \%$ of the births to mothers aged 30 with a known paternal age are to fathers aged 33 , then $10 \%$, or 100 , of the births with a missing paternal age will be assigned a paternal age of 33 years. For a more detailed discussion, see Dudel and Klüsener (2019).

\footnotetext{
${ }^{6}$ In 2010, for instance, the proportion of births attributable to all assisted reproductive technologies was between $1 \%$ and $2 \%$ in the countries we study (Dyer et al. 2016).
} 
For some countries, additional methods were applied. Here, we provide only an overview. More detailed discussions can be found in Dudel and Klüsener (2019).

For a number of the countries we study, the raw data covers an age range that is more narrow than 15 to 59 years. This is the case for England and Wales (15-55), France (17-46), western, eastern, and total Germany (17-59), Japan (17-59), Portugal (15-49), and Sweden (15-50). For some of the countries, the age range differs due to data privacy concerns. Some of the statistical offices decided to restrict the age range because the cross-tabulations of maternal and paternal ages would otherwise result in cell counts below a certain threshold (e.g., three births). For these countries, we used the penalized composite link model (PCLM) of Rizzi, Gampe, and Eilers (2015), as implemented by Pascariu et al. (2018), to split open-ended age intervals into single ages for England and Wales, France, Portugal, and Sweden. For example, for England and Wales, the open-ended interval 55+ was split into single age intervals for ages 55 to 58, and an open-ended interval for ages 59+. For western and eastern Germany and Japan, we split the interval covering age 17 and under by distributing the births to ages 15,16 , and 17 based on the distributions of births for these ages observed for the other countries. However, the number of such births was very low.

For Portugal and Taiwan, we had access to birth counts for five-year age groups only. We first calculated the ASFRs for five-year age groups, and then split them into one-year intervals. For this procedure we also used the PCLM approach. In addition, we had to deal with the exceptional case of Sweden, for which the available data provide the parental ages not at the time of childbirth, but at the end of the year in which the child was born. To account for this, we applied an interpolation method used for this purpose in the HFD (Jasilioniene et al. 2015).

To compare male and female fertility, we also derived ASFRs for women using the same data sources as those we used for men (i.e., births counts from the data obtained from the statistical offices, including the discussed modifications for Italy and Japan; exposures from the HMD). Thus, the ASFRs for men and women are based on the same underlying data. The ASFRs for women are available as part of the replication materials on the Open Science Framework. The differences between the female ASFRs derived from our data and those derived from other data sources like the Human Fertility Database (HFD) are small; thus, using the ASFRs for women derived from the HFD would essentially lead to the same results. For women, we cover the age range between 15 and 49 years.

\section{Contrasting male and female fertility across 17 high-income countries}

\section{Main questions and analytical strategy}

Our analysis will focus on two main questions. First, we will present new findings on trends in quantum differences for 17 high-income countries, showing how the male total fertility rate (TFR) and the female TFR differ. An intuitive and commonly used way to compare male and female fertility levels is to calculate the ratio of the male TFR to the female TFR (e.g., Schoumaker 2019; Keilmann et al. 2014). If this ratio is equal to one, 
the period fertility levels of men and women are the same; if it is higher than one, male fertility is higher; and if it is below one, male fertility is lower. ${ }^{7}$ To disentangle the factors driving the differences, we will also present results on the cohort fertility rate (CFR), which, unlike the TFR, is not affected by tempo effects. Because of the high data demands for the calculation of CFRs, we can study these rates for a few countries only. In addition, we will perform a counterfactual analysis in which we will attempt to disentangle deviations stemming from age differences in couples from deviations resulting from variations in the sex ratios of males and females. This counterfactual analysis can be conducted for all countries.

The second question we intend to analyze focuses on trends in gender differences in fertility timing: to what extent have age differences between mothers and fathers been diminishing over time? This question is based on the theoretical considerations discussed above that posit that increasing gender equality over time might lead to smaller age differences. To address this issue, we focus on differences in the mean age at childbirth between men and women measured in years; an easily interpretable outcome that has been used in the previous literature (e.g., Kolk 2015). We also seek to determine whether more gender-equal countries are indeed at the forefront of this trend. To investigate this question, we group our countries using welfare state typologies (Esping-Andersen 1990, Arts and Gelissen 2002, Aspalter 2006, Fenger 2007) as an orientation: the social democratic Nordic countries (Denmark, Finland, Sweden); the corporatist Western European countries (France; Germany); the rather conservative at least historically Southern European countries (Italy, Portugal, Spain); the former communist countries of Eastern Europe (Estonia, Hungary, Poland); the liberal and predominantly English-speaking countries (Australia, Canada, England and Wales, United States of America); and the East Asian countries (Japan, Taiwan).

\section{Male-female disparities in fertility levels}

In all of the countries, the male TFR trend generally follows the female TFR trend (detailed results for all countries are shown in the appendix, Figure A1-A17). In Sweden, for instance, the male TFR exhibits the same rollercoaster pattern (Hoem 2005) as the female TFR. The Swedish male TFR is, however, lower for almost all years, except for the first two observation years (1968 and 1969). Moreover, the male TFR in Sweden is slightly more volatile than the female TFR; a finding that holds for the majority of the countries we study.

In Figure 1, we report for each country the trend in the ratio of the male to the female TFR, arranged by country group. In the set of countries and years we cover, the ratio of the male TFR to the female TFR ranges from 0.84 (eastern Germany, 1997) to 1.13 (the U.S., 1969). Thus, while male and female fertility levels, as measured by the TFR, appear

\footnotetext{
${ }^{7}$ Specifically, the ratio of the male TFR to the female TFR is closely related to the birth squeeze index $U$ proposed by Schoen (1985), and for the countries we study are very similar. $U$ is defined as $\left[T F R_{m}-\right.$ $\left.T F R_{f}\right] /\left[0.5 * T F R_{m}+0.5 * T F R_{f}\right]$, where $T F R_{m}$ denotes the TFR of males and $T F R_{f}$ is the TFR of females. It differs from the TFR ratio $R=T F R_{m} / T F R_{f}$ by a multiplicative factor $M$ and the constant $1 . M$ is given by $M=0.5[R+1]$. Then $U=[R-1] / M$ and $R=U M+1$. This means that $U$ and $R$ will differ more if $M$ is further away from 1 . But in our analyses, $M$ is usually close to 1 . Thus, for the countries and years we study, $R \approx U+1$ and the TFR ratio and the birth squeeze index can be interpreted in very similar ways.
} 

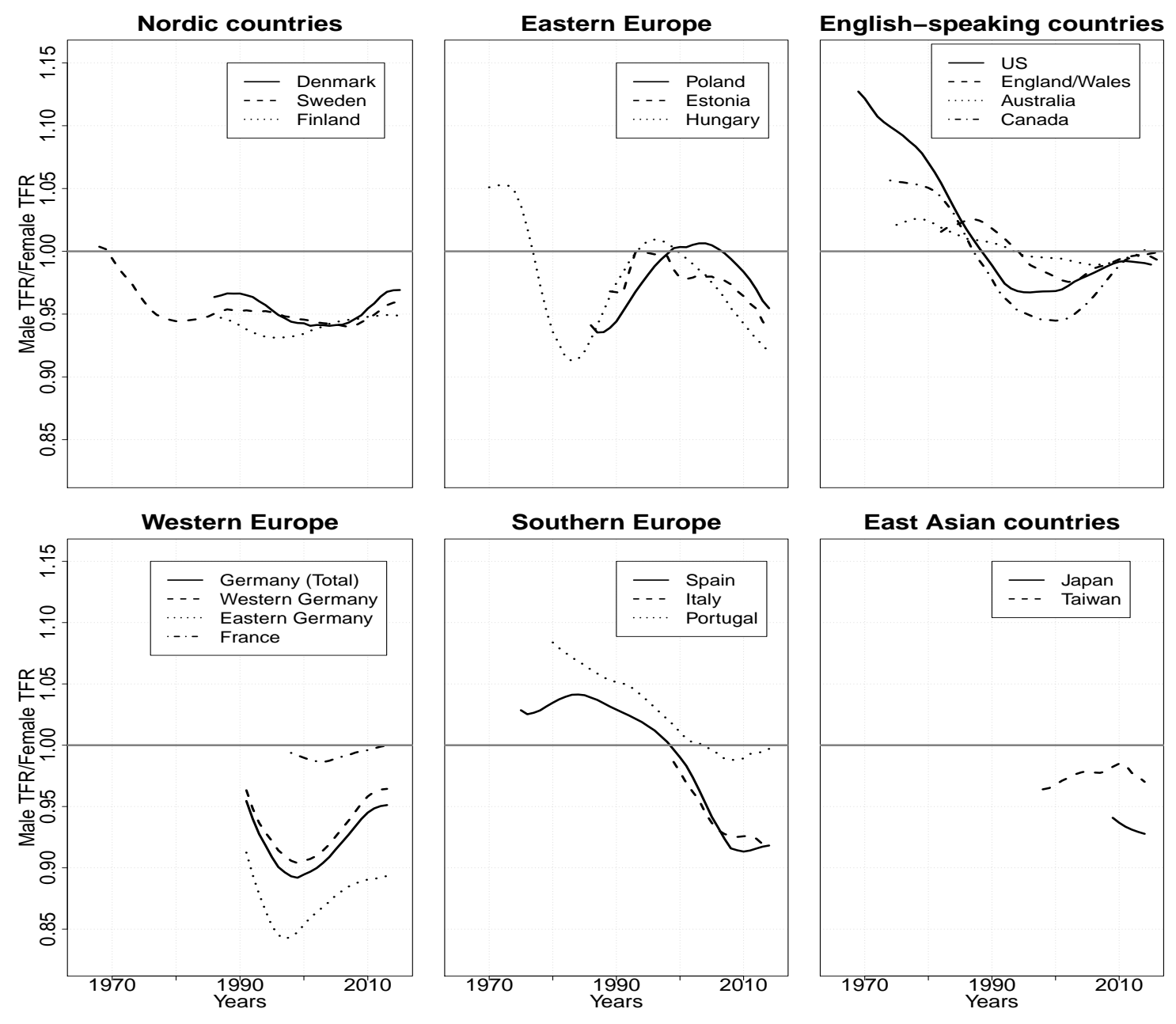

Figure 1: Male/Female TFR ratios by country group. Source: Own calculations.

to be highly correlated, we observe no clear one-to-one relationship between them (see also Karmel 1947). Moreover, there seems to be a tendency for ratios to go from higher to lower over time.

The trends within each of our country groups are mostly consistent. In the Nordic countries we cover, the male fertility level has been relatively constant for the last 30 years at around $95 \%$ of the female fertility level. In the Eastern European countries, the ratio follows a hump-shaped curve: i.e., there was an initial period of decline, which was then followed by an increase and another decline. A surge in the ratio occurred in all three Eastern European countries at the end of the communist period and in the 1990s, and was followed by a decline after 2000 . We will discuss potential explanations for these patterns below. In all three Southern European countries, the TFR ratio dropped considerably. In Portugal and Spain, for which we have longer time series than for Italy, the ratio was above one at the beginning of the observation period. But by the end of the period, the ratio was below one in all three countries, with Italy and Spain displaying particularly low values, at around 0.92. While the pattern in the English-speaking countries is less consistent, we can see that in all four countries the ratio dropped from above one to below one, and then 
recently increased slightly to reach values of around one. In the Western European and the East Asian countries, no clear patterns emerge. This may be because only a few countries and years are observed for these country groups. It is, however, interesting to note that in Germany since 1990, post-communist eastern Germany has followed a U-shaped pattern similar to that of western Germany, but at lower levels. This trend diverges from the hump-shaped patterns we obtained for this period for the post-communist countries of Estonia, Hungary, and Poland.

\section{A cohort perspective on level differences}

As the TFR is affected by tempo effects, it is also of interest to investigate whether and, if so, to what degree differences vary if cohort fertility rates are studied. The time series for a small number of the countries in our sample are long enough to obtain cohort data for at least some cohorts, if we restrict the age range to 15 to 50. These cohort data are derived from period ASFRs based on the assumption that the in- and out-migration levels of men are not selective given their achieved fertility. For Sweden, we can derive CFRs for the cohorts born between 1953 and 1965, as we have data starting from 1968. For the US and Hungary, we can analyze the CFRs for the 1954-1965 and the 1955-1964 birth cohorts, respectively. Our cohort analysis is mainly focused on these three countries, as cohort data is available for only a few or for no cohorts in the other countries. However, we also show results for Canada, Australia, and Spain, as we have relatively long series for these countries as well.

The results are shown in Figure 2. For Sweden, the cohort patterns are very similar to the period patterns. For each cohort, the average number of children is $5 \%$ lower among males than among females. In Hungary, the rollercoaster pattern observed in the period perspective (see Fig. 1) is not visible in the cohort pattern, at least for the birth cohorts we are able to cover (1955 to 1964). The ratio for Hungary is roughly the same as the ratio for Sweden. In the U.S., male fertility was higher than female fertility among the older cohorts (1954 cohort: 104\%), whereas female fertility was higher than male fertility among the younger cohorts (e.g., 1965: 97\%). While these cohort patterns are generally similar to the TFR trends in the U.S., the differences between male and female fertility are less extreme. Overall, the flat CFR ratio for Hungary suggests that the distinctive rollercoaster pattern of the Hungarian TFR ratio stems largely from differences in paternal and maternal age and in postponement patterns. We can also see that the TFR ratio trend in the U.S. has been affected by these factors, while the cohort and the period ratios in Sweden hardly differ.

\section{Counterfactual assessment of period fertility}

To further disentangle the determinants of disparities between male and female fertility for a larger set of countries, we derive male fertility rates for a hypothetical scenario in which all women have their children with men of the same age. This implies that we erase the paternal age information for all births. Then we assume for each birth that the mothers age (e.g., 25) is the same as the fathers age. As a result differences in the reproductive age range, tempo distortions due to postponement, and age differences within couples can no longer affect the fertility differences between males and females. Thus, we are left with 


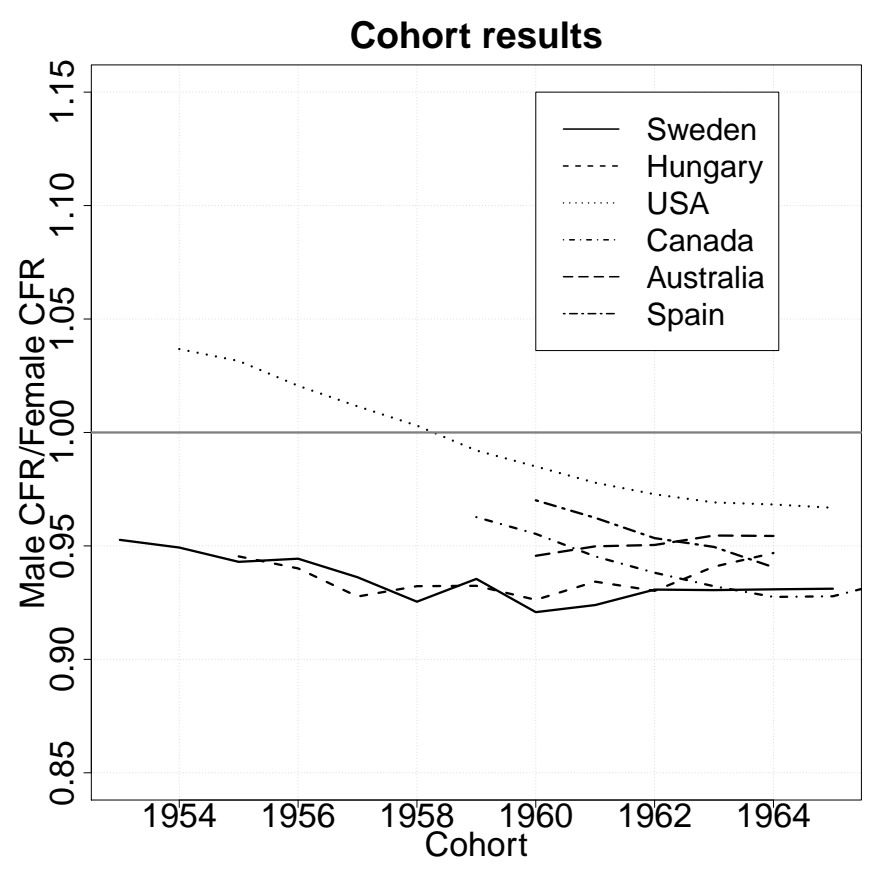

Figure 2: Male/Female Ratio of the Cohort Fertility Rate for Sweden, Hungary, and the U.S. Source: Own calculations.

just the differences that stem from sex ratio differences in each cohort of potential mothers and fathers.

Selected resulting graphs are presented in Figure 3, which covers one country of each country group; while the complete set of graphs are provided in Figures B1-B17 in the appendix. For orientation, we added a line slightly above 0.95 , which would be the TFR ratio if the sex ratio at birth was 105 males to 100 females, and if there was no sex-selective mortality and migration until the end of the reproductive lifespan. If the counterfactual TFR ratio is above or below this line, fertility differences between males and females would likely be driven by imbalanced sex ratios due to migration and/or mortality. Specifically, if the sex ratio at birth was indeed 105 males to 100 females, then a counterfactual TFR ratio above the line would be indicative of excess females due to migration (e.g., more women immigrating than men) and/or mortality (females having higher survival rates); and vice versa. The effects of migration and mortality might also go in the opposite direction (e.g., more men immigrating, but women having higher survival rates), and could even cancel each other out. Figure 3 also shows the observed TFR ratios. If the observed and the counterfactual TFR ratios differ, we can assume that, in addition to migration and mortality, the age differences between mothers and fathers play a role in the fertility differences between males and females.

The counterfactual results for Sweden, Hungary, and the U.S. are close to the results for the CFR ratios. Specifically, for Sweden, the counterfactual differences in male and female fertility are close to the observed ratio, as the latter does not seem to be affected by age differences (the dashed line and the solid line are close), or to be distorted by imbalanced sex ratios due to migration or mortality (the dashed line is on the gray dotted line, slightly 

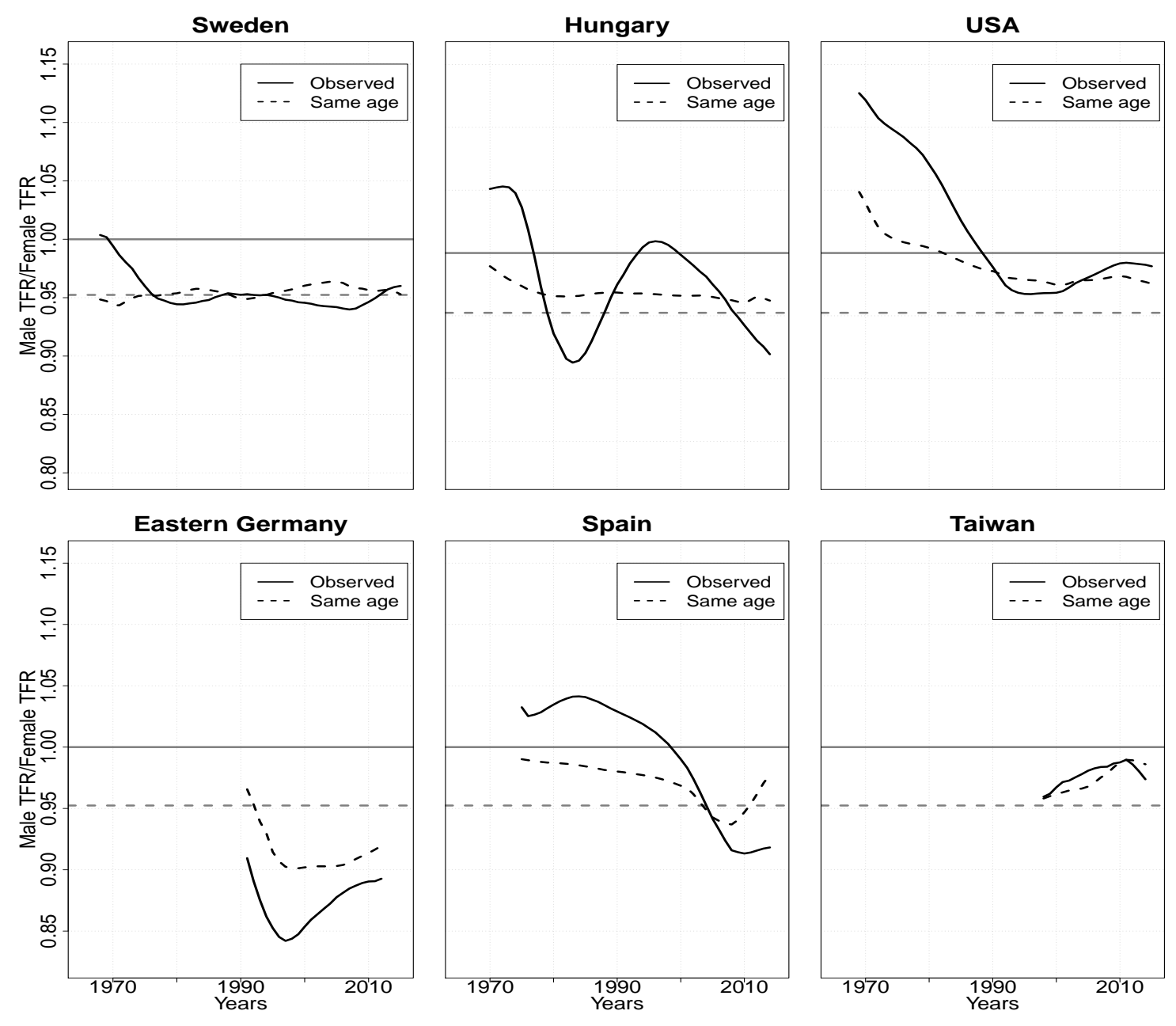

Figure 3: Hypothetical Male/Female TFR ratios in which fathers are assigned the maternal age at birth by country group. Source: Own calculations.

above 0.95 ). The pattern for Hungary seems to be primarily the result of differences in the timing of fertility (the dashed line and the dotted line are close, while the solid line differs considerably), although a minor influence of migration and mortality is visible. Looking at the U.S., we can see that differences in sex ratios likely caused differences in fertility levels, at least before 1990 (the dashed line is getting closer to the dotted line over time); and that age differences had an additional effect (the solid line is above the dashed line before 1990).

For Spain, it appears that age differentials contributed to differences in fertility levels. No such pattern is observed for Taiwan. Interestingly, eastern Germany is the only example shown here with a counterfactual TFR ratio that is mostly below 0.95 , and is thus below the value that would arise if there were no imbalances in the sex ratio due to migration and mortality. As female mortality was considerably lower than male mortality in eastern Germany (Kühn et al. 2019), this leaves migration as the likely cause. Indeed, females have been more likely to leave eastern Germany than males, which has led to an imbalanced sex ratio (Kröhnert and Vollmer 2012). It has been speculated that this imbalance could result 
in fertility being lower for males than for females (Dudel and Klüsener 2016). Overall, our counterfactual analysis suggests that most of the observed temporal variation in TFR ratios can be related to age differences between fathers and mothers who originated from cohorts of different sizes.

\section{Trends in timing of births}

To assess differences in the timing of births, we look at the mean age difference between fathers and mothers. If this difference is positive, males are, on average, older than females. The results are shown in Figure 4 (detailed results are available in the supplementary materials, Figures C1-C17). ${ }^{8}$

When we look at the differences in the mean age at childbirth, we can see that the similarities within our country groups are less visible compared to the outcomes for the TFR ratios. This is perhaps most visible in East Asia. Taiwan in the early 2000s had the largest age differences among our observed countries and periods, with fathers being, on average, four years older than mothers. Meanwhile, the few data points we have for Japan show that the country had the smallest age differences in our dataset, at two years. The volatility of the pattern in Taiwan also stands out: in the late 1990s/early 2000s, the average age difference in that country increased from 3.5 years to more than four years, and then fell back to three years in 2014.

Turning to the Nordic countries, we can see that in Sweden, the mean age difference was close to three years in the late 1960s, and stayed at around that level up to 1980. It declined to 2.8 years between 1980 and 1990, and has been close to that value ever since. But in the other Nordic countries, we detect no coherent pattern for age differences, unlike for differences in fertility levels. While all of the Nordic countries had smaller age differences at the end of the observation period, the trend patterns varied. In Sweden and Finland, the changes were rather smooth. This was not the case in Denmark, which had a much larger age gap than the other two countries before 2000. In 2000, the mean age difference in Denmark was around 3.3 years and almost one year higher than that in Finland (app. 2.4 years). This changed swiftly after 2000, as Denmark experienced a drastic decline in the mean parental age difference at birth. Thus, Denmark, together with Finland, currently has the smallest mean age difference among all of the observed European countries, at around 2.5 years.

When we look at Southern Europe, we also see substantial variation. Italy currently has the largest mean age difference out of all of the Southern European countries, at more than 3.5 years; but the gap in that country has been declining. Currently, the mean age difference is around 3 years in Spain, and is 2.5 years in Portugal. The age gap in Spain today is only slightly smaller than the gap recorded in the late 1970s. The mean age difference in that

\footnotetext{
${ }^{8}$ In interpreting the results, it is important to note that the raw data for Portugal and Taiwan are in five-year age intervals, and that the degree to which we are deriving appropriate numbers by using the splitting approach to estimate data by single-year ages is much more relevant for the paternal age calculations than for the TFR calculations. We investigated the reliability of our approach by aggregating the Spanish data into five-year age groups, and then splitting the data again into single-year age groups. We then compared the derived mean paternal age based on the split data with the age derived from the original data by single-year ages. These tests found only small differences, which suggests that the potential bias introduced by the splitting is rather small (for details, see Dudel and Klüsener 2019)
} 

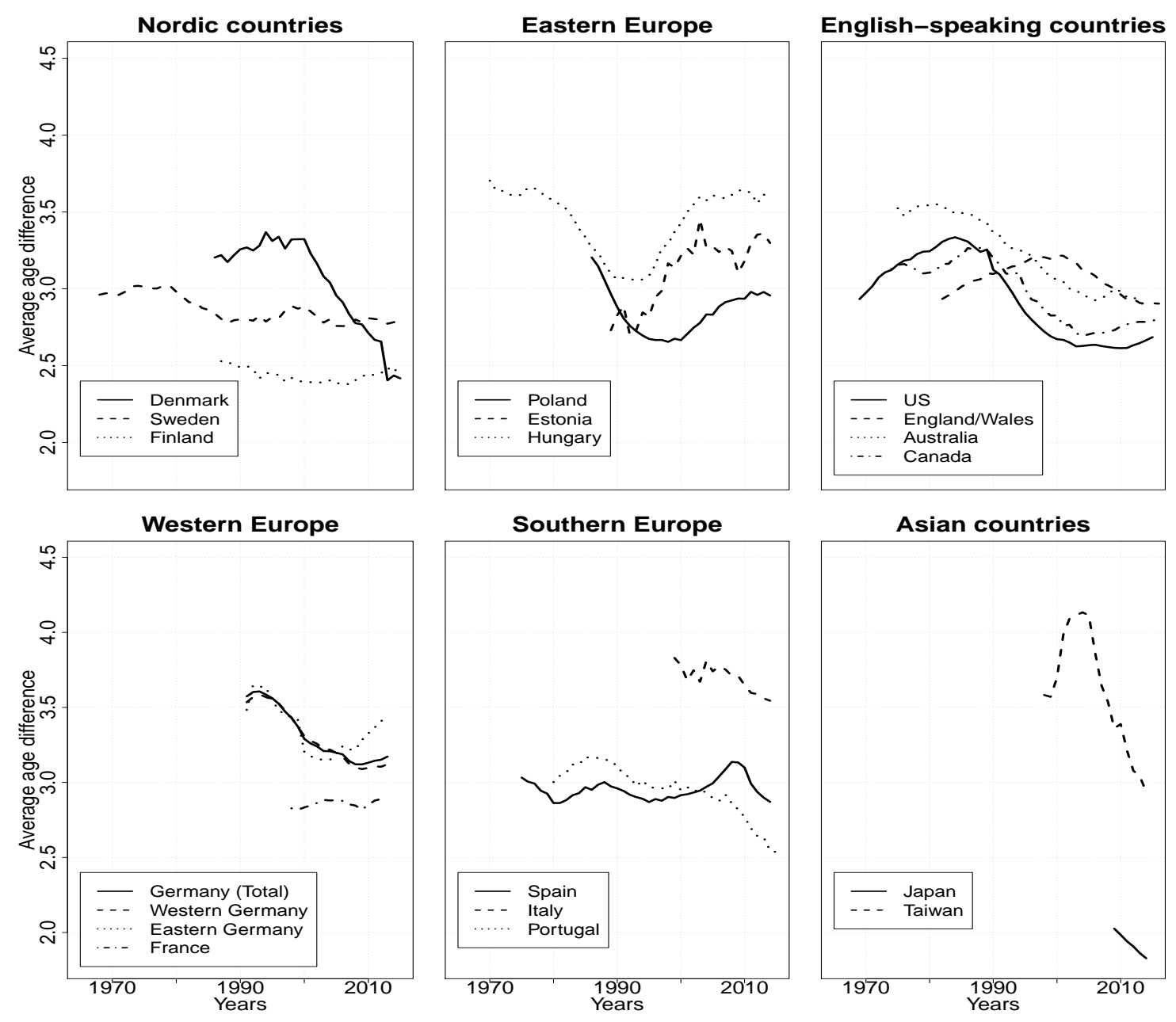

Figure 4: Trends in the average age difference between the father and the mother. Source: Own calculations.

country had increased prior to the 2008 economic crisis, and then declined after the onset of the crisis. The pattern in Portugal, on the other hand, has diverged from that in Spain since the early 2000s, with the overall age gap decreasing by more than half a year since the 1990s.

Looking at the (predominately) English-speaking countries, we can see that the neighboring countries of Canada and the U.S. display marked similarities in age difference levels and trend patterns. In these countries, age disparities increased slightly in the 1970s and 1980s, to around 3.25 years; and then declined in the 1990s, leveling off at around 2.6 years. In Australia, the mean age difference also declined after 1990, from 3.5 to 3 years. The trend in England and Wales was similar to that in Canada and the U.S. (i.e., an upward trend was followed by a downward trend), but the transition to a downward trend occurred later, at around 2000.

Turning to Eastern Europe, we can observe some similarities across the countries in our sample. In Hungary and Poland, for which we have data for the communist period, it is clear that the age difference was steeply decreasing prior to 1990. In all three countries, the smallest age differences were recorded in the early 1990s. Since then, age heterogeneity 
has again been growing in Eastern Europe, with the mean age difference in Hungary returning to levels recorded in the 1970s. In our group of Western European countries, we can again compare only France and eastern and western Germany. It is, however, noteworthy that while the age difference has declined in western Germany since the early 1990 s, from around 3.6 years to 3.2 years; the trend in eastern Germany has followed the pattern in Eastern Europe, with the mean age difference increasing since 2000.

Our findings for parental age differences are much less systematic by country group than the outcomes for quantum differences. Except in Eastern Europe, we can observe a general tendency in recent years toward a decline in mean parental age differences. Yet it does not seem possible to explain the current parental age differences simply by citing differences in gender equality levels. A case in point is Japan, which currently has the smallest parental age differences, despite having low levels of gender equality.

While we observe rather diverse patterns in age differences across countries and country groups, the underlying demographic mechanism is in all cases gender differentials in postponement. Specifically, in all of the countries we study, the mean age at childbirth has been increasing continuously since 1990 for both men and women (see supplementary materials for details); i.e., both men and women have been postponing childbirth. In combination with a higher mean age at childbirth for men, this finding suggests that changes in the parental age gap at childbirth are due to differentials in the speed at which postponement advances: if it progresses more quickly among men than among women, the age gap increases; but if, on the other hand, it advances more rapidly among women than men, the age gap decreases. For instance, in Taiwan between 2000 and 2005, the mean age at childbirth increased for men by around 1 year and for women by 0.6 years; thus, the parental age difference increased, as Figure 4 shows. Between 2006 and 2010 in Taiwan, postponement slowed down among men, but accelerated among women: i.e., the mean age at childbirth increased by 0.8 years for men and by 1.3 years for women, which led to a decline in the average age difference.

\section{Insights and perspectives}

Based on a new, extensive database on male fertility in high-income countries, we explore trends in the differences in the quantum and timing of male and female fertility. We find that, first, the level of male fertility relative to the level of female fertility can vary considerably across countries and over time. Male fertility can both be higher and lower than female fertility; although in recent years it has generally been lower rather than higher. This observation is consistent with the results of Schoumaker (2019) based on survey and census data. Our counterfactual calculations provide support for the claim that temporal fluctuations in the ratio between male and female TFR are often driven by age differences between partners and differences in postponement behavior. Our second main finding is that age differences between fathers and mothers stayed constant or decreased in most of the countries in our study, except in the Eastern European countries and eastern Germany. While this general tendency is in line with expectations based on gender theories, the differences that currently exist across countries seem to be affected by more factors than just differences in gender equality levels. 
While our findings indicate that male fertility has generally been lower than female fertility in recent years, this trend does not seem to hold globally. Schoumaker (2019, 2017) showed that in contexts in which polygyny is practiced and populations are rapidly growing, male fertility levels can sometimes be twice as high as female fertility levels. His results suggest that this pattern is driven to a large extent by age differences between couples. This finding is in line with the results of our counterfactual analysis, which indicate that extreme cases tend to disappear when the fathers are assigned to the same cohort as the mothers, and that large gender differentials in fertility levels are often driven by differences in fertility timing. At the other extreme, the lowest TFR ratio reported in the literature is for England and Wales in 1973, at around 0.89 (Schoen 1985). The value we have found for eastern Germany, 0.84, is below this level, and might indicate that eastern German males have been experiencing what Schoen (1985) called a birth squeeze: i.e., in eastern Germany, the unequal number of men and women in the reproductive age range is having an impact on the fertility of men. Generally, the variation in TFR ratios we observe across countries and over time is not negligible. Country groups with cultural and/or political similarities seem to have more similar trend patterns. This finding requires further investigation.

The mean age differences between men and women we have detected in our data are close to the orders of magnitude found in other studies (e.g., Kolk 2015). They are, however, lower than the high values observed in some African countries, where mean differences of more than 10 years have been estimated (Schoumaker 2017). Nevertheless, the variation across countries and over time in our 17 high-income countries is substantial. This heterogeneity of age differences is somewhat puzzling. In particular, our findings suggest that while European countries that score high on the gender equality index have smaller age differences, Japan does not seem to fit this picture. Even though Japan scores low on gender inequality indices (World Economic Forum 2017), the age differences among parents in this country are the lowest we have found in our study. This finding requires further investigation. Another factor that might be important is the cross-country variation in the share of migrants and the parental age differences that prevail in their countries of origin. We are, however, unable to study this potential factor, given that for most of the countries and years in our sample, we are unable to separate births by nationality or migration background status. We thus leave the exploration of this question to future research.

The new database we created to study male fertility is not limited to the questions we have investigated in this paper, and is expected to have many other applications. It can, for example, be used in macro-level investigations of associations between male fertility levels and important economic and social indicators, including gender equality measures. There are many influential publications that have studied these relationships among women (e.g., Brewster and Rindfuss 2000, Myrskylä, Kohler, and Billari 2009), and comparing the outcomes for female fertility with the results for male fertility might provide important insights. Such analyses will likely further improve our understanding of the role of gender in current fertility trends. The database can also be used in comparative analyses of trends and patterns in the paternal age at childbirth, which is an important predictor of health outcomes of children, and has been attracting increasing attention in recent years (e.g., Khandwala et al. 2017). 
With this article, we have been able to provide some initial insights into differences in male and female fertility trends based on the research potential offered by our new comparative male fertility dataset, which is available in the Human Fertility Collection (2019). This rich dataset will help to improve our understanding of male fertility, and of how it relates to female fertility. Thus, the database offers many promising avenues for future research, and we invite other researchers to make use of this new data resource.

\section{References}

Arts, Wil, and John Gelissen. 2002. Three Worlds of Welfare Capitalism or More? A Stateof-the-Art Report. Journal of European Social Policy 12, no. 2 (May): 13758. https://doi: 10.1177/0952872002012002114.

Aspalter, Christian. 2006. The East Asian welfare model. International Journal of Social Welfare 15, no. 4: 290-301. doi:10.1111/j.1468-2397.2006.00413.x.

Bagavos, Christos, and Alexandra Tragaki. 2017. The compositional effects of education and employment on Greek male and female fertility rates during 20002014. Demographic Research 36 (Art. 47): 14351452.

Billari, Francesco, C., Alice Goisis, Aart C. Liefbroer, Richard A. Settersten, Arnstein Aassve, Gunhild Hagestad, and Zsolt Spéder. 2011. Social age deadlines for the childbearing of women and men. Human Reproduction 26, no. 3 (March): 616622.

Blake, Judith. 1974. The changing status of women in developed countries. Scientific American 231 (3): 137-147.

Bongaarts, John, and Griffith Feeney. 1998. On the quantum and tempo of fertility. Population and Development Review 24 (2): 271291.

Bozon, Michel. 1991. Women and the Age Gap Between Spouses: An Accepted Domination? Population 3: 113-148.

Brewster, Karin L., and Ronald R. Rindfuss. 2000. Fertility and women's employment in industrialized nations. Annual Review of Sociology 26 (1): 271296.

Budig, Michelle J. and Paula England. 2001. The Wage Penalty for Motherhood. American Sociological Review 66(2): 204-22.

Carmichael, Gordon A. 2013. Estimating Paternity in Australia, 1976-2010. Fathering 11 (3): 256-279.

Coleman, David A. 2000. Male fertility trends in industrial countries: Theories in search of some evidence. In Fertility and the Male Life Cycle in the Era of Fertility Decline, edited by Caroline Bledsoe, Susana Lerner, and Jane I. Guyer, 2960. Oxford: Oxford University Press.

Dinkel, Reiner Hans, and Ina Milenovic. 1993. Male and Female Fertility: A Comparison of Age-Specific and Cohort Fertility of Both Sexes in Germany. Genus 49 (1/2): 147-158.

Dribe, Martin, and Maria Stanfors. 2017. Age homogamy and modernization: Evidence from turn-of-the-twentieth century Sweden. Essays in Economic \& Business History 35 (1): 265-289.

Dyer, Silke, Georgina M. Chambers, Jacques de Mouzon, K.G. Nygren, Fernando Zegers-Hochschild, Ragaa Mansour, Osamu Ishihara, Manish Banker, G. David Adamson. 2016. International Committee for Monitoring Assisted Reproductive Technologies world report: Assisted Reproductive Technology 2008, 2009 and 2010. Human Reproduction 31 (7): 15881609. 
Dudel, Christian, and Sebastian Klüsener. 2016. Estimating male fertility in eastern and western Germany since 1991: A new lowest low? Demographic Research 35 (Art. 53): 15491560.

Dudel, Christian, and Sebastian Klüsener. 2018. Estimating mens fertility from vital registration data with missing values. Population Studies (Latest Articles): 111.

Dudel, Christian, and Sebastian Klüsener. 2019. Male Fertility Data for 16 High-Income Countries: Methods and Data Description. MPIDR Technical Report TR-2019-001.

Esping-Andersen, Gøsta. 1990. Three worlds of welfare capitalism. Princeton: Princeton University Press.

Esping-Andersen, Gøsta. 1999. Social Foundations of Postindustrial Economies. Oxford: Oxford University Press.

Esteve, Albert, Christine R. Schwartz, Jan van Bavel, Iñaki Permanyer, Martin Klesment, and Joan GarcíaRomán. 2016. The End of Hypergamy: Global Trends and Implications. Population and Development Review 42(4): 615-625.

Fenger, Menno H. 2007. Welfare regimes in Central and Eastern Europe: Incorporating postcommunist countries in a welfare regime typology. Contemporary issues and ideas in social sciences 3 (2).

Field, Erica, Vera Molitor, Alice Schoonbroodt, and Michèle Tertilt. 2016. Gender gaps in completed fertility. Journal of Demographic Economics 82 (2): 167206.

Fodor, Éva, and Anik Balogh. 2010. Back to the kitchen? Gender role attitudes in 13 East European countries. Zeitschrift für Familienforschung 22 (3): 289307.

Fox, Jonathan, Sebastian Klüsener, and Mikko Myrskylä. 2018. Is a positive relationship between fertility and economic development emerging at the sub-national regional level? Theoretical considerations and evidence from Europe. European Journal of Population (Online First): 132.

Gameiro, Sofia and Amy Finnigan. 2017. Long-term adjustment to unmet parenthood goals following ART: A systematic review and meta-analysis. Human Reproduction Update 23 (3): 322337.

Gaunt, Ruth. 2006. Couple Similarity and Marital Satisfaction: Are Similar Spouses Happier? Journal of Personality 74 (5): 1401-1420.

Goldscheider, Frances, Eva Bernhardt, and Trude Lappegård. 2015. The Gender Revolution: A Framework for Understanding Changing Family and Demographic Behavior. Population and Development Review 41 (2): 207-239.

Grigoriev, Pavel, Domantas Jasilionis, Vladimir M. Shkolnikov, France Meslé, and Jaques Vallin. 2015. Spatial variation of male alcohol-related mortality in Belarus and Lithuania. The European Journal of Public Health 26 (1): 95101.

Grow, André, Christine Schnor, and Jan Van Bavel. 2017. The reversal of the gender gap in education and relative divorce risks: A matter of alternatives in partner choice? Population Studies 71 (sup1): 15-34.

Hoem, Jan M. 2005. Why does Sweden have such high fertility? Demographic Research 13 (Art. 22): 559572.

Human Fertility Collection. 2019. Max Planck Institute for Demographic Research (Germany) and Vienna Institute of Demography (Austria), available at www . fertilitydata.org.

Human Fertility Database. 2019. Max Planck Institute for Demographic Research (Germany) and Vienna Institute of Demography (Austria), available at www .humanfertility .org. 
Human Mortality Database. 2019. University of California, Berkeley (USA), and Max Planck Institute for Demographic Research (Germany), available at www . mortality . org or www . humanmortality . de.

Jalovaara, Marika, Gerda Neyer, Gunnar Andersson, Johan Dahlberg, Lars Dommermuth, Peter Fallesen, and Trude Lappegård. 2017. Education, gender, and cohort fertility in the Nordic countries. European Journal of Population (Online First): 127.

Jasilioniene, Aiva, Dmitri A. Jdanov, Tomáš Sobotka, Evgeny M. Andreev, Kryštof Zeman, Vladimir M. Shkolnikov, Joshua R. Goldstein, Edward J. Nash, Dimiter Philipov, and German Rodriguez. 2015. Methods Protocol for the Human Fertility Database. Available online: https://www. humanfertility.org/Docs/methods.pdf.

Karmel, Peter H. 1947. The relations between male and female reproduction rates. Population Studies 1 (3): 249274.

Kashyap, Ridhi. 2017. The Dynamics of Prenatal Sex Selection and Excess Female Child Mortality in Contexts with Son Preference. PhD diss., University of Oxford.

Keilman, Nico, Krzysztof Tymicki, and Vegard Skirbekk. 2014. Measures for human reproduction should be linked to both men and women. International Journal of Population Research 2014 (908385).

Kenrick, Douglas T., and Richard C. Keefe. 1992. Age preferences in mates reflect sex differences in human reproductive strategies. Behavioral and Brain Sciences 15: 75133.

Khandwala, Yash S., Chiyuan A. Zhang, Ying Lu, and Michael L. Eisenberg. 2017. The age of fathers in the USA is rising: An analysis of 168867480 births from 1972 to 2015. Human Reproduction 32 (10): 21102116.

Klesment, Martin, and Jan Van Bavel. 2017. The reversal of the gender gap in education, motherhood, and women as main earners in Europe. European Sociological Review 33 (3): 465481.

Kohler, Hans-Peter, Francesco C. Billari, and José Antonio Ortega. 2002. The emergence of lowest-low fertility in Europe during the 1990s. Population and Development Review 28 (4): 641680.

Kolk, Martin. 2015. Age differences in unions: Continuity and divergence among Swedish couples between 1932 and 2007. European Journal of Population 31 (4): 365382.

Kong, Augustine, Michael L. Frigge, Gisli Masson, Soren Besenbacher, Patrick Sulem, Gisli Mangusson, Sigurjon A. Gudjonsson, Asgeir Sigurdsson, Aslaug Jonasdottir, Adalbjorg Jonasdottir, Wendy S. W. Wong, Gunnar Sigurdsson, G. Bragi Walters, Stacy Steinberg, Hannes Helgason, Gudmar Thorleifsson, Daniel F. Gudbjartsson, Agnar Helgason, Olafur Th. Magnusson, Unnur Thorsteinsdottir, and Kari Stefansson. 2012. Rate of de novo mutations and the importance of father's age to disease risk. Nature 488: 471475.

Kröhnert, Steffen, and Sebastian Vollmer. 2012. GenderSpecific Migration from Eastern to Western Germany: Where Have All the Young Women Gone? International Migration 50 (5): 95112.

Kühn, Mine, Christian Dudel, Tobias Vogt, and Anna Oksuzyan. 2019. Trends in gender differences in health at working ages among West and East Germans. Social Science and Medicine: Population Health 7: 100326.

Lappegård, Trude, Marit Rønsen, and Kari Skrede. 2011. Fatherhood and fertility. Fathering 9 (1): 103120. 
Lazarus, John. 2002. Human sex ratios: Adaptations and mechanisms, problems and prospects. In Sex Ratios: Concepts and Research Methods, edited by Ian C. W. Hardy, 287311. Cambridge: Cambridge University Press.

Leon, David A., Vladimir M. Shkolnikov, and Martin McKee. 2009. Alcohol and Russian mortality: A continuing crisis. Addiction 104 (10): 16301636.

Leridon, Henri. 2004. Can assisted reproduction technology compensate for the natural decline in fertility with age? A model assessment. Human Reproduction 19 (7): 15481553.

Lutz, Helma. 2010. Gender in the migratory process. Journal of Ethnic and Migration Studies 36 (10): 16471663.

Markle, Gerald E. 1974. Sex ratio at birth: Values, variance, and some determinants. Demography 11 (1): 131142.

Mathews, T. J., and Brady E. Hamilton. 2005. Trend Analysis of the Sex Ratio at Birth in the United States. National Statistics Vital Reports 53 (20). Hyattsville, Maryland: National Center for Health Statistics.

McLaughlin, Eithne, and Caroline Glendinning. 1994. Paying for care in Europe: Is there a feminist approach. In Family Policy and the Welfare of Women, edited by Linda Hantrais \& Stephen P. Mangen, 52-69. Loughborough: Cross-National Research Group.

Myrskylä, Mikko, Hans-Peter Kohler, and Francesco C. Billari. 2009. Advances in development reverse fertility declines. Nature 460 (7256): 741-743.

Nisén, Jessica, Pekka Martikainen, Karri Silventoinen, and Mikko Myrskylä. 2014. Age-specic fertility by educational level in the Finnish male cohort born 19401950. Demographic Research 31 (Art. 5): 119136.

Nordfalk, Francisca, Ulla A. Hvidtfeldt, and Niels Keiding. 2015. TFR for males in Denmark Calculation and tempo-correction. Demographic Research 32 (Art. 52): 14211434.

Pascariu, Marius D., Silvia Rizzi, Jonas Schoeley, and Maciej Danko. 2018. ungroup: Penalized composite link model for efcient estimation of smooth distributions from coarsely binned data. R package version 1.0.0. https://cran.r-project.org/web/packages/ungroup/ungroup. pdf.

Paavilainen, Miia, Aini Bloigu, Elina Hemminki, Mika Gissler, and Reija Klemetti. 2016. Aging fatherhood in Finland: First-time fathers in Finland from 1987 to 2009. Scandinavian Journal of Public Health 44 (4): 423430.

Poston, Dudley L., Baumle, A. K. and Michael Micklin. 2006. Epilogue: Needed research in demography. In Handbook of Population, edited by Dudley L. Poston and Michael Micklin, 853881. New York: Springer.

Presser, Harriet B. 1975. Age differences between spouses: Trends, patterns, and social implications. American Behavioral Scientist 19 (2), 190-205.

Rendall, Michael S., Lynda Clarke, H. Elizabeth Peters, Nalini Ranjit, and Georgia Verropoulu. 1999. Incomplete reporting of men's fertility in the United States and Britain: A research note. Demography 36 (1): 135144.

Rizzi, Silvia, Jutta Gampe, and Paul H. C. Eilers. 2015. Efcient estimation of smooth distributions from coarsely grouped data. American Journal of Epidemiology 182: 138147.

Schoen, Robert. 1985. Population growth and the birth squeeze. Social Science Research 14 (3): 251-265. 
Schoumaker, Bruno. 2017. Measuring male fertility rates in developing countries with Demographic and Health Surveys: An assessment of three methods. Demographic Research 36 (Art. 28): 803850.

Schoumaker, Bruno. 2019. Male Fertility Around the World and Over Time: How Different is it from Female Fertility? Population and Development Review: 1-29.

Sobotka, Tomáš. 2004. Is lowestlow fertility in Europe explained by the postponement of childbearing? Population and Development Review 30 (2): 195220.

Szołtysek, Mikołaj, Sebastian Klüsener, Radosław Poniat, and Siegfried Gruber. 2017. The Patriarchy Index: A new measure of gender and generational inequalities in the past. Cross-Cultural Research 51 (3): 228262.

Trivers, Robert. 1972. Parental investment and sexual selection In Sexual Selection and the Descent of Man: The Darwinian Plot, edited by Bernard G. Campbell, 136-179. Chicago: Aldine Publishing Company.

UN Department of Economic and Social Affairs. 2015. Demographic Yearbook 2015. New York: United Nations.

van Poppel, Frans, Aart C. Liefbroer, Jeroen K. Vermunt, and Wilma Smeenk. 2001. Love, necessity and opportunity: Changing patterns of marital age homogamy in the Netherlands, 18501993. Population Studies 55 (1): 113.

Vere, James P. 2008. The perils of father-reported fertility data for household labor supply models. Population Studies 62 (2): 235243.

World Economic Forum. 2017. The Global Gender Gap Report 2017. Cologne/Geneva: World Economic Forum.

Zhang, Li. 2011. Male Fertility Patterns and Determinants. Dordrecht: Springer. 
Supplementary materials 


\section{Total fertility rates by country and gender}

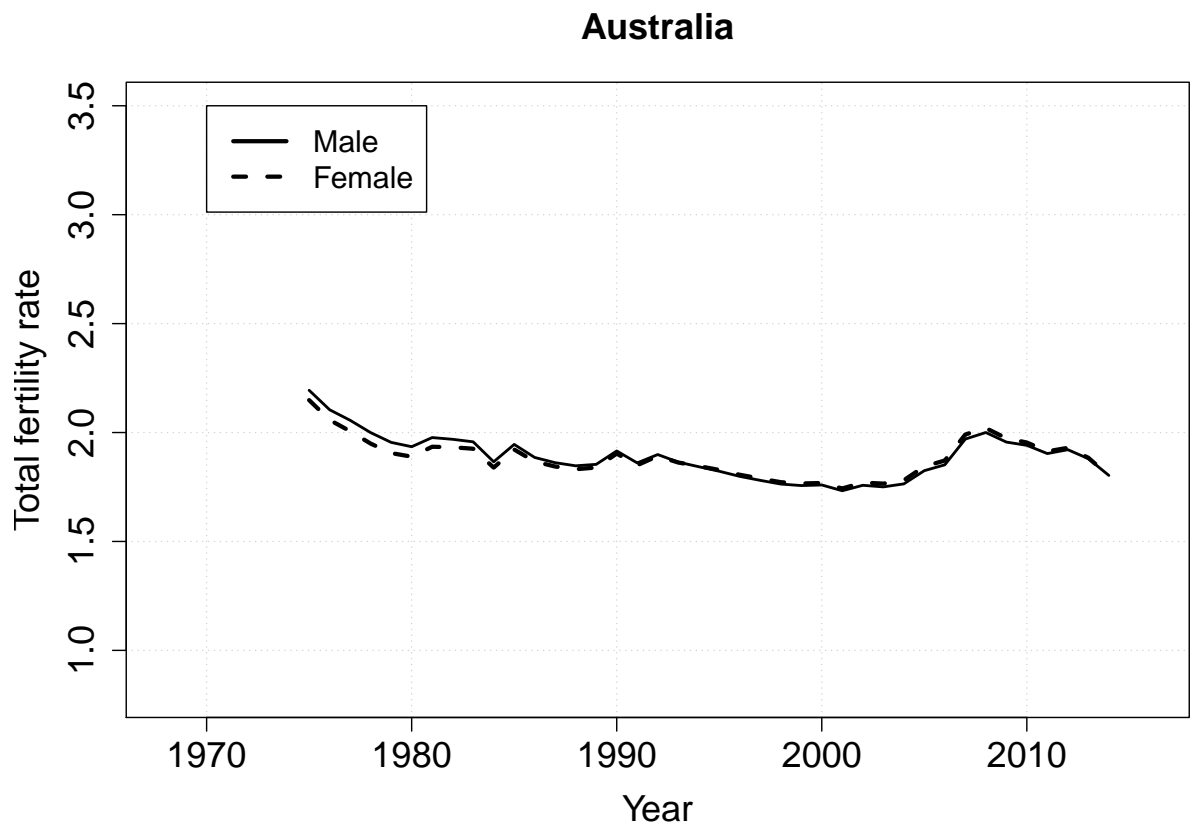

Figure A1: Total fertility rate by gender, Australia.

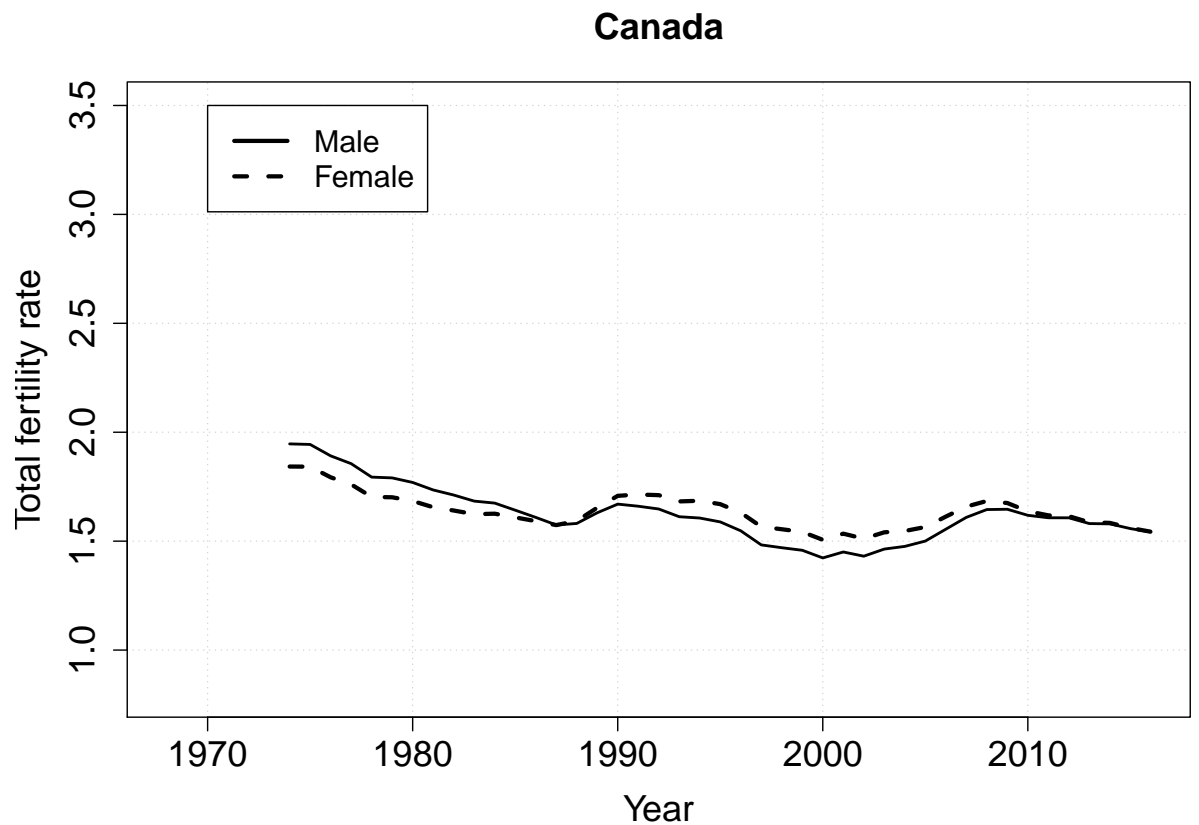

Figure A2: Total fertility rate by gender, Canada. 


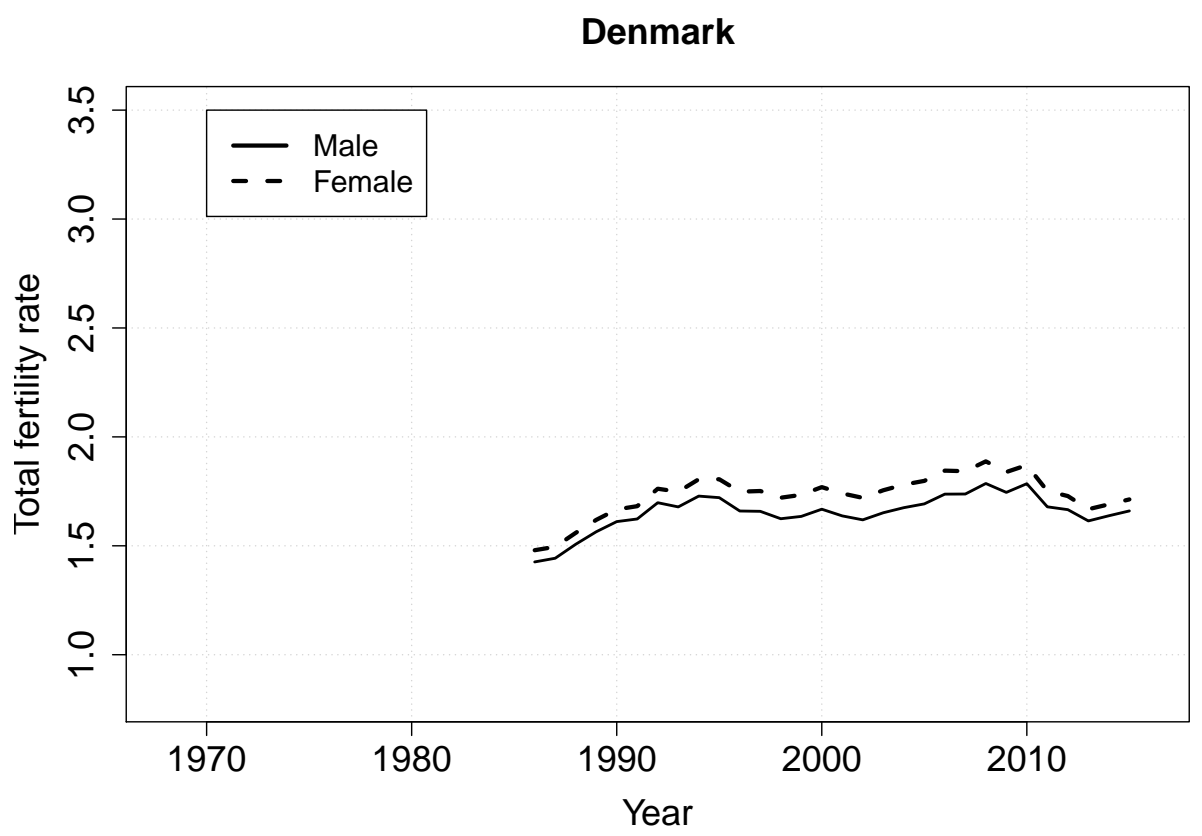

Figure A3: Total fertility rate by gender, Denmark.

\section{England}

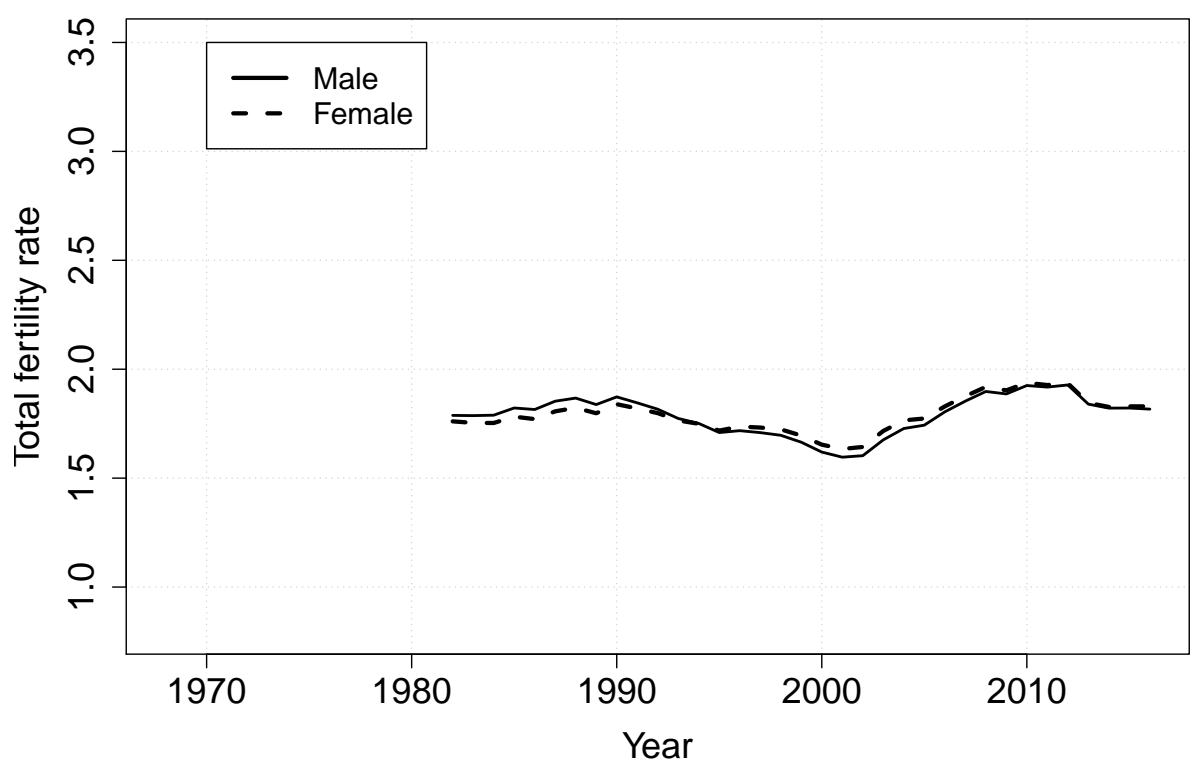

Figure A4: Total fertility rate by gender, England. 


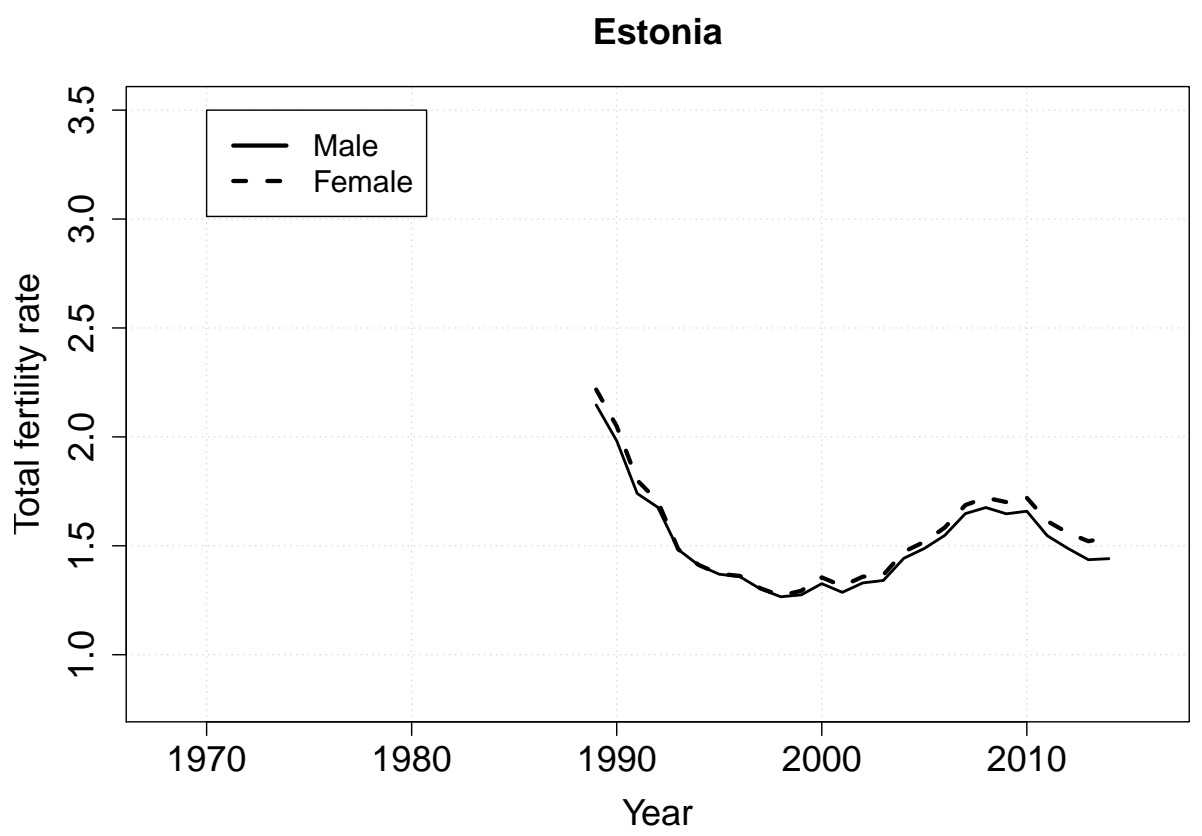

Figure A5: Total fertility rate by gender, Estonia.

\section{Finland}

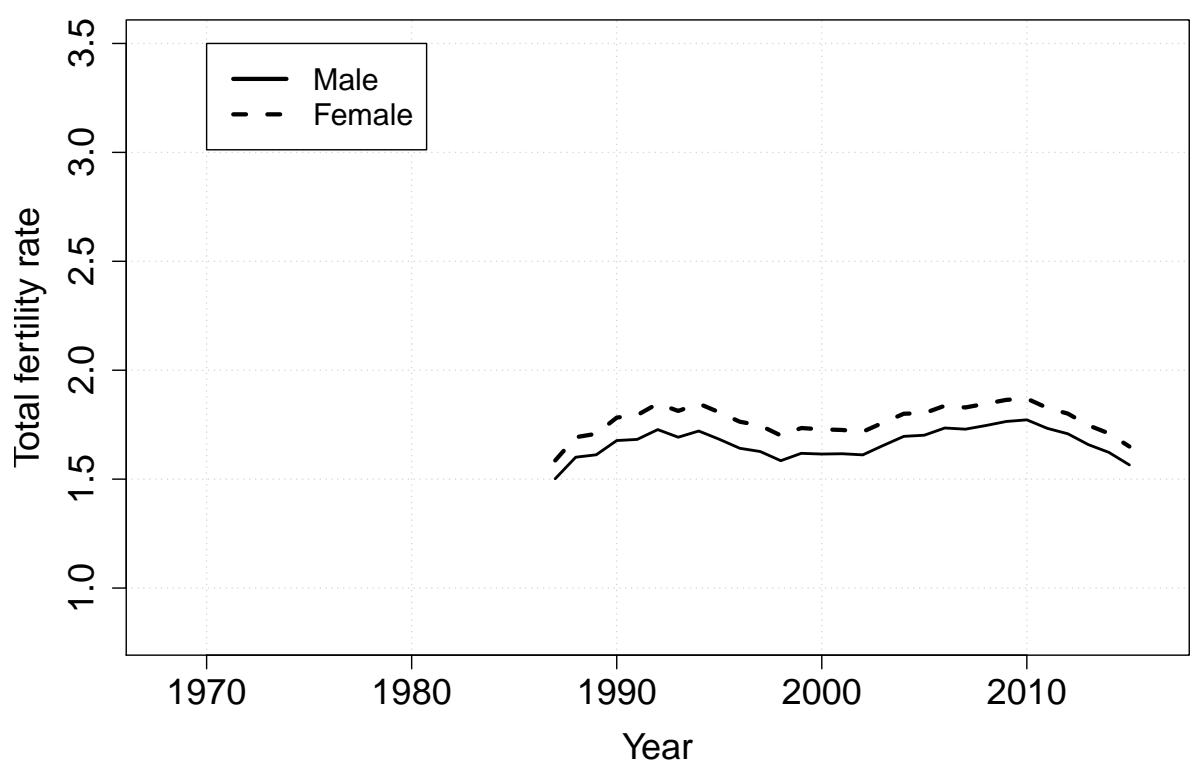

Figure A6: Total fertility rate by gender, Finland. 
France

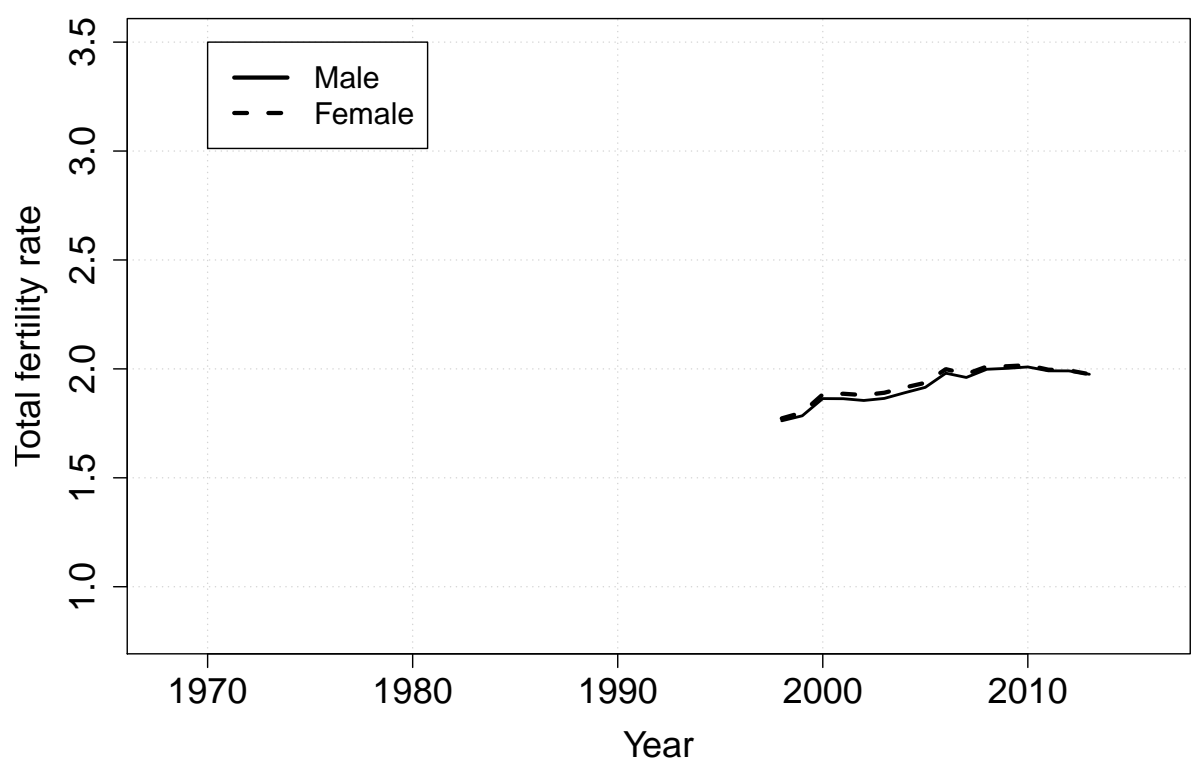

Figure A7: Total fertility rate by gender, France.

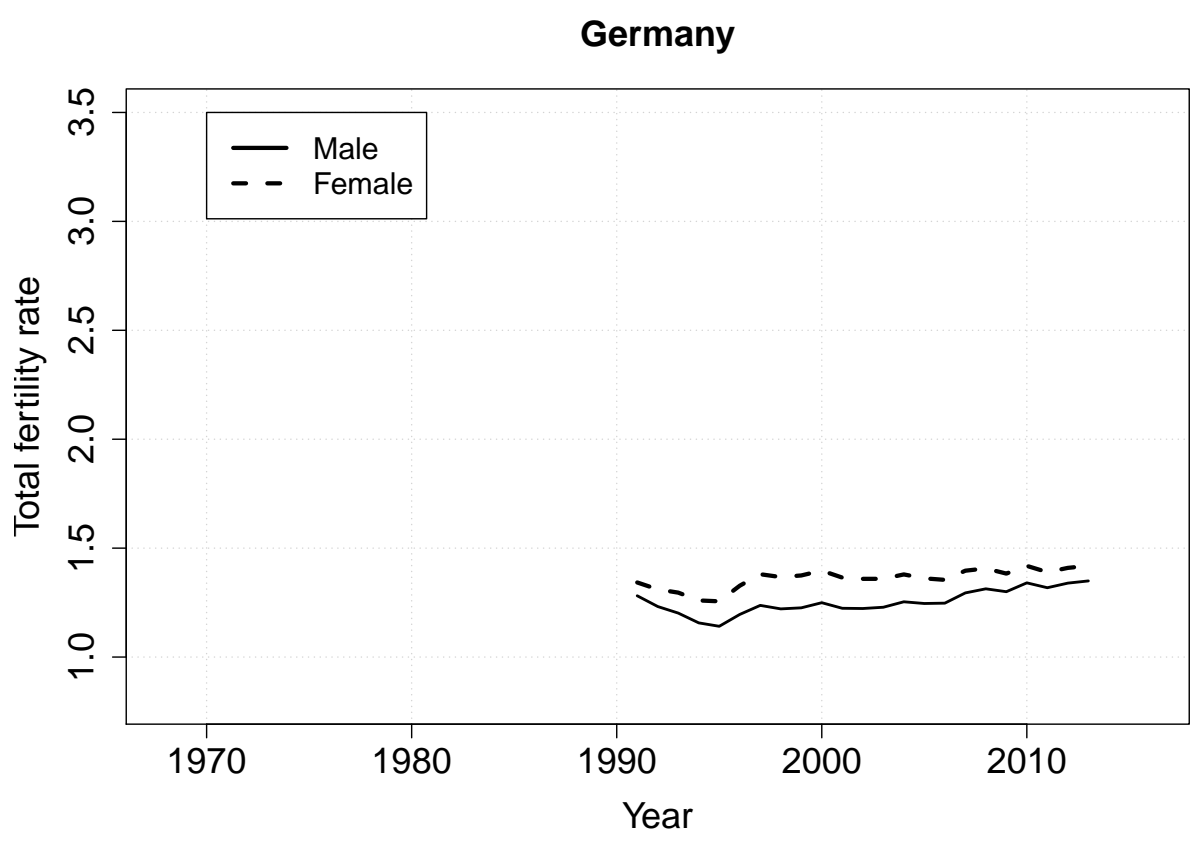

Figure A8: Total fertility rate by gender, Germany. 


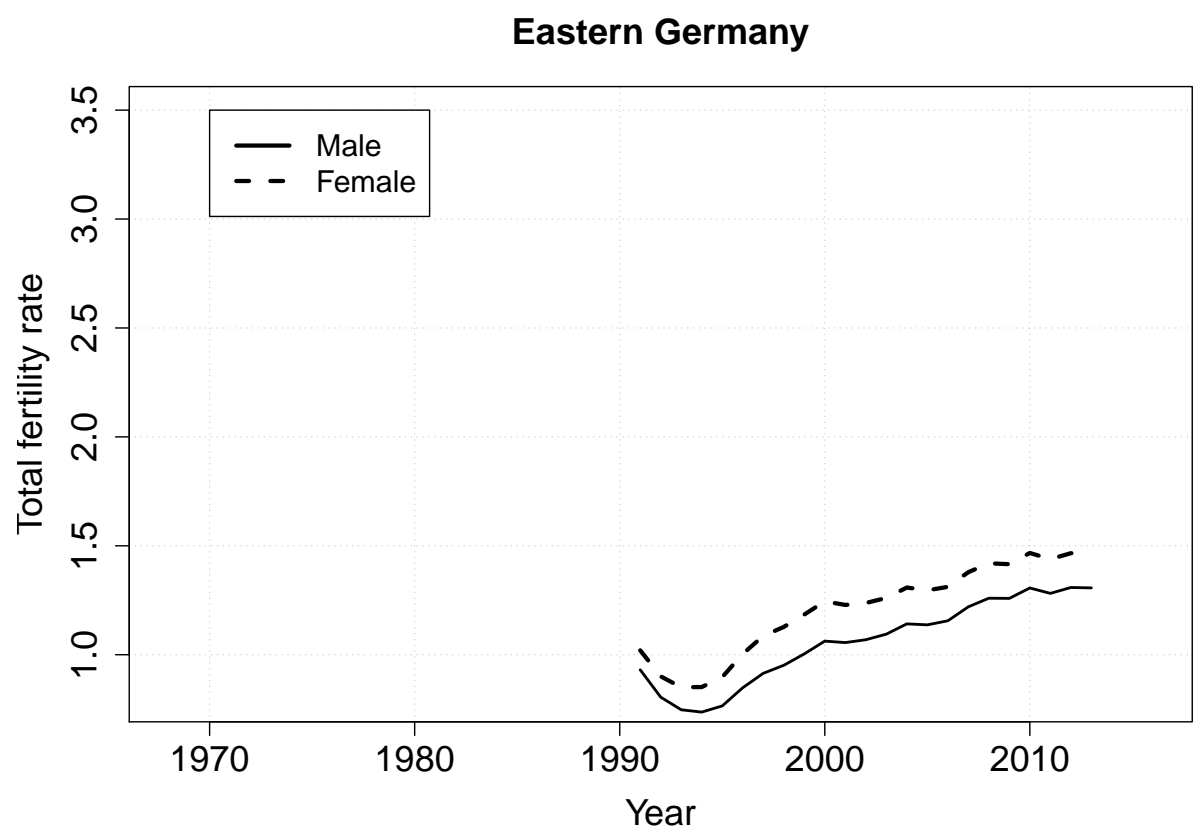

Figure A9: Total fertility rate by gender, eastern Germany.

Western Germany

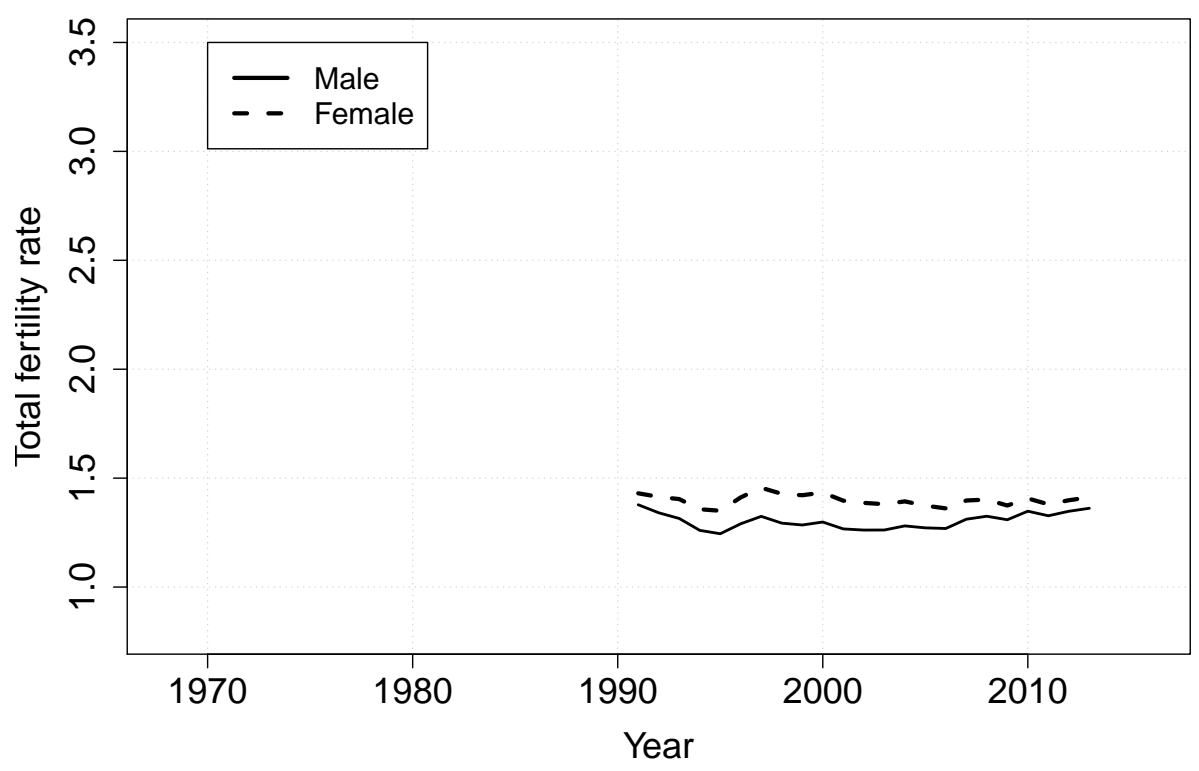

Figure A10: Total fertility rate by gender, western Germany. 


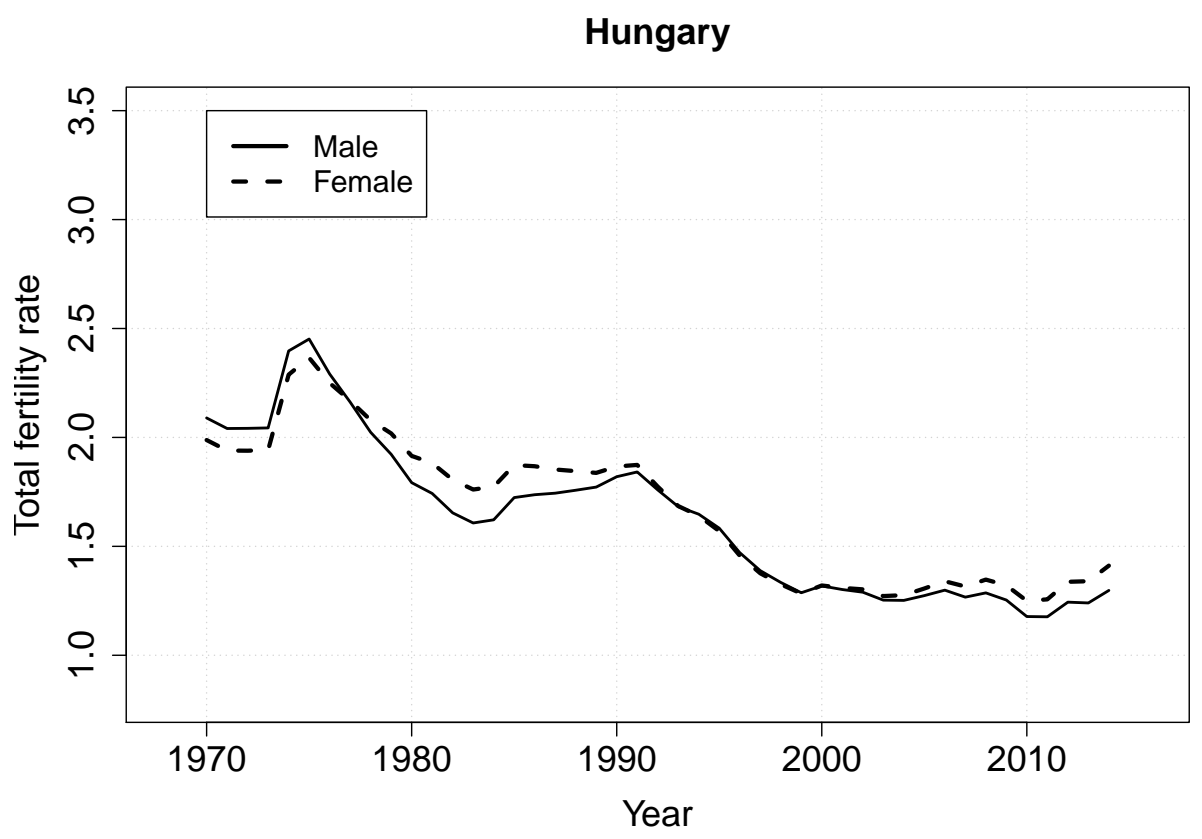

Figure A11: Total fertility rate by gender, Hungary.

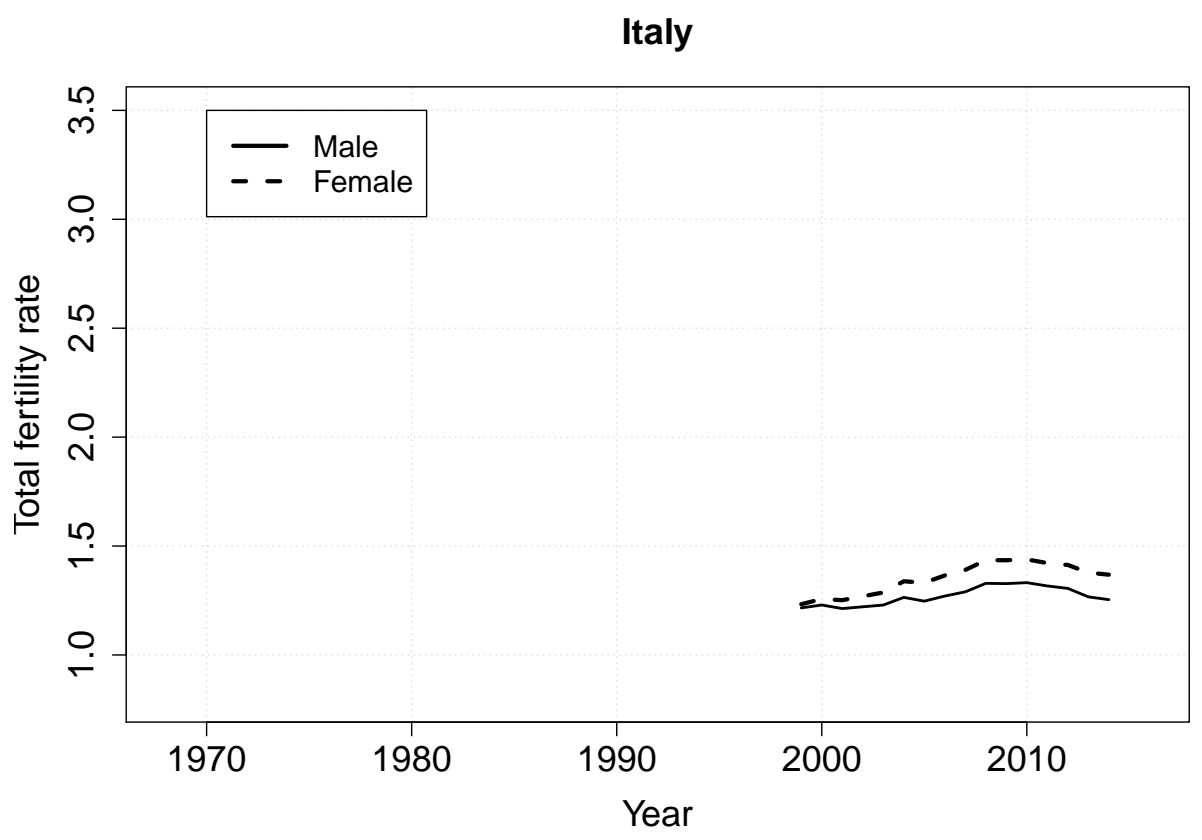

Figure A12: Total fertility rate by gender, Italy. 


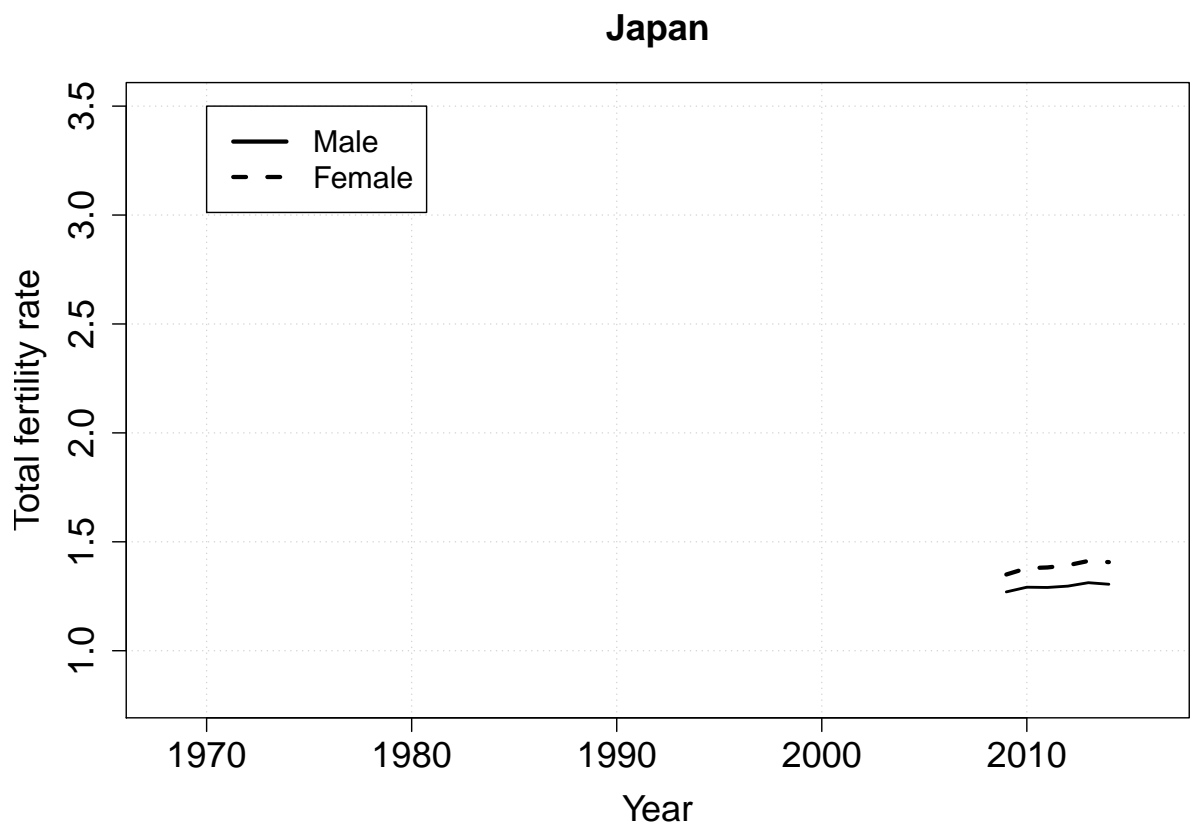

Figure A13: Total fertility rate by gender, Japan.

\section{Poland}

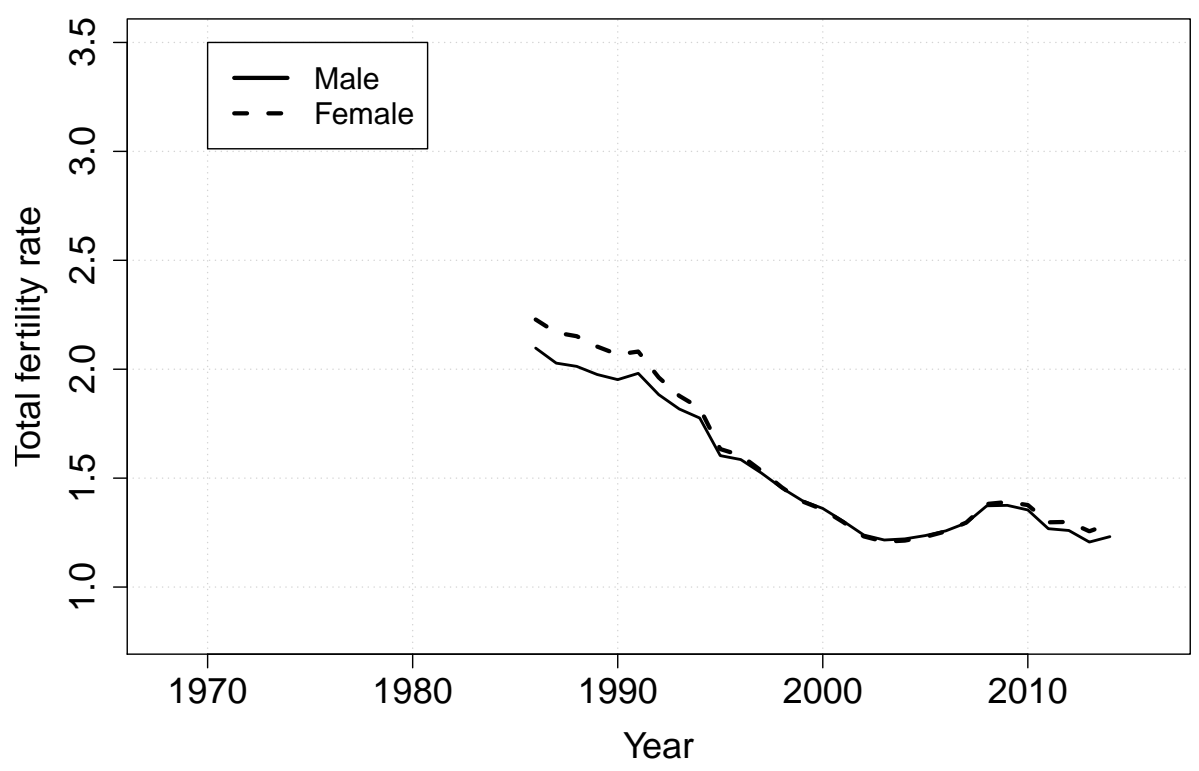

Figure A14: Total fertility rate by gender, Poland. 


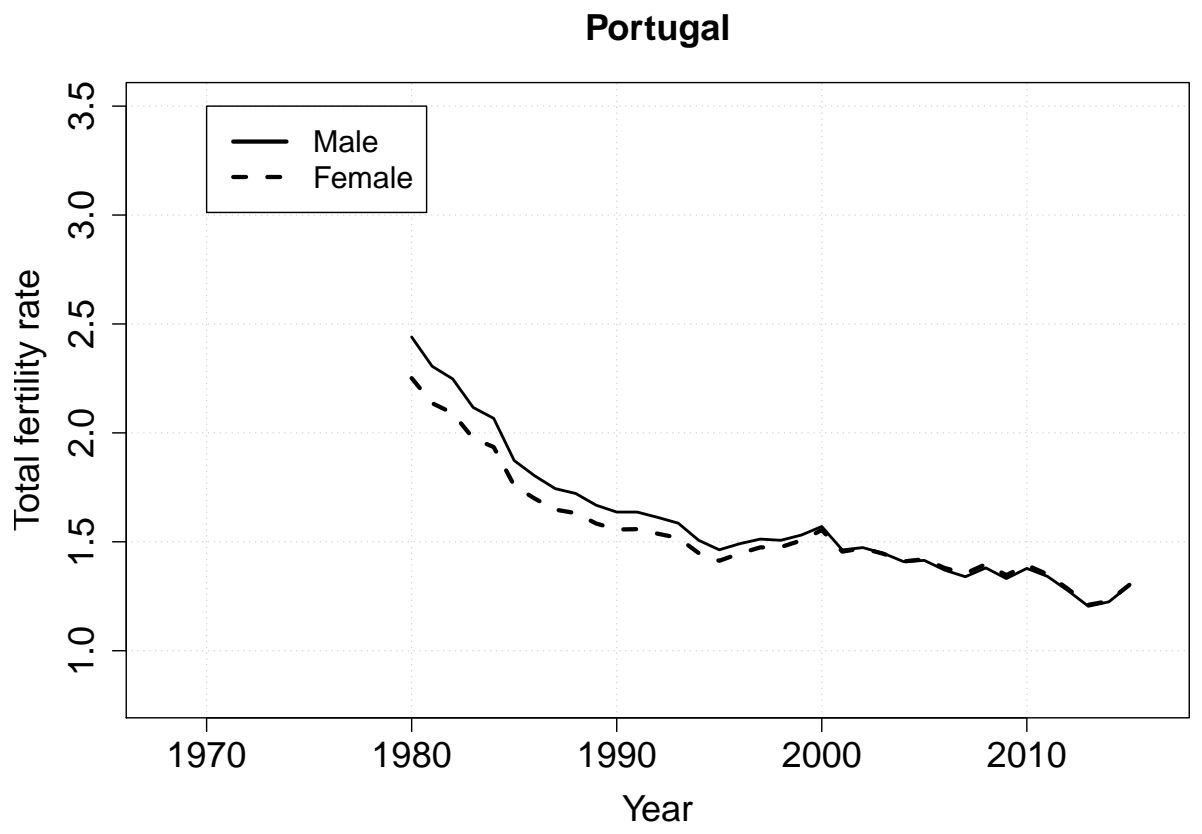

Figure A15: Total fertility rate by gender, Portugal.

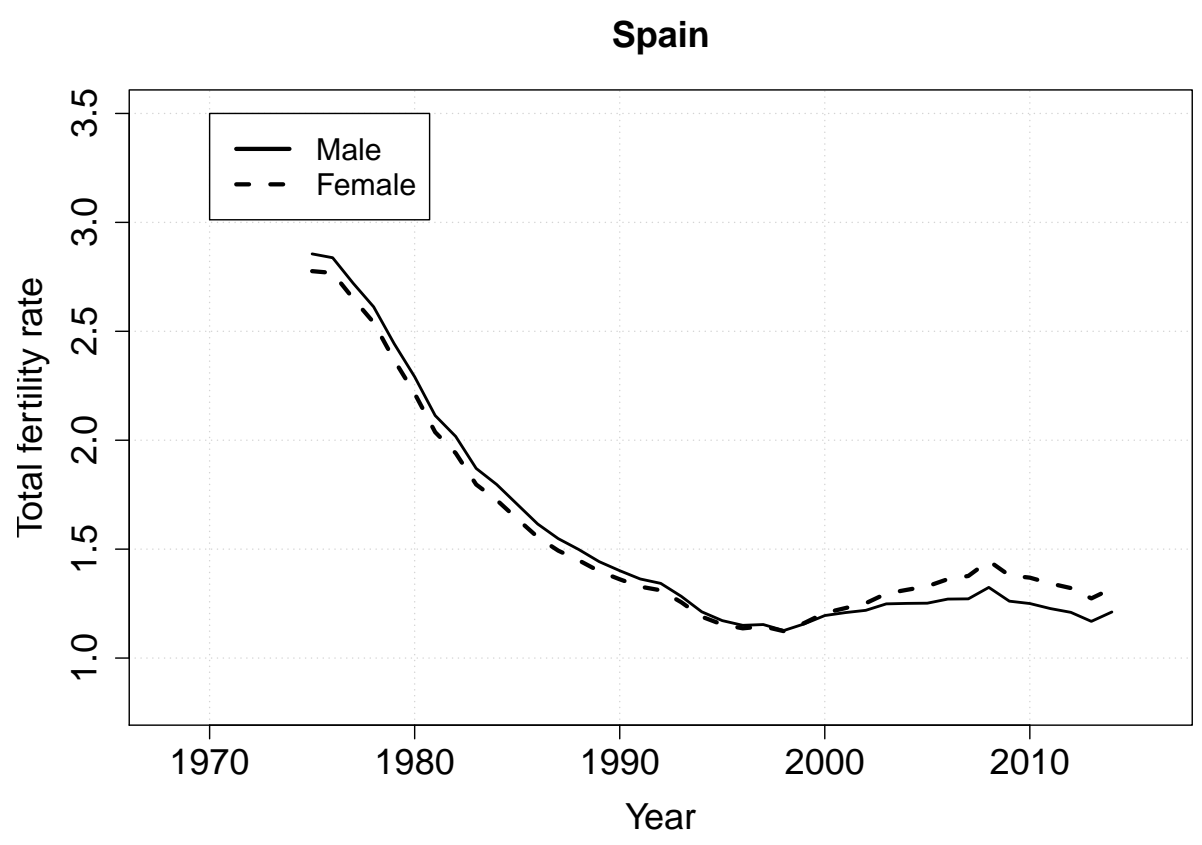

Figure A16: Total fertility rate by gender, Spain. 


\section{Sweden}

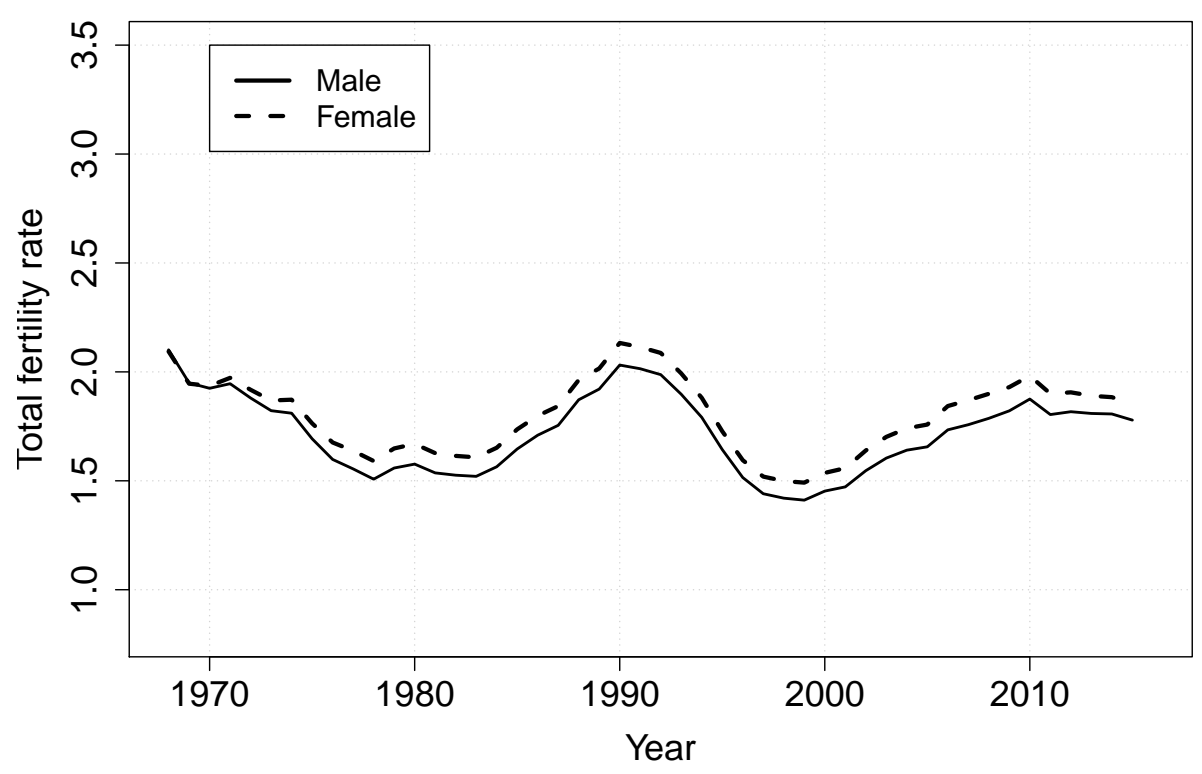

Figure A17: Total fertility rate by gender, Sweden.

\section{Taiwan}

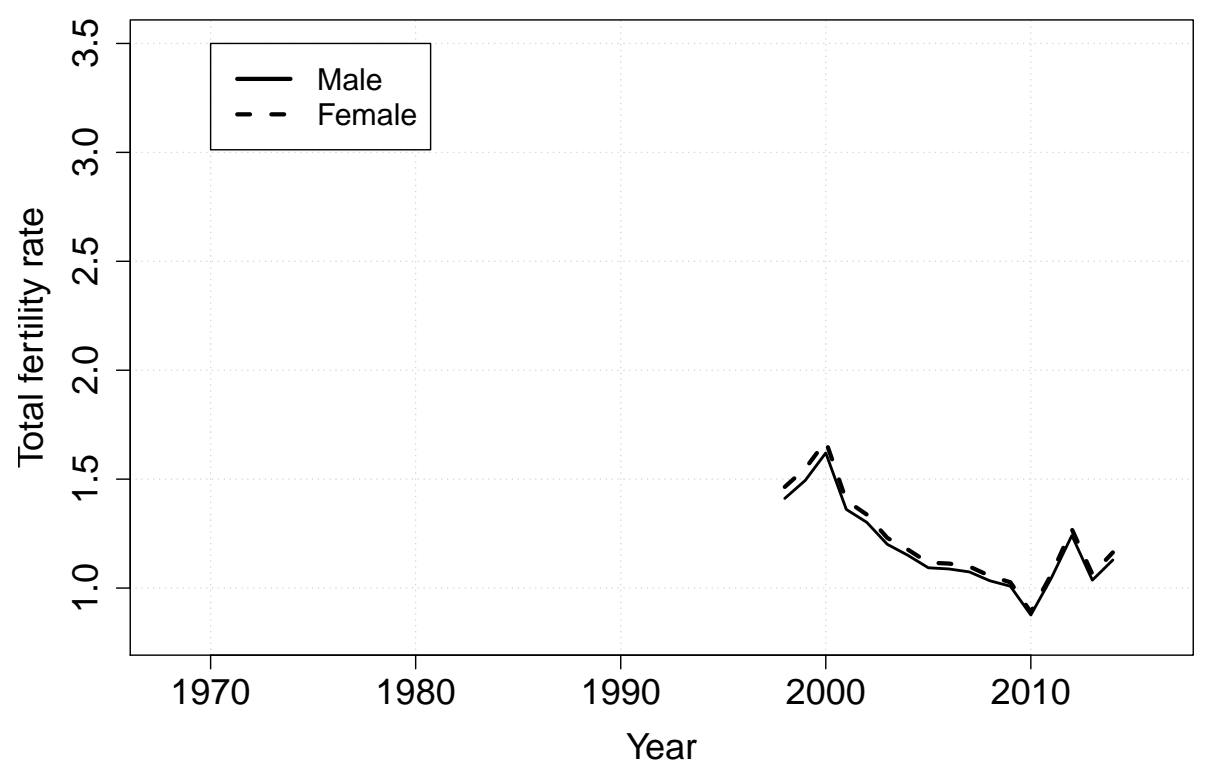

Figure A18: Total fertility rate by gender, Taiwan. 


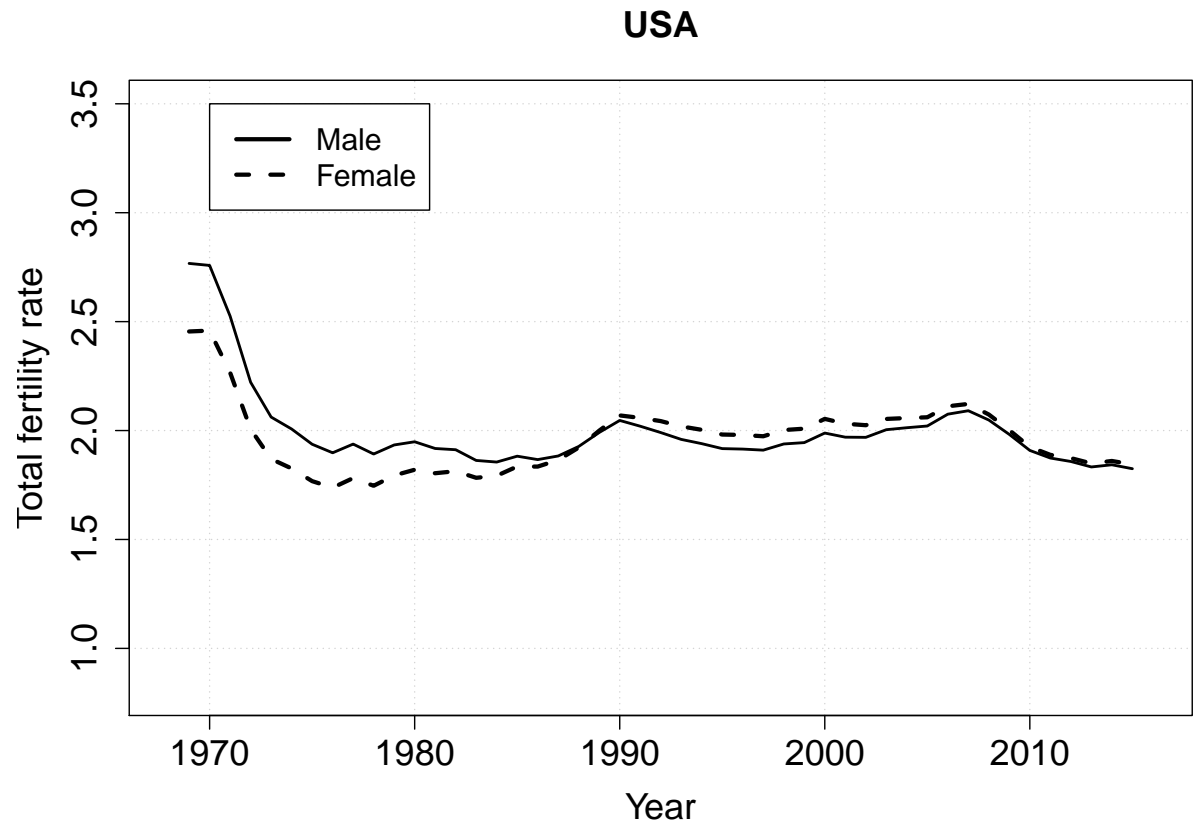

Figure A19: Total fertility rate by gender, USA. 


\section{Hypothetical male TFR/female TFR ratios}

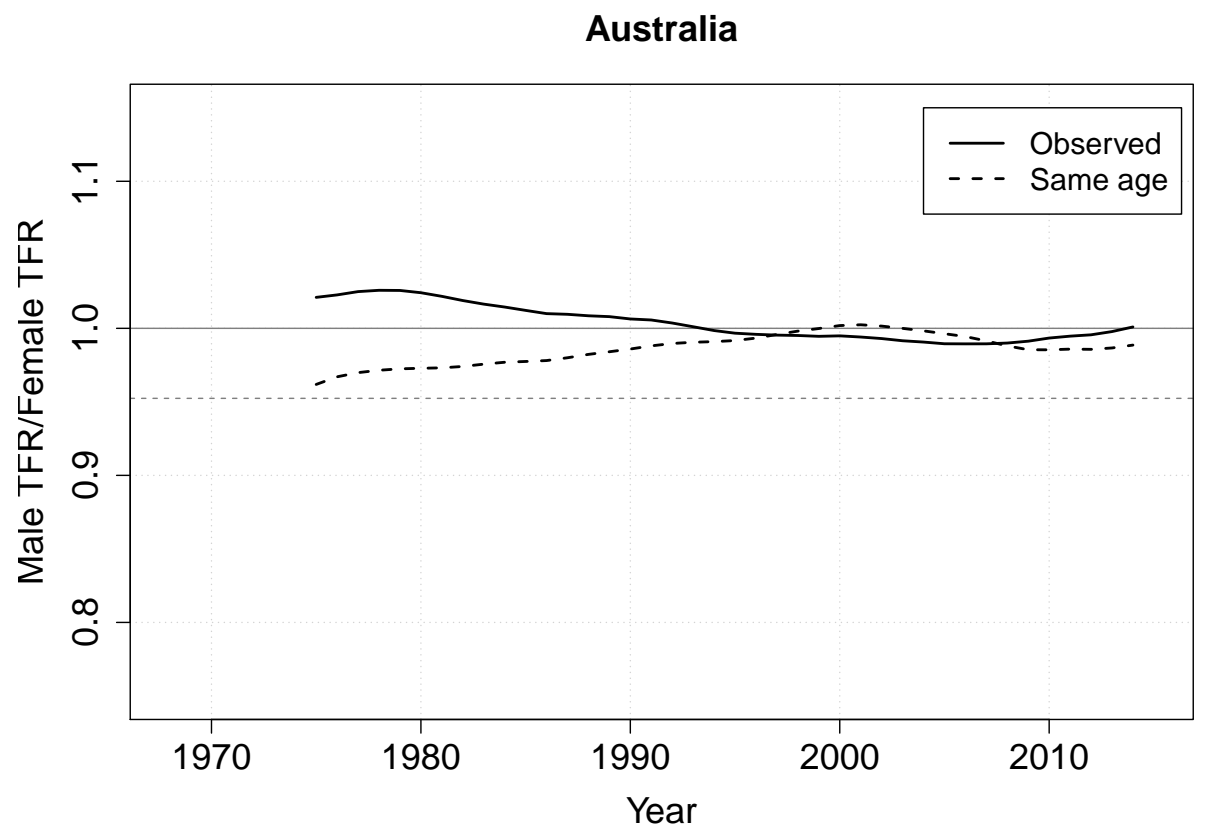

Figure B1: Hypothetical Male/Female TFR ratios in which fathers are assigned the maternal age at birth, Australia. 


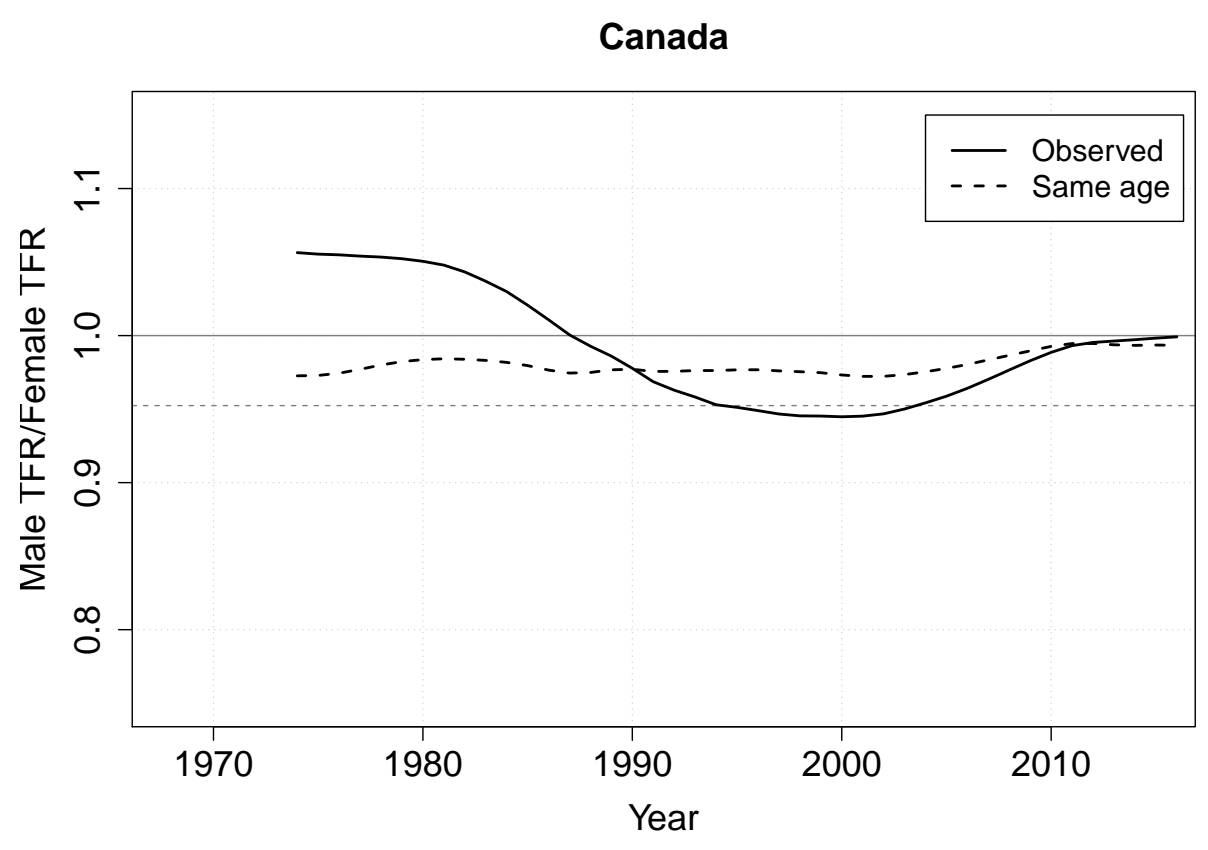

Figure B2: Hypothetical Male/Female TFR ratios in which fathers are assigned the maternal age at birth, Canada.

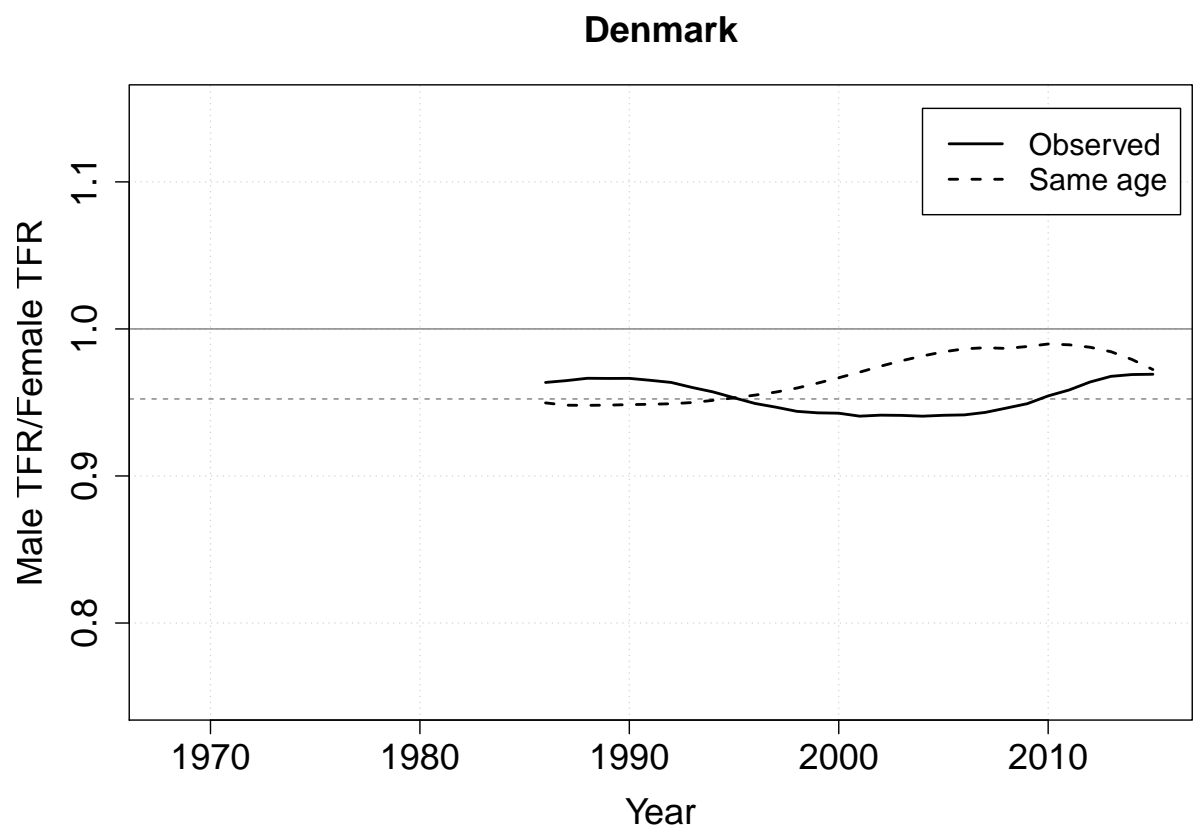

Figure B3: Hypothetical Male/Female TFR ratios in which fathers are assigned the maternal age at birth, Denmark. 


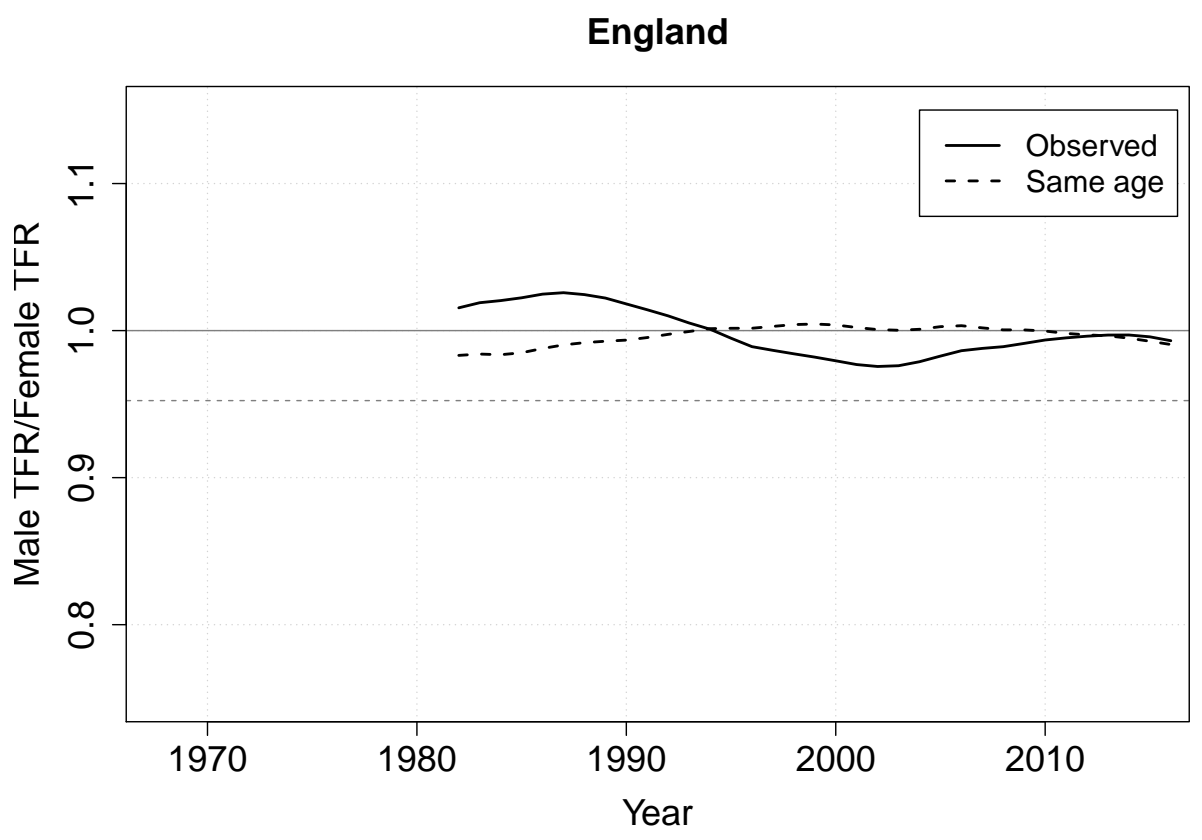

Figure B4: Hypothetical Male/Female TFR ratios in which fathers are assigned the maternal age at birth, England.

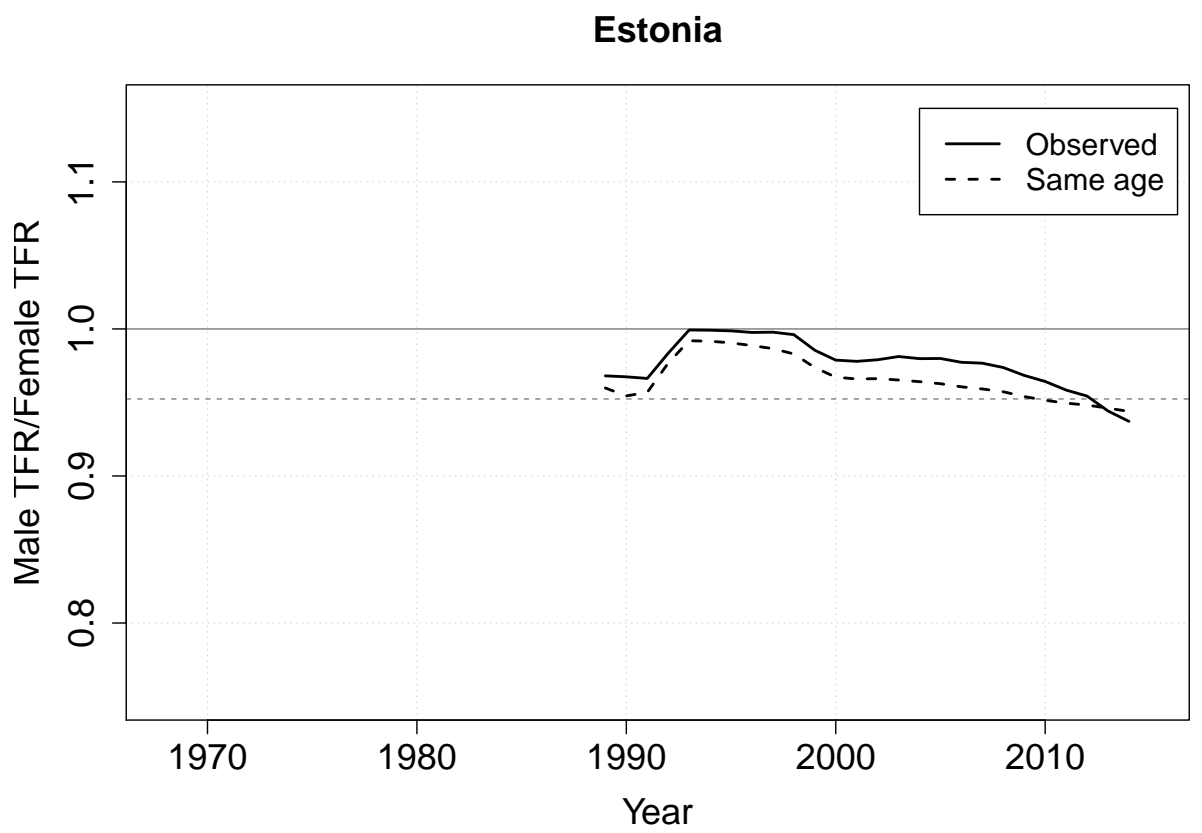

Figure B5: Hypothetical Male/Female TFR ratios in which fathers are assigned the maternal age at birth, Estonia. 


\section{Finland}

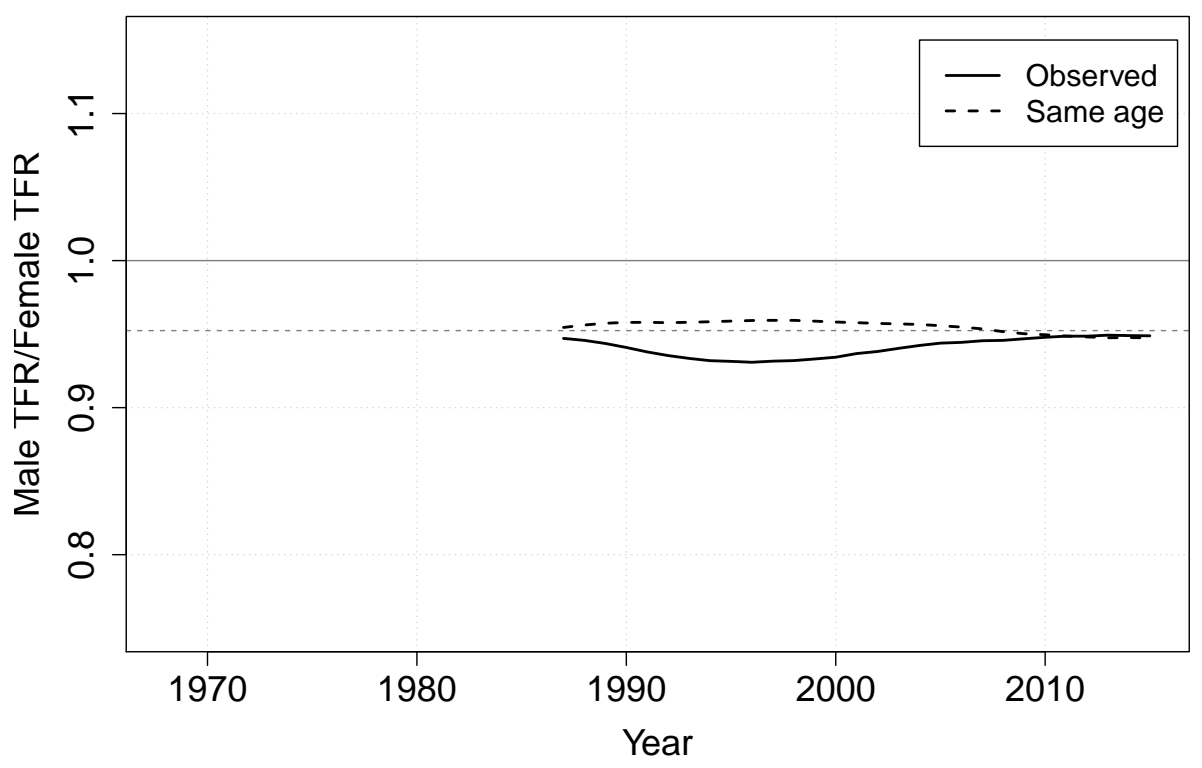

Figure B6: Hypothetical Male/Female TFR ratios in which fathers are assigned the maternal age at birth, Finland.

France

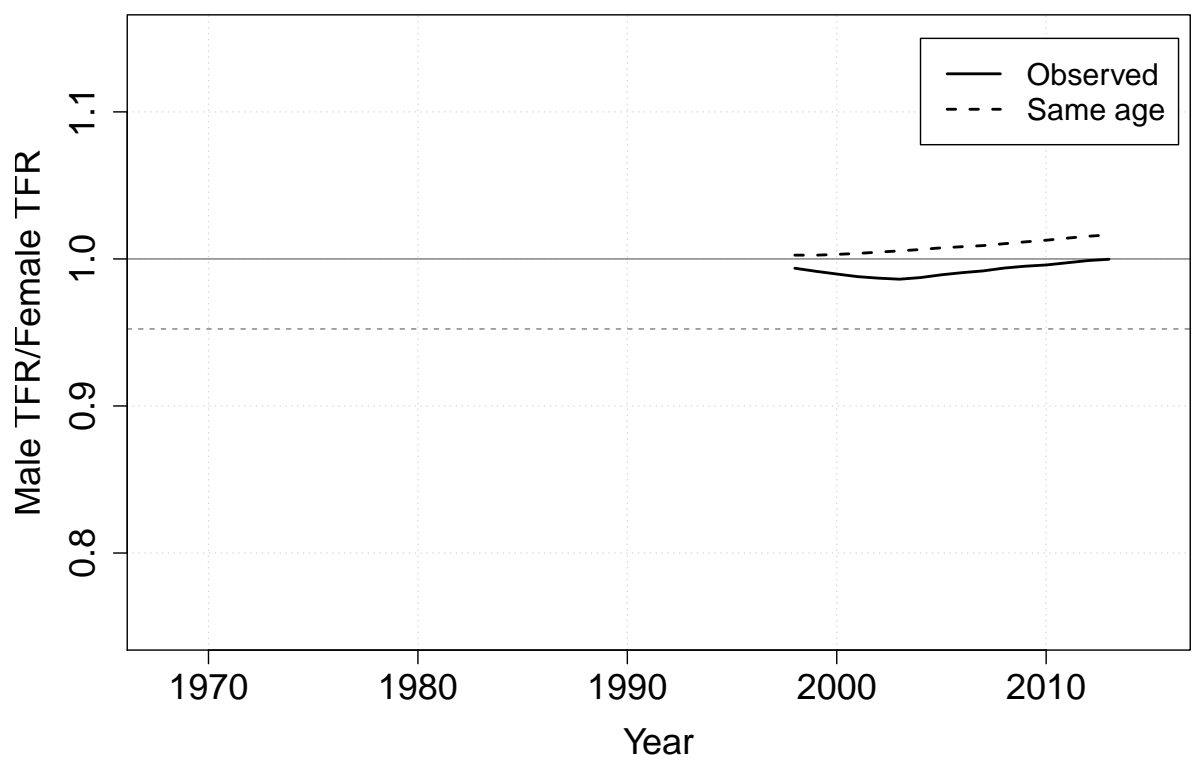

Figure B7: Hypothetical Male/Female TFR ratios in which fathers are assigned the maternal age at birth, France. 


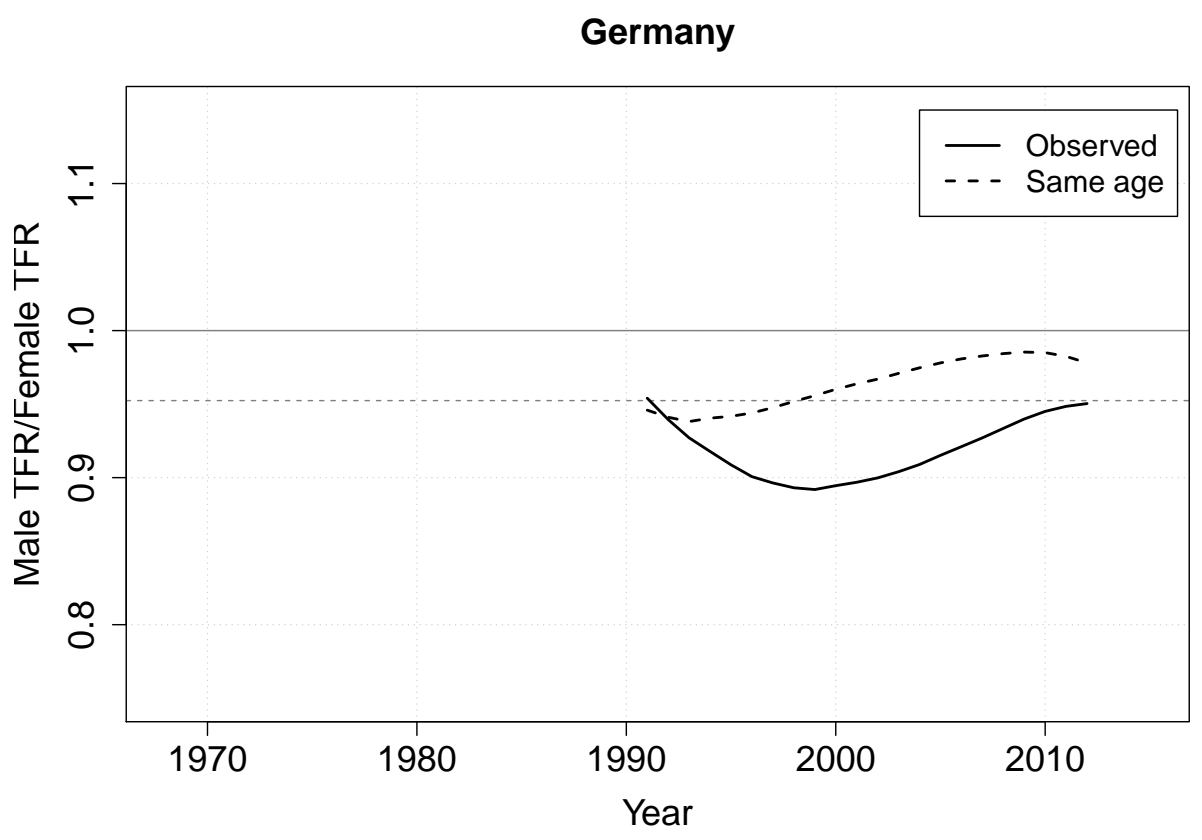

Figure B8: Hypothetical Male/Female TFR ratios in which fathers are assigned the maternal age at birth, Germany.

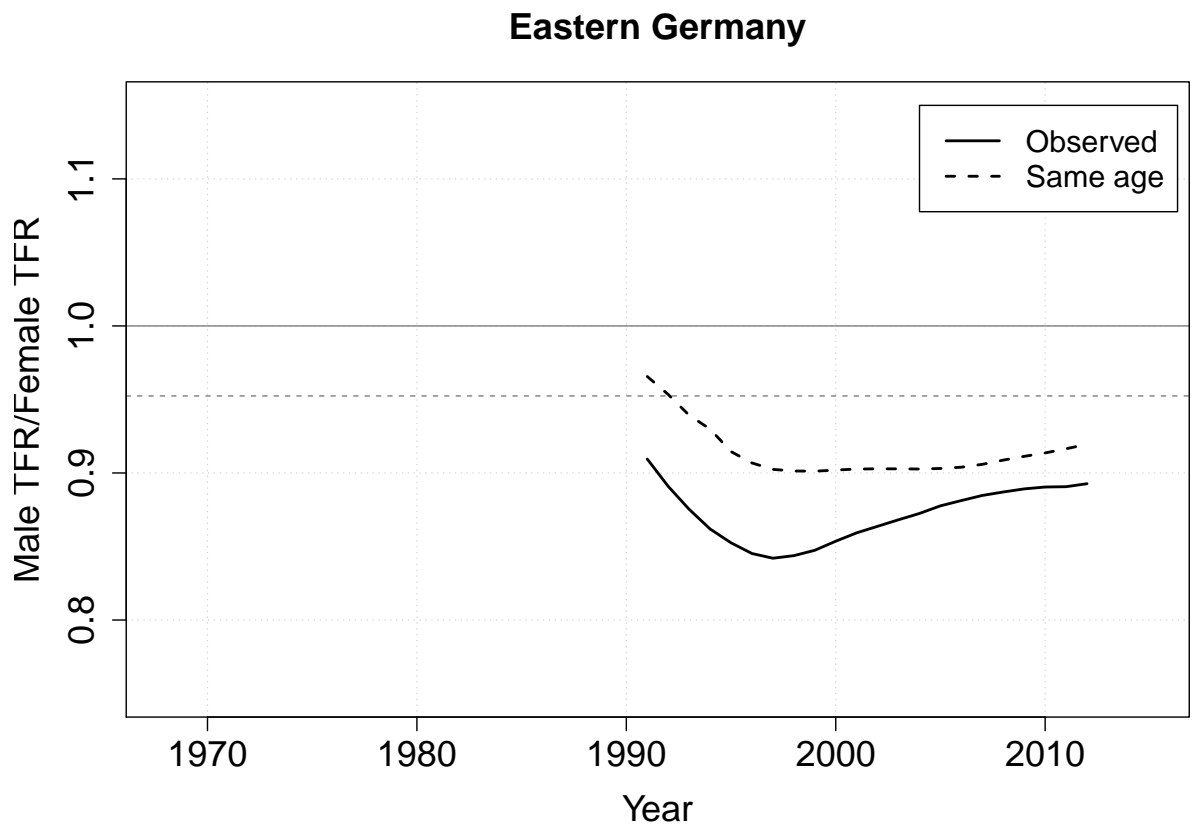

Figure B9: Hypothetical Male/Female TFR ratios in which fathers are assigned the maternal age at birth, eastern Germany. 


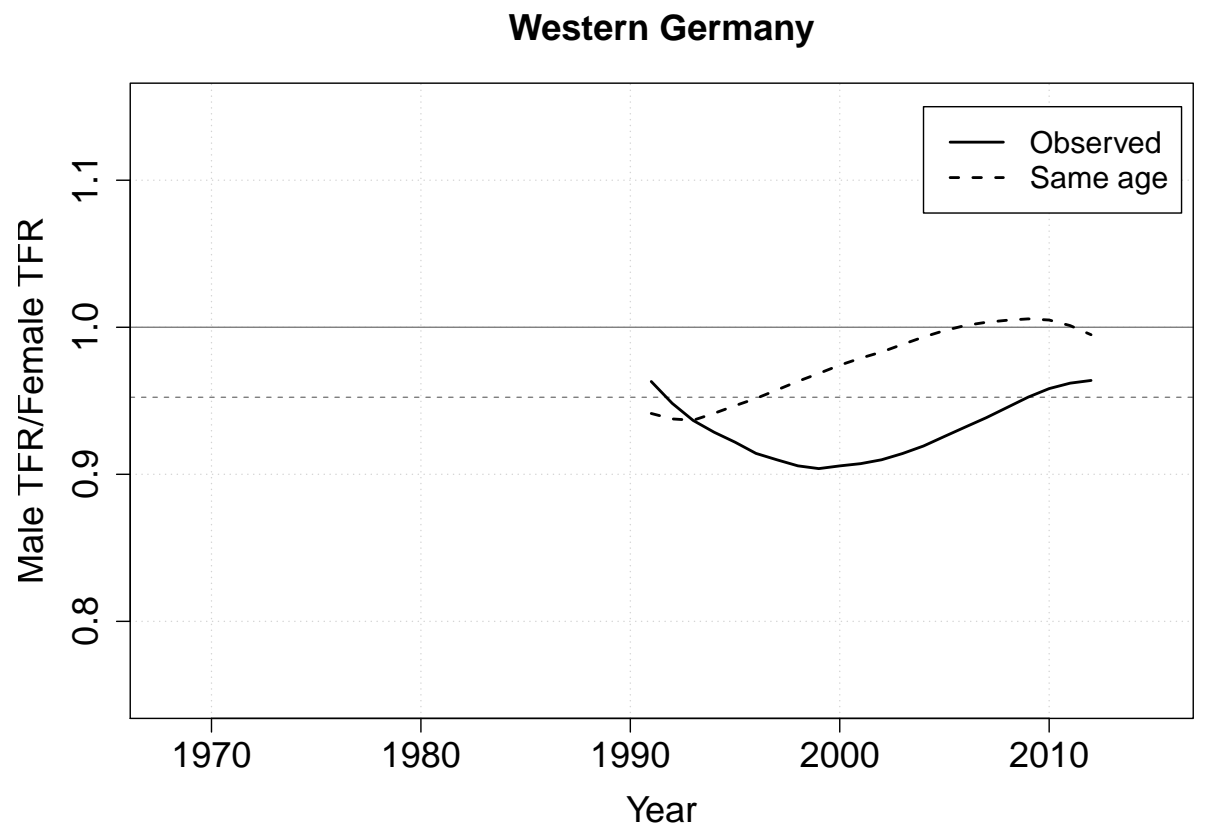

Figure B10: Hypothetical Male/Female TFR ratios in which fathers are assigned the maternal age at birth, western Germany. 


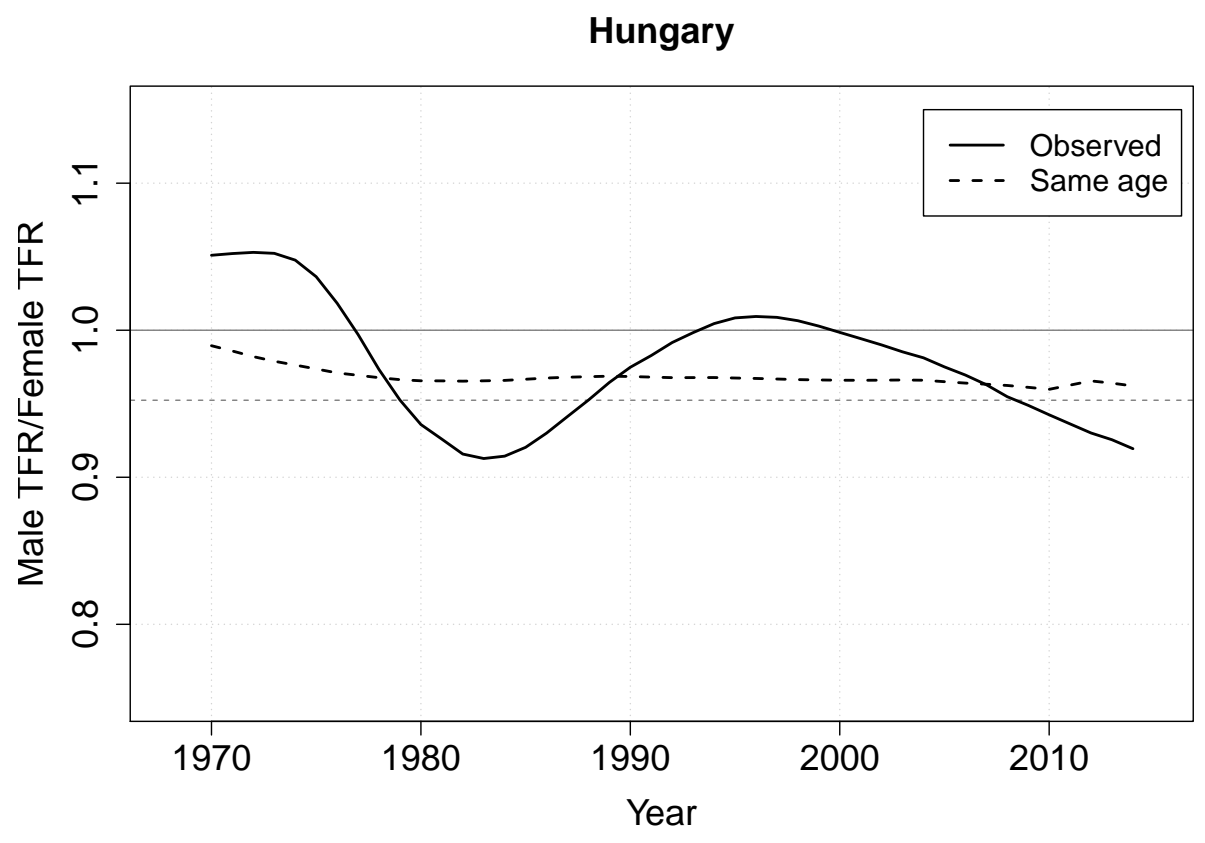

Figure B11: Hypothetical Male/Female TFR ratios in which fathers are assigned the maternal age at birth, Hungary.

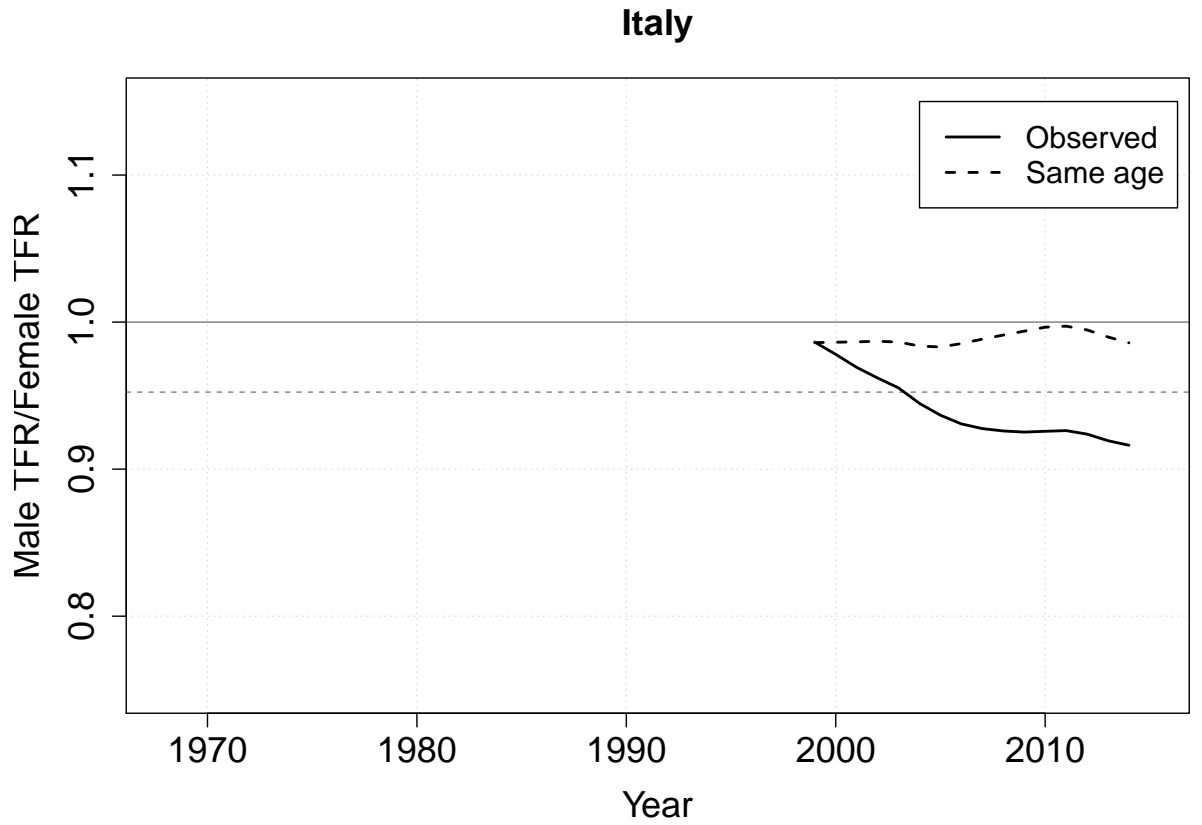

Figure B12: Hypothetical Male/Female TFR ratios in which fathers are assigned the maternal age at birth, Italy. 


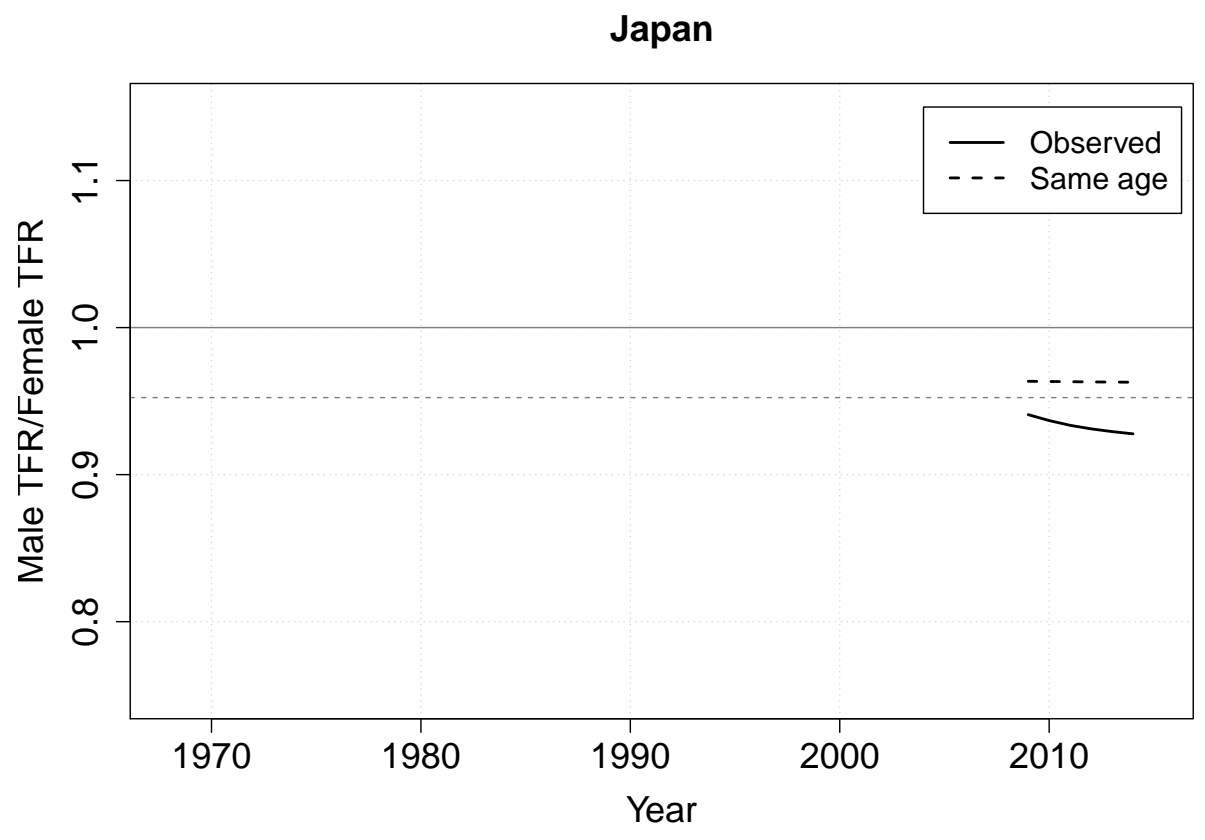

Figure B13: Hypothetical Male/Female TFR ratios in which fathers are assigned the maternal age at birth, Japan.

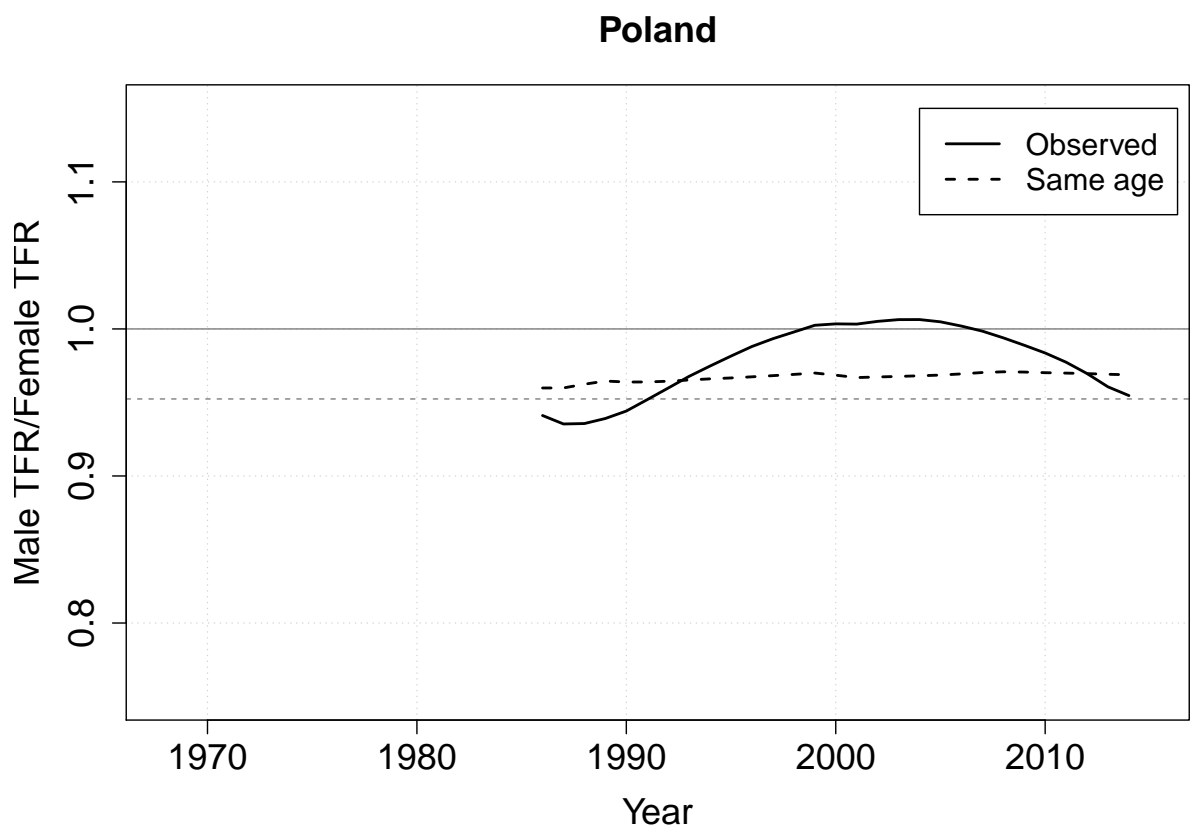

Figure B14: Hypothetical Male/Female TFR ratios in which fathers are assigned the maternal age at birth, Poland. 


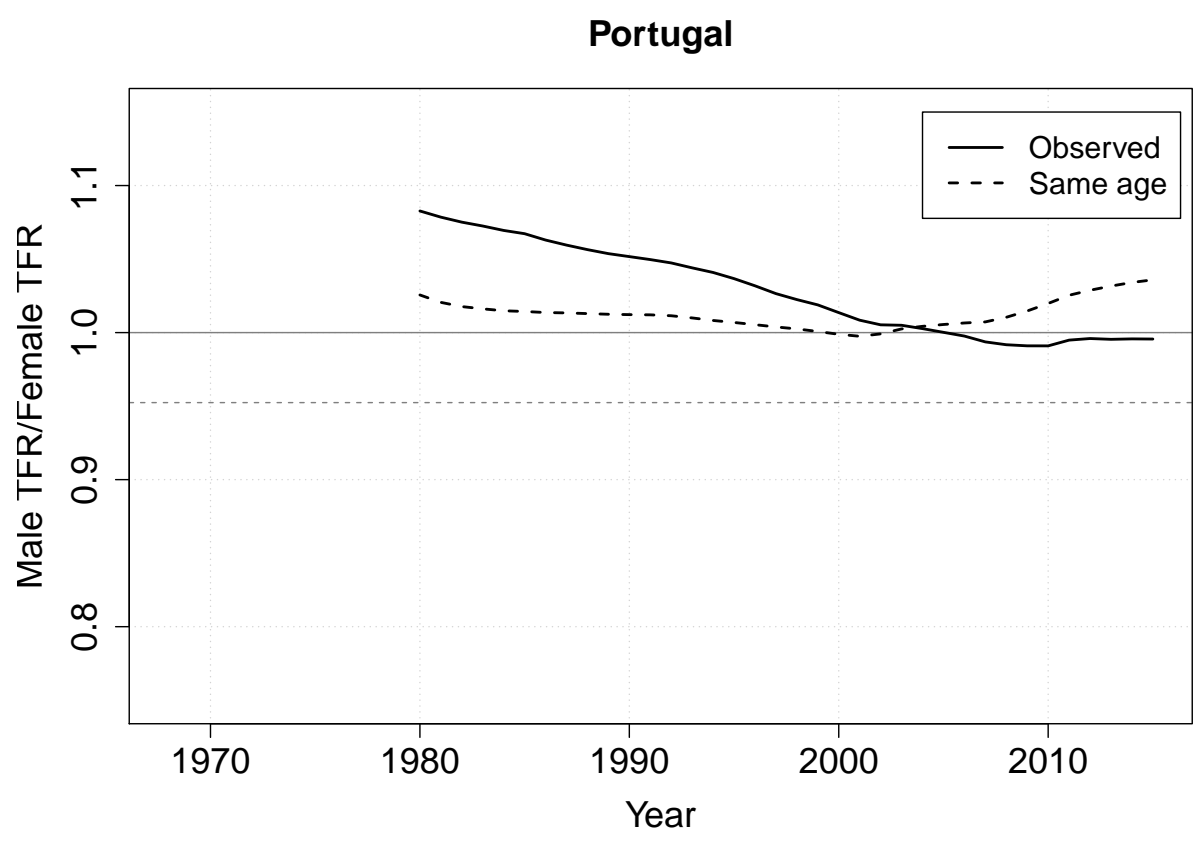

Figure B15: Hypothetical Male/Female TFR ratios in which fathers are assigned the maternal age at birth, Portugal.

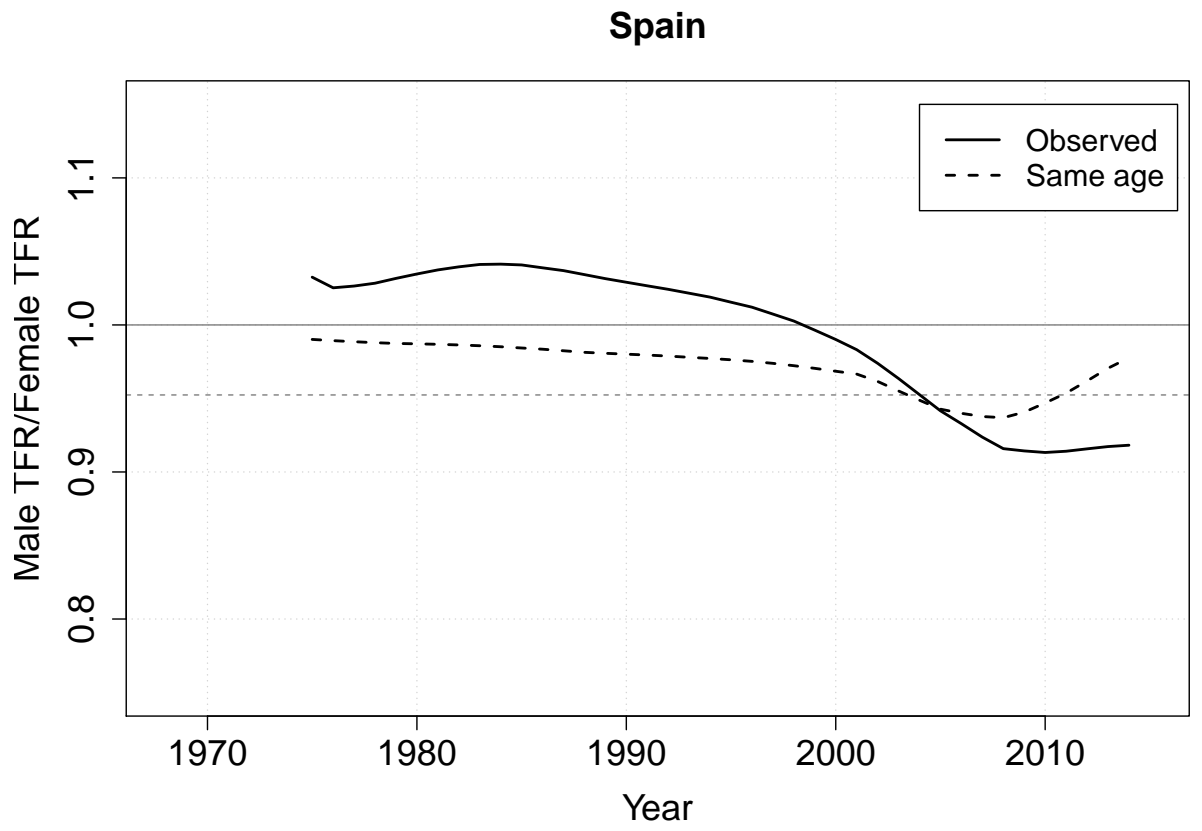

Figure B16: Hypothetical Male/Female TFR ratios in which fathers are assigned the maternal age at birth, Spain. 


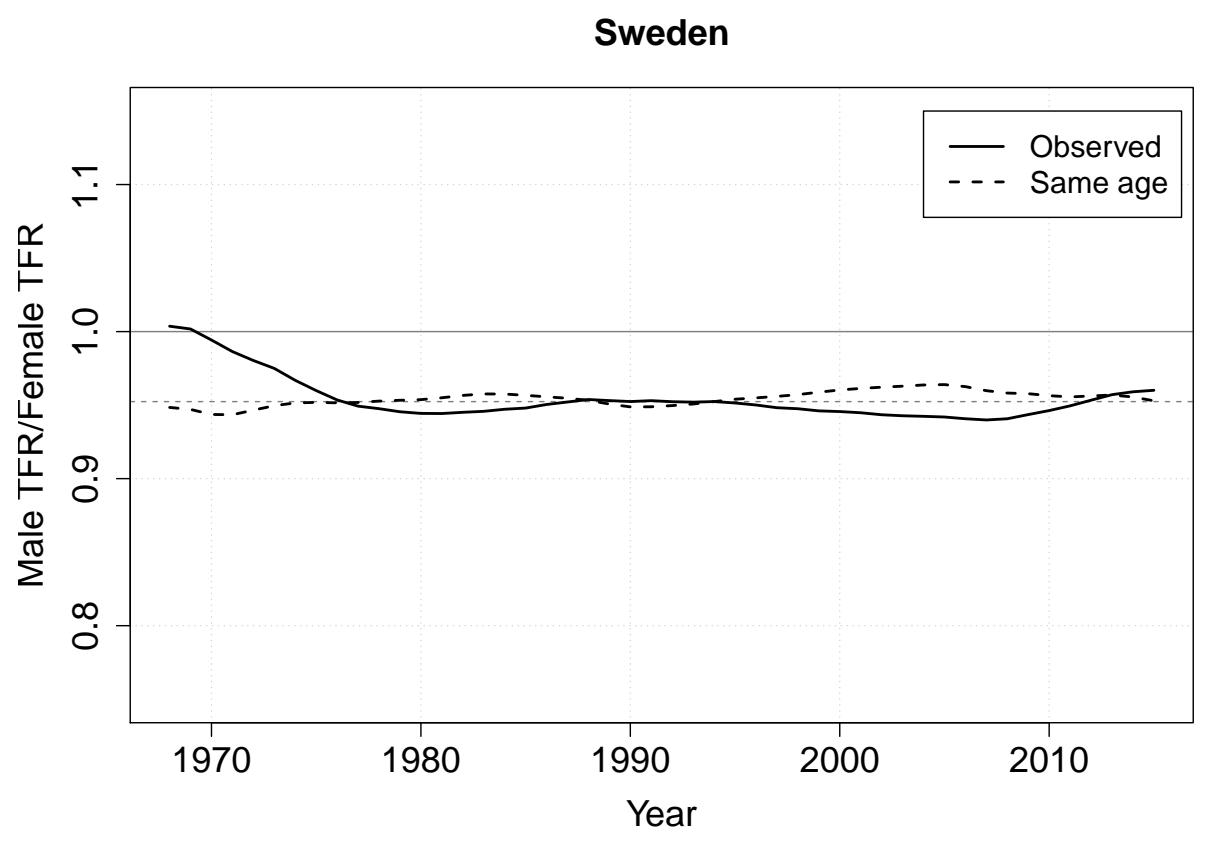

Figure B17: Hypothetical Male/Female TFR ratios in which fathers are assigned the maternal age at birth, Sweden.

Taiwan

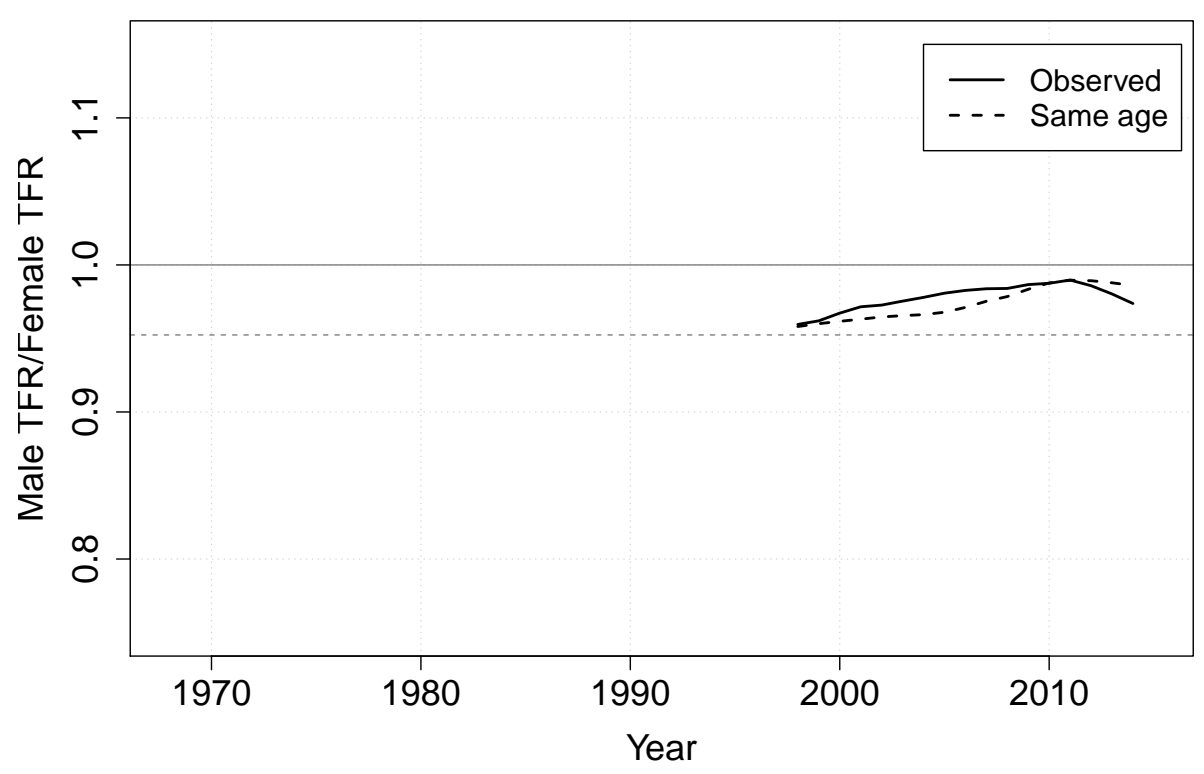

Figure B18: Hypothetical Male/Female TFR ratios in which fathers are assigned the maternal age at birth, Taiwan. 


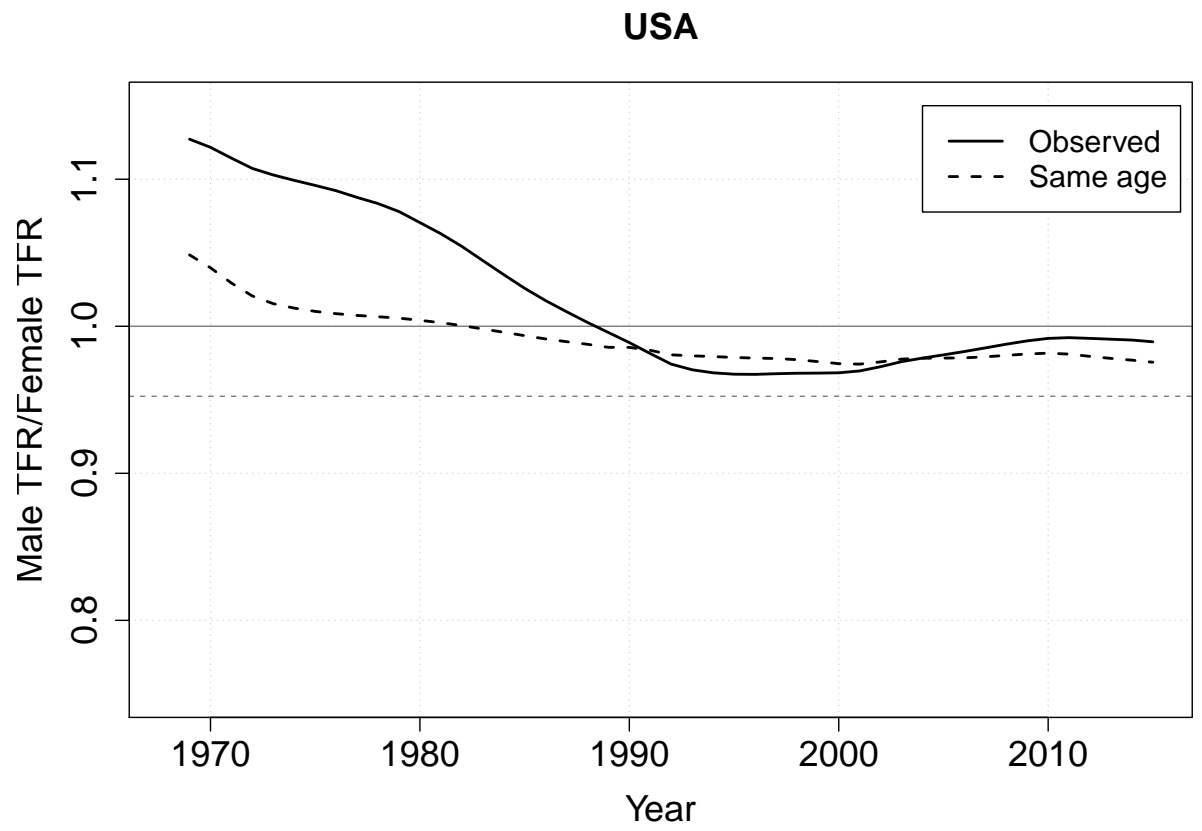

Figure B19: Hypothetical Male/Female TFR ratios in which fathers are assigned the maternal age at birth, USA. 


\section{Mean age at childbirth by country and gender}

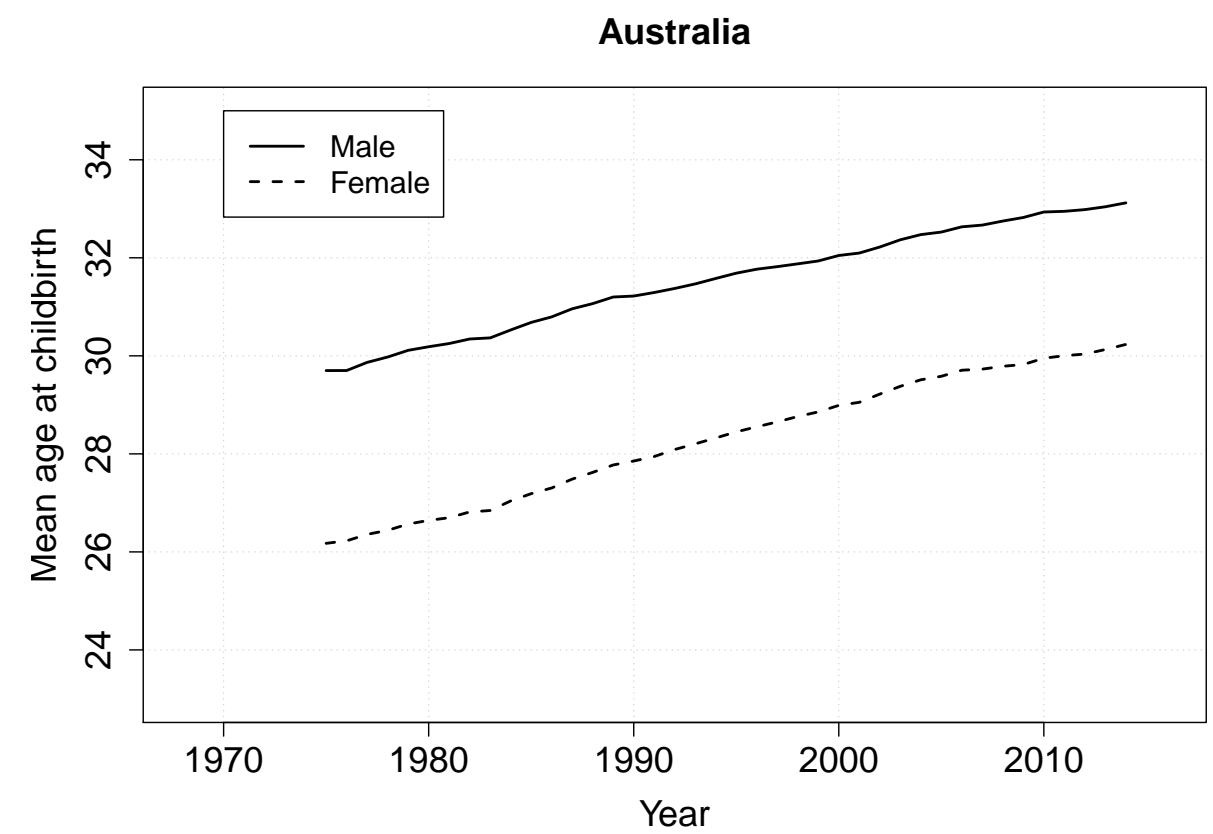

Figure $\mathrm{C} 1$ : Mean age at childbirth by gender, Australia.

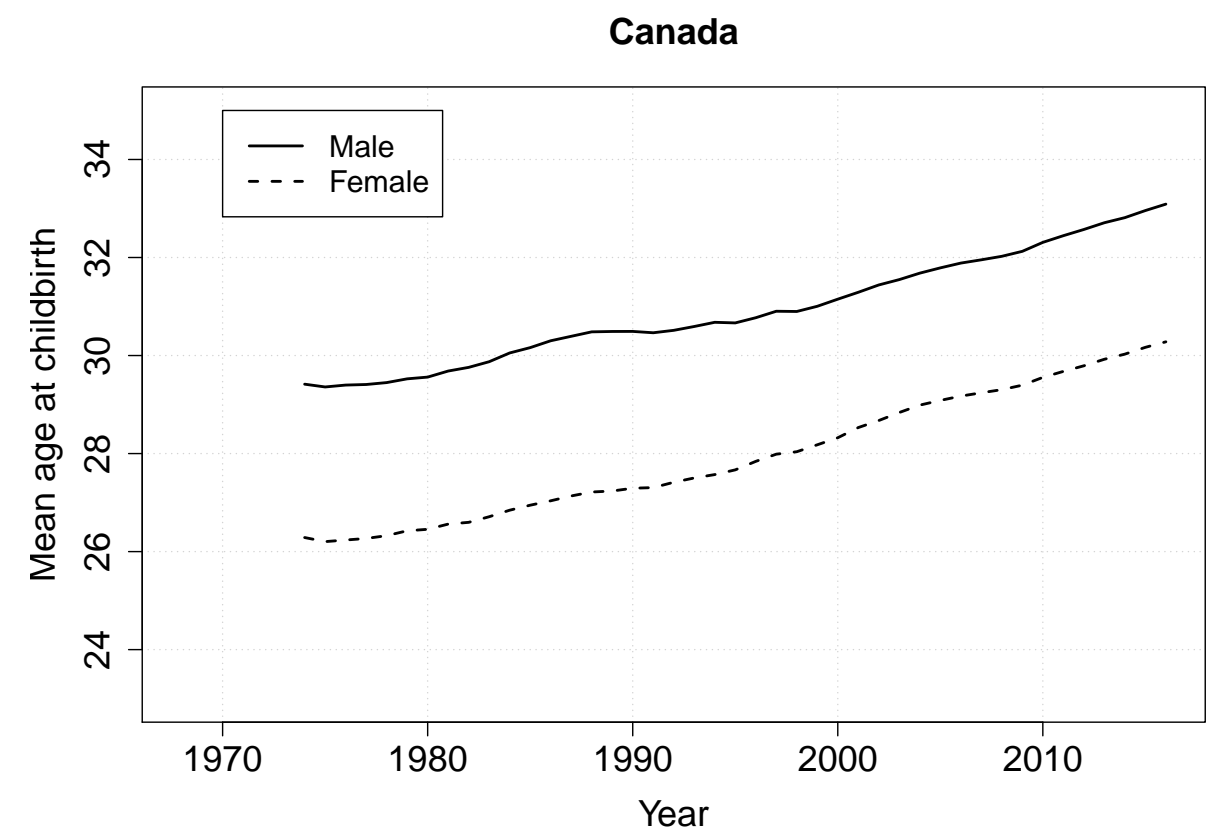

Figure C2: Mean age at childbirth by gender, Canada. 


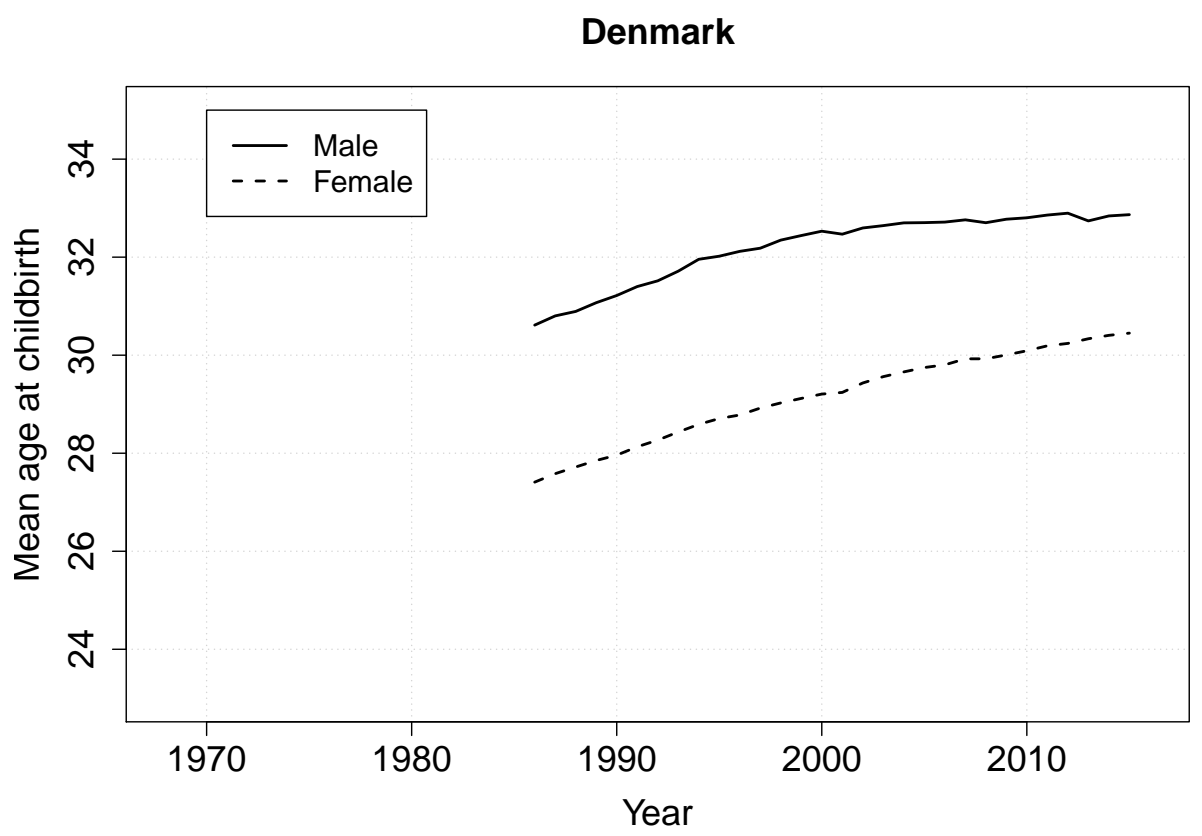

Figure C3: Mean age at childbirth by gender, Denmark.

\section{England}

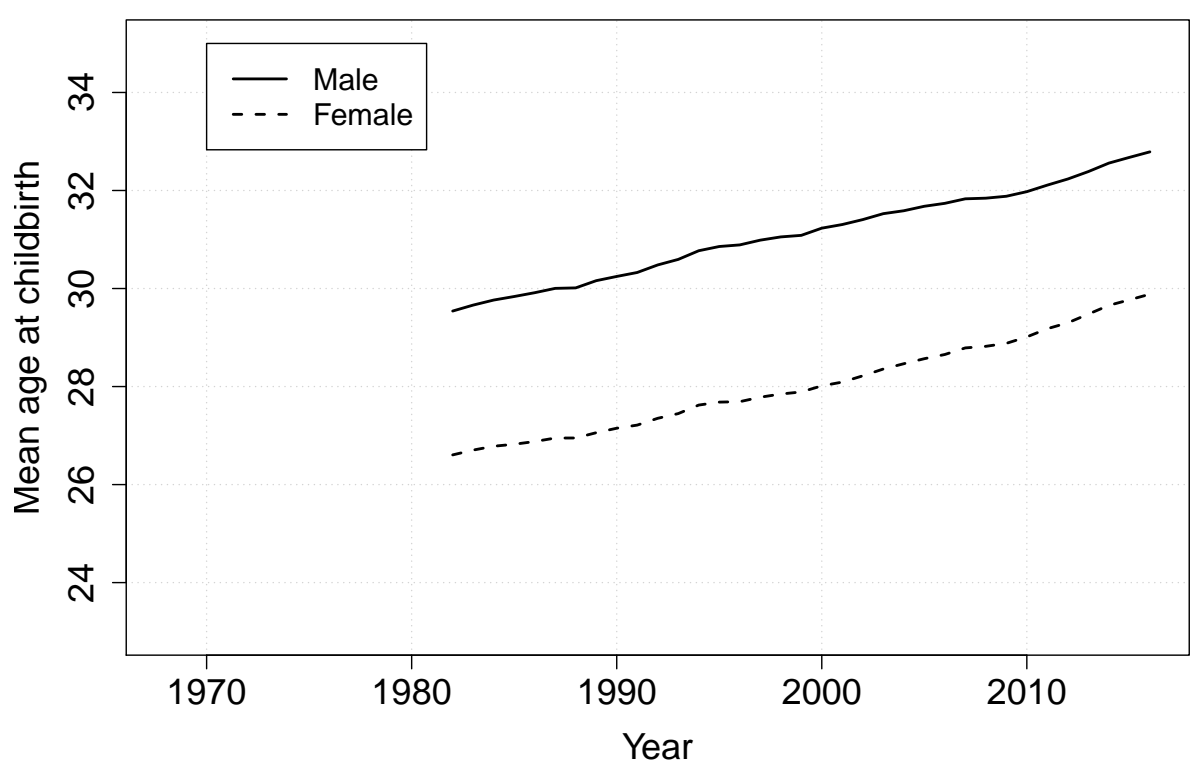

Figure C4: Mean age at childbirth by gender, England. 


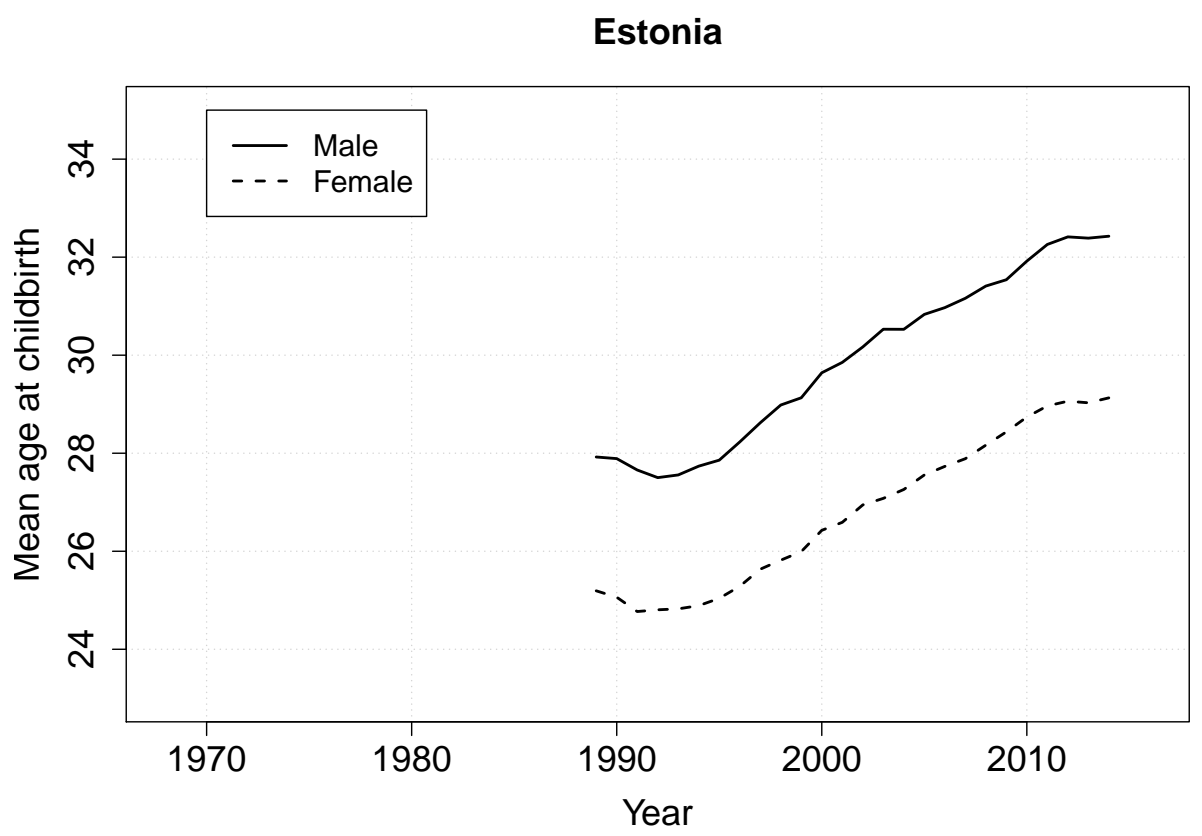

Figure C5: Mean age at childbirth by gender, Estonia.

\section{Finland}

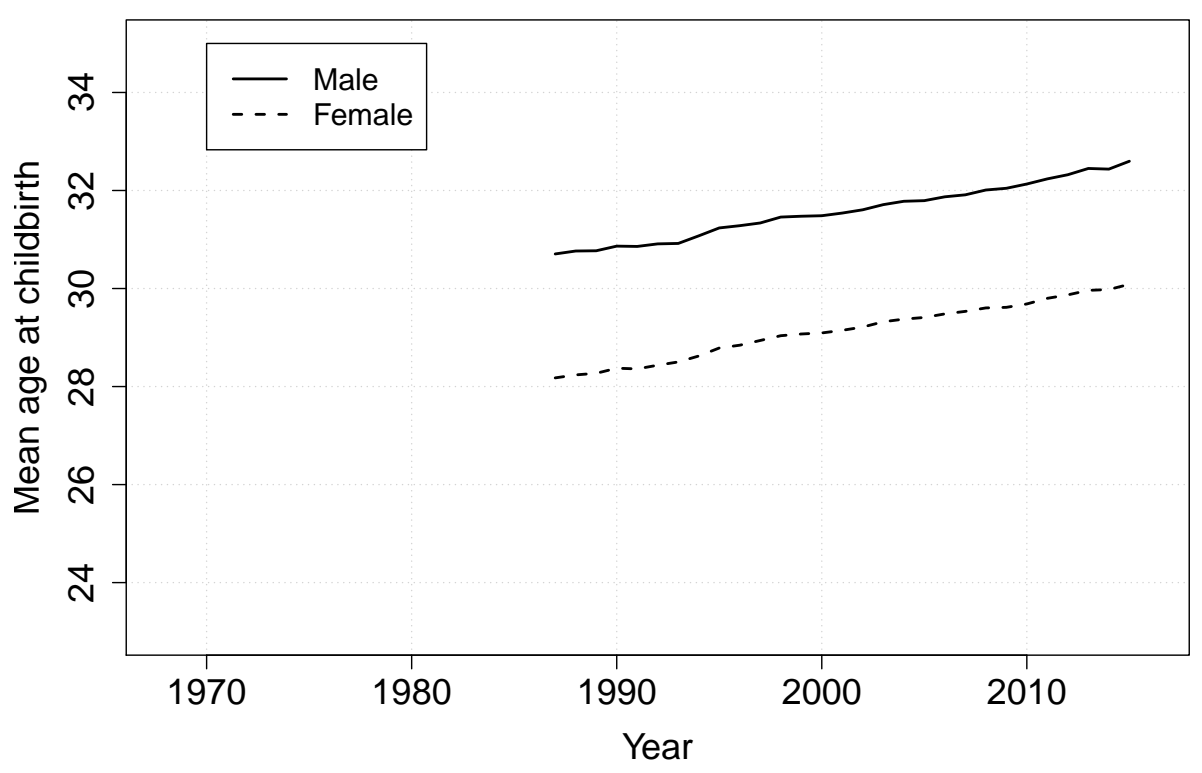

Figure C6: Mean age at childbirth by gender, Finland. 


\section{France}

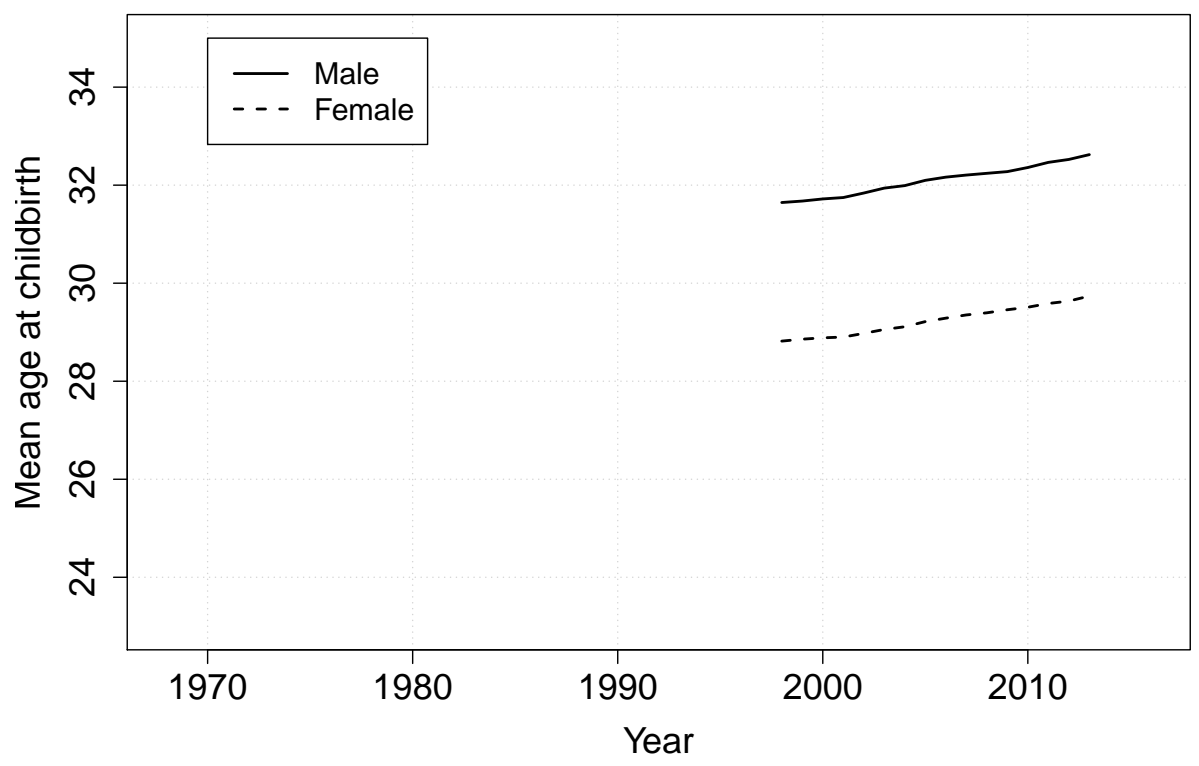

Figure C7: Mean age at childbirth by gender, France.

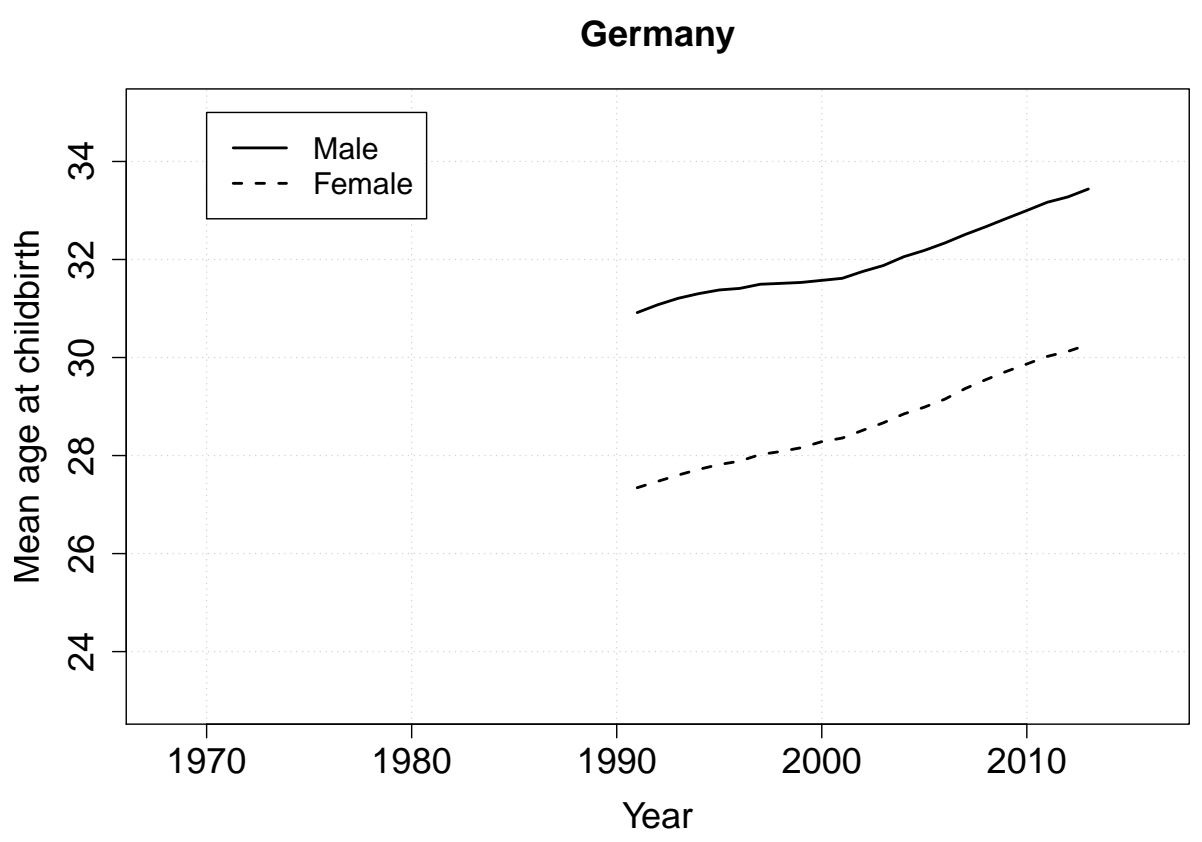

Figure C8: Mean age at childbirth by gender, Germany. 


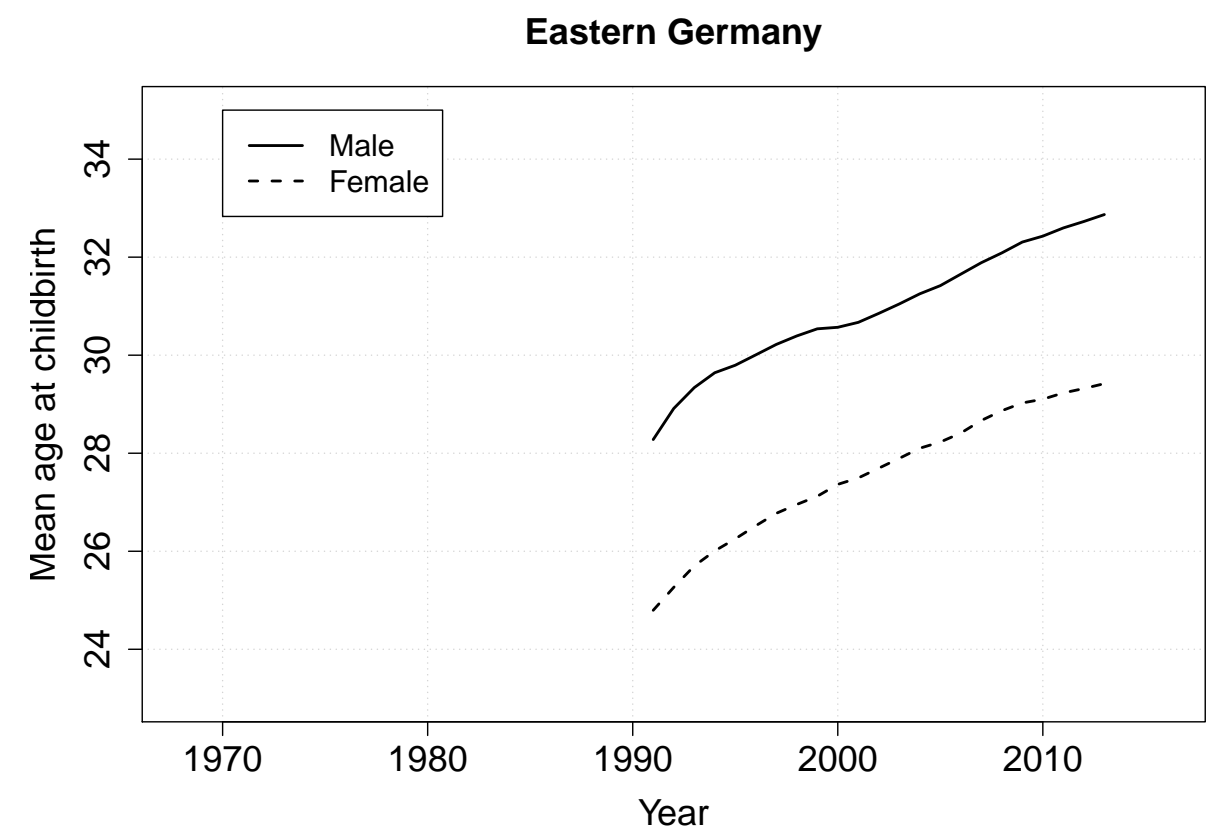

Figure C9: Mean age at childbirth by gender, eastern Germany.

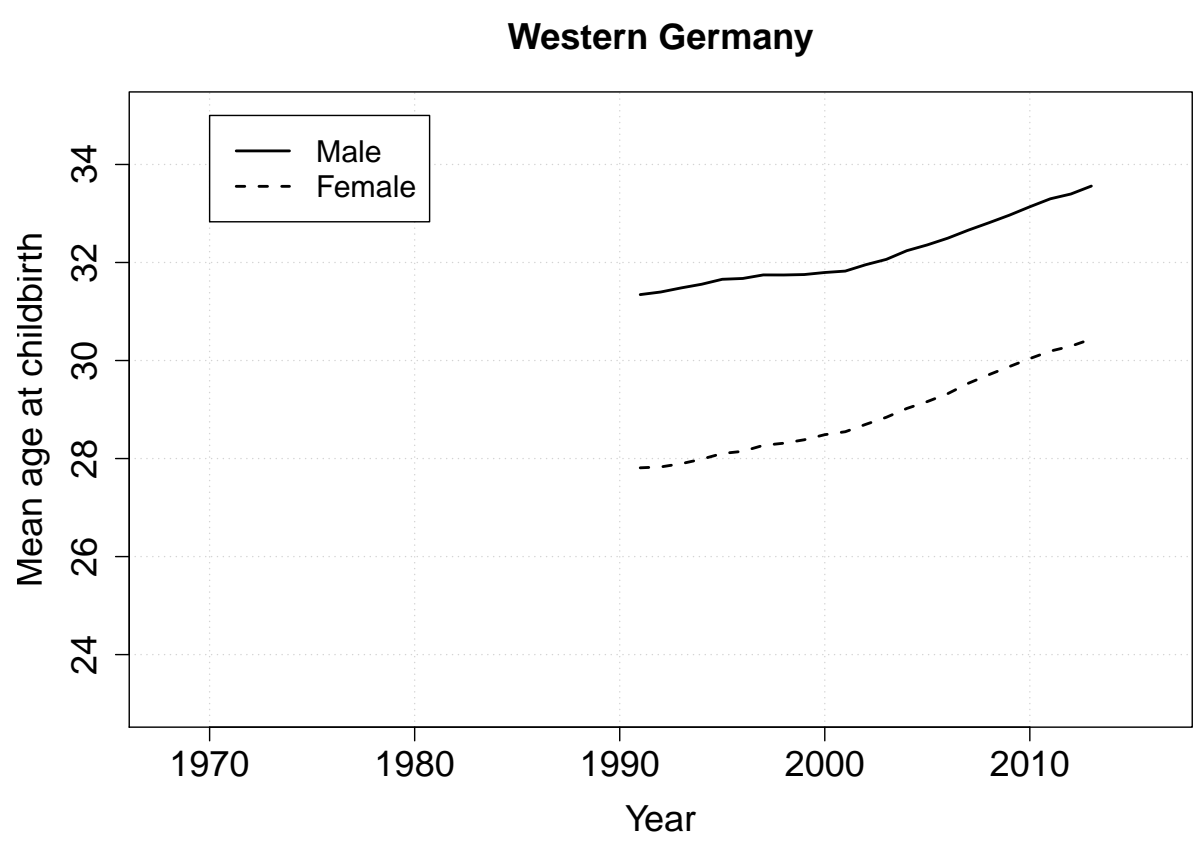

Figure C10: Mean age at childbirth by gender, western Germany. 


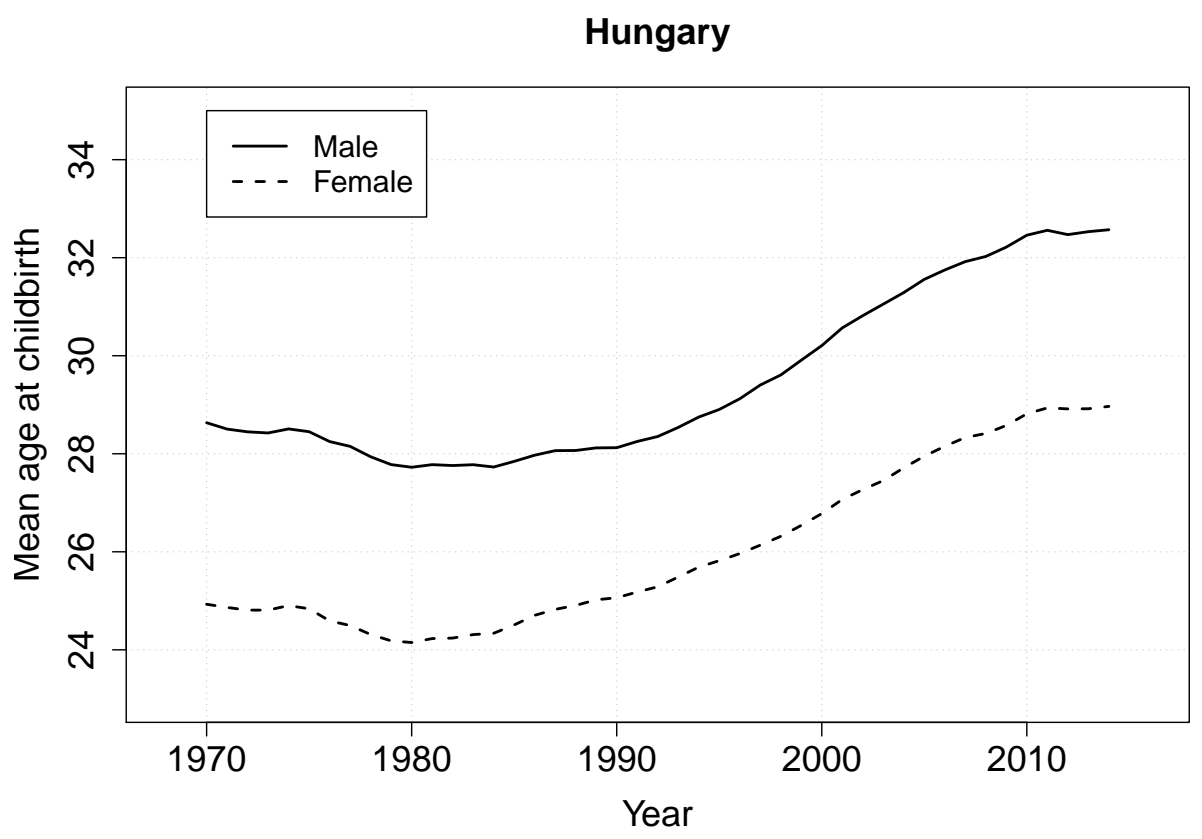

Figure C11: Mean age at childbirth by gender, Hungary.

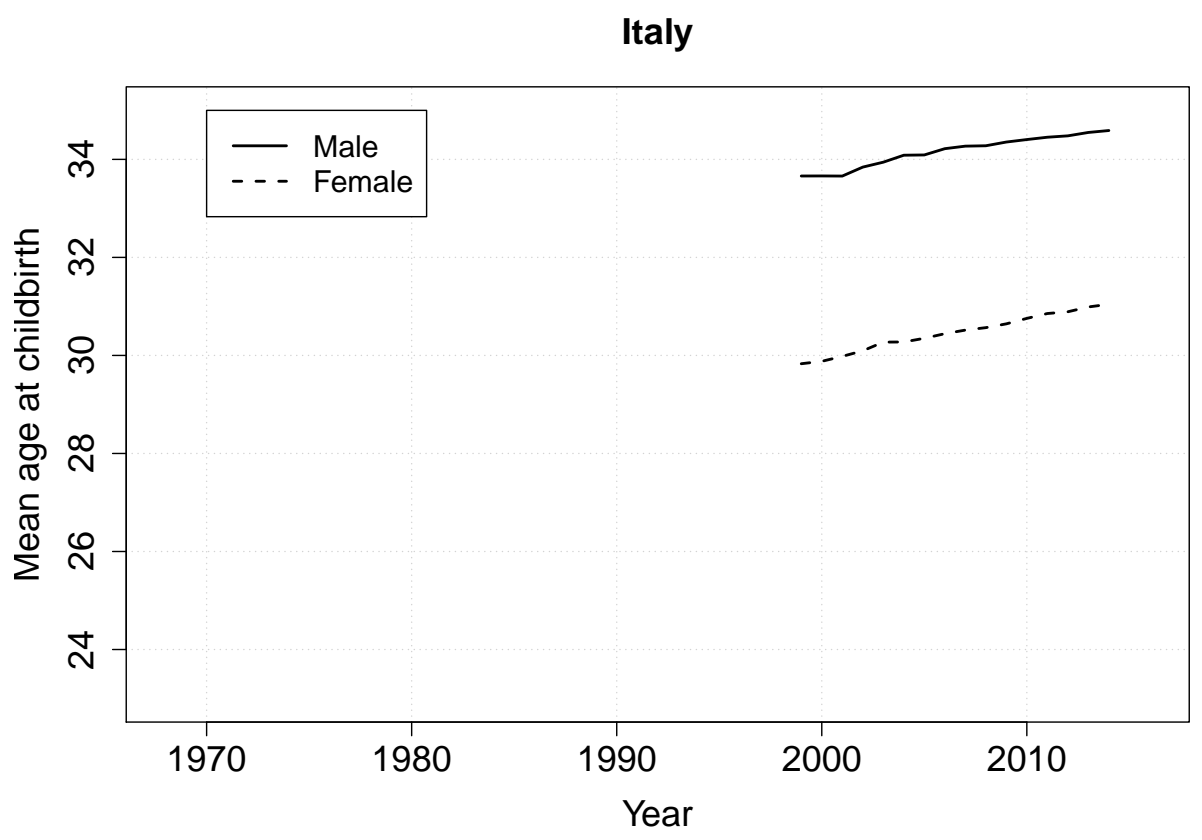

Figure C12: Mean age at childbirth by gender, Italy. 


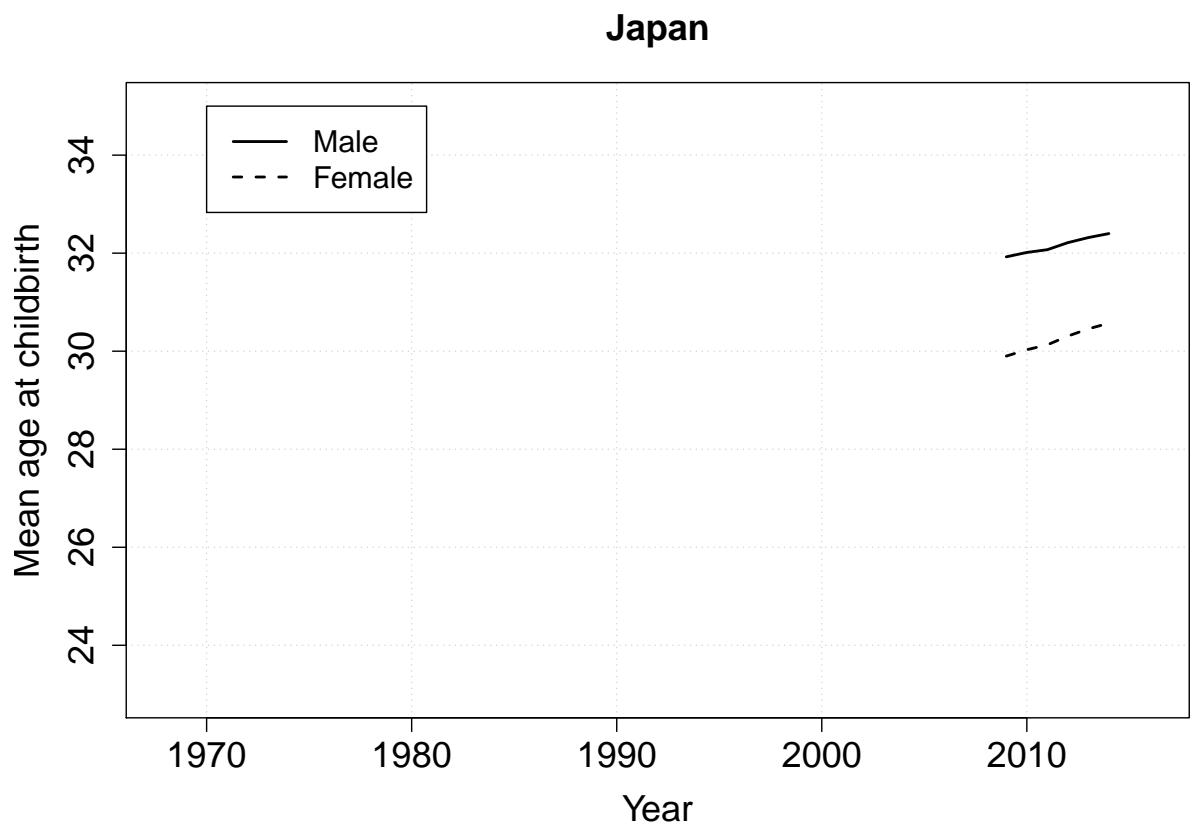

Figure C13: Mean age at childbirth by gender, Japan.

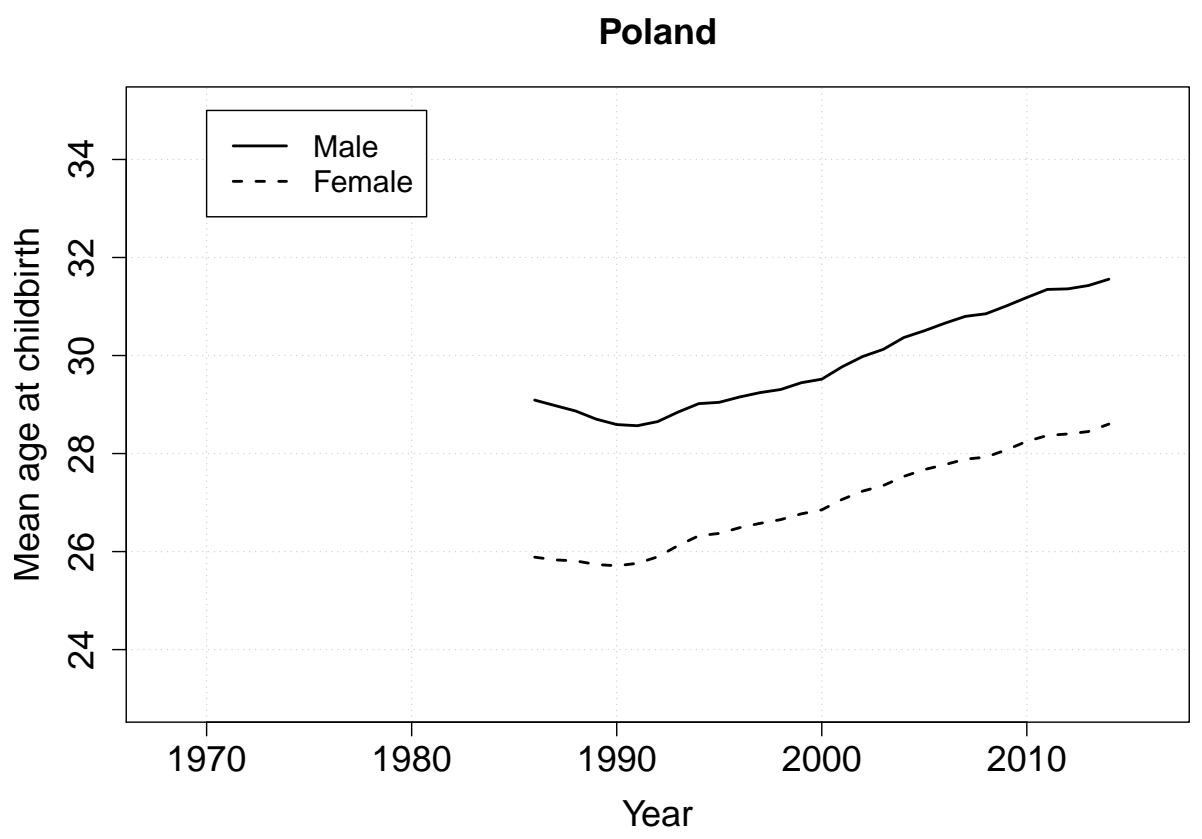

Figure C14: Mean age at childbirth by gender, Poland. 


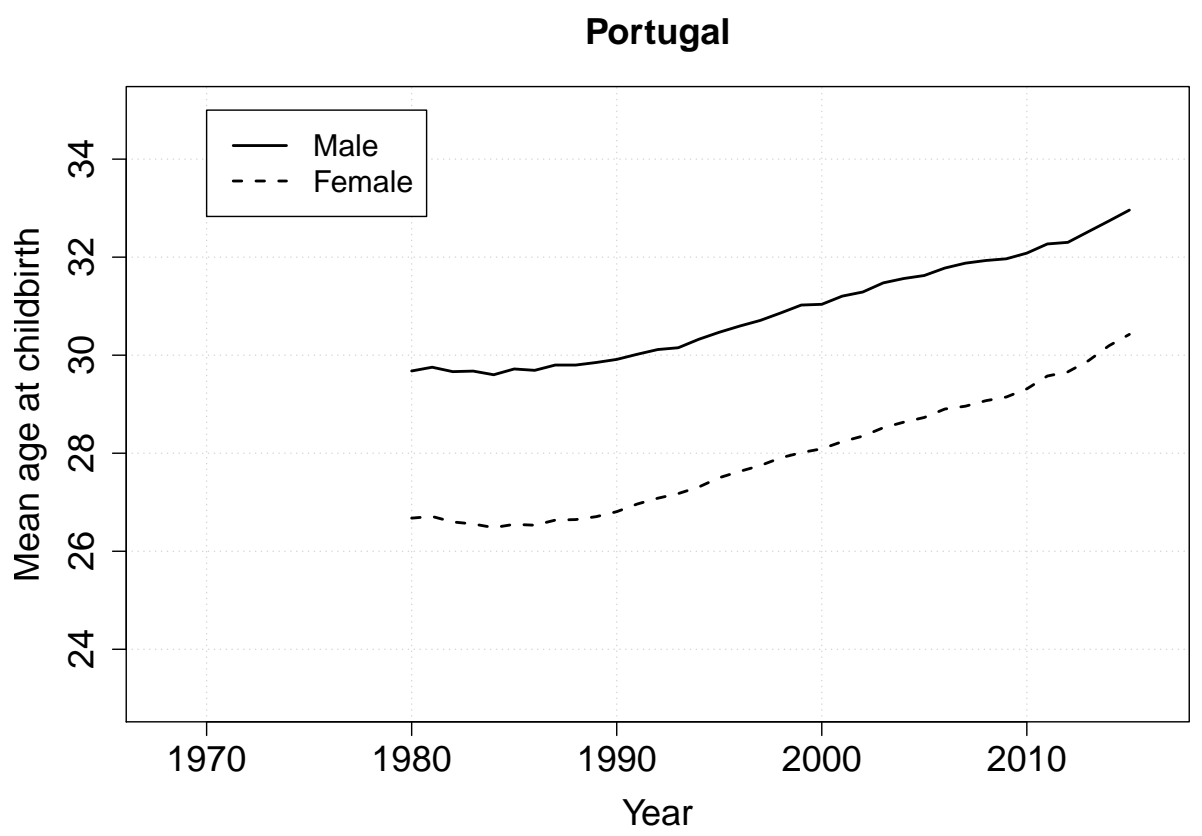

Figure C15: Mean age at childbirth by gender, Portugal.

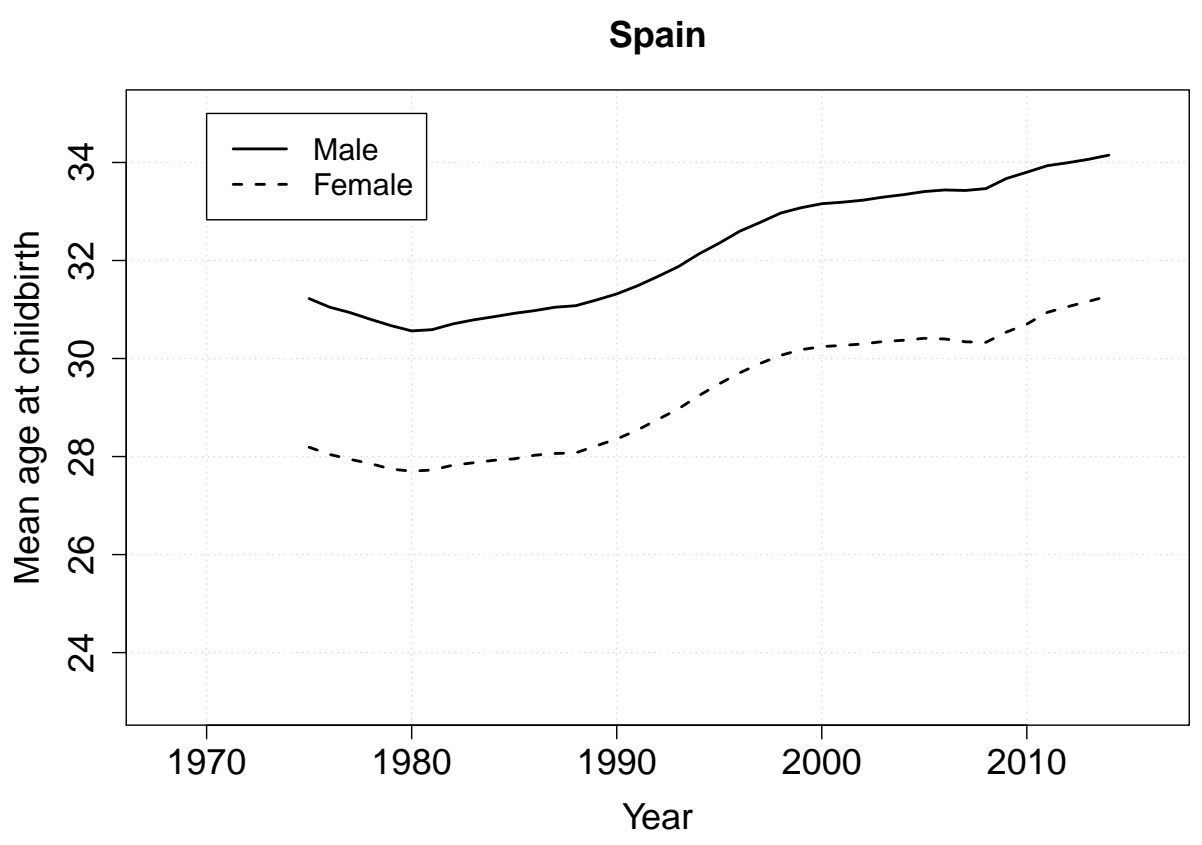

Figure C16: Mean age at childbirth by gender, Spain. 


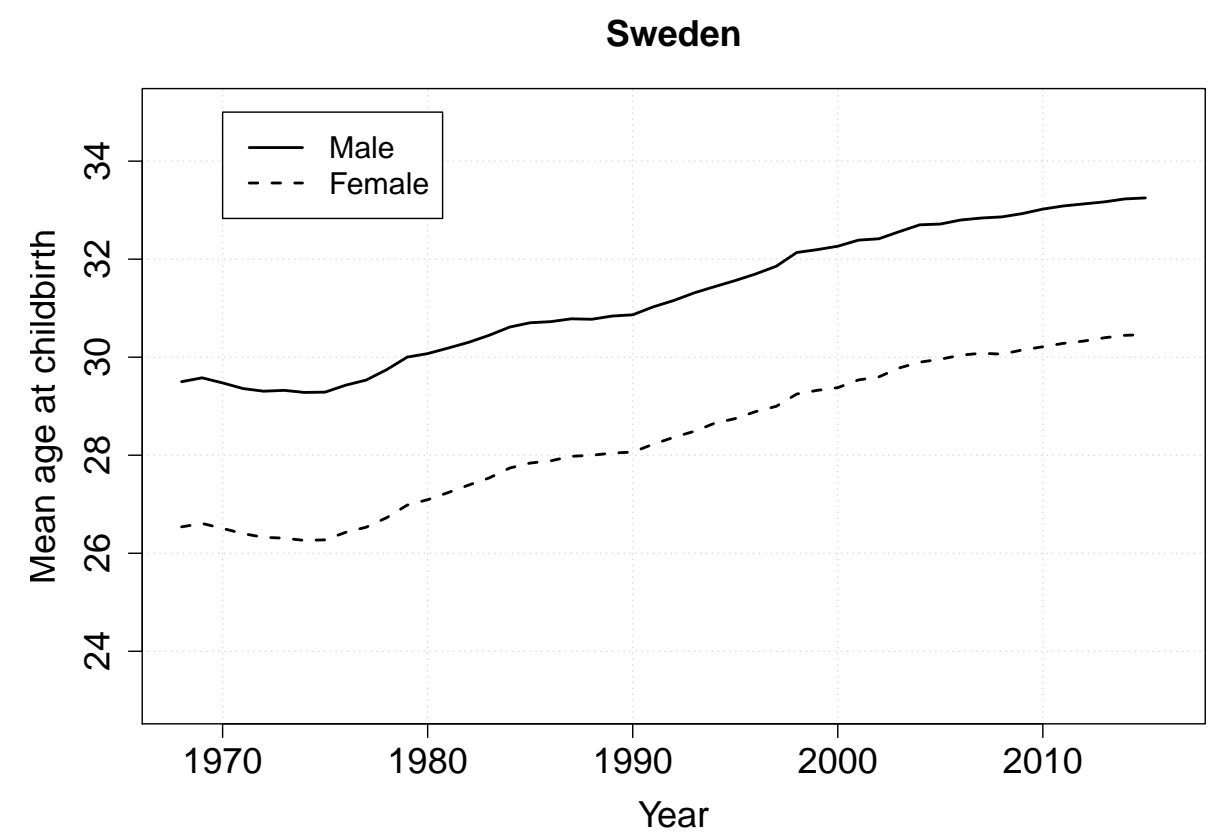

Figure C17: Mean age at childbirth by gender, Sweden.

\section{Taiwan}

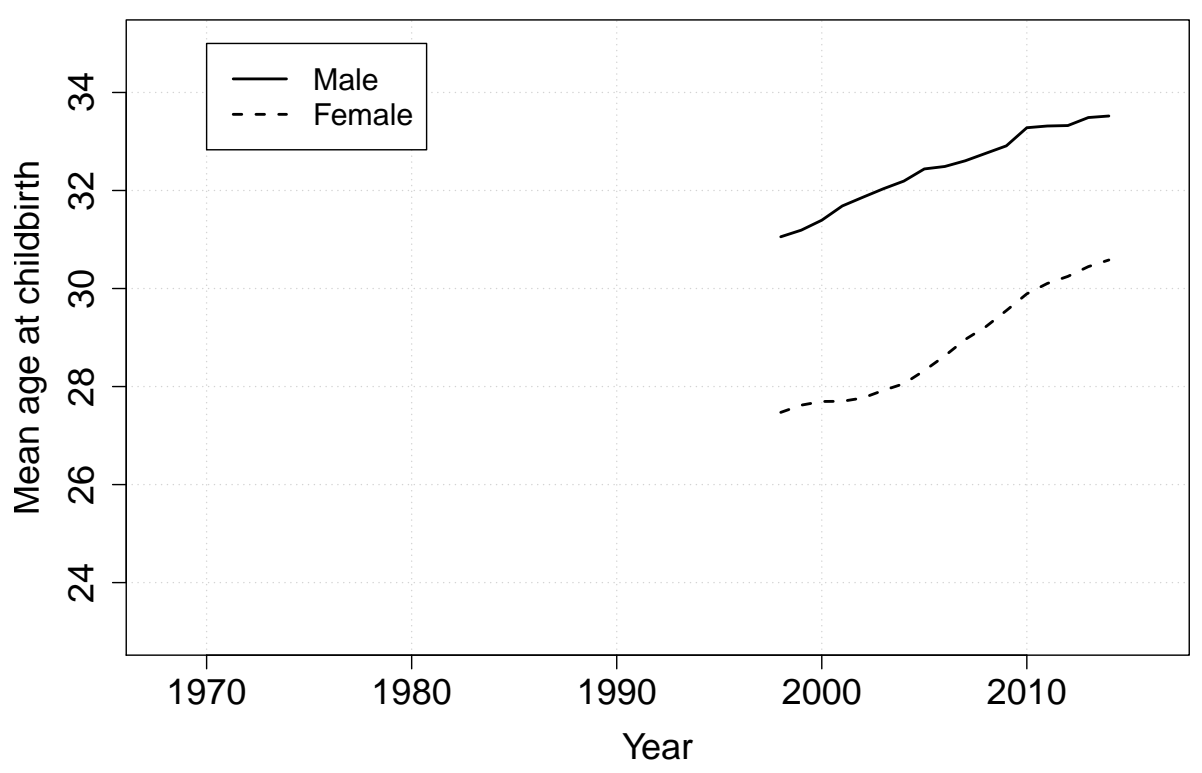

Figure C18: Mean age at childbirth by gender, Taiwan. 


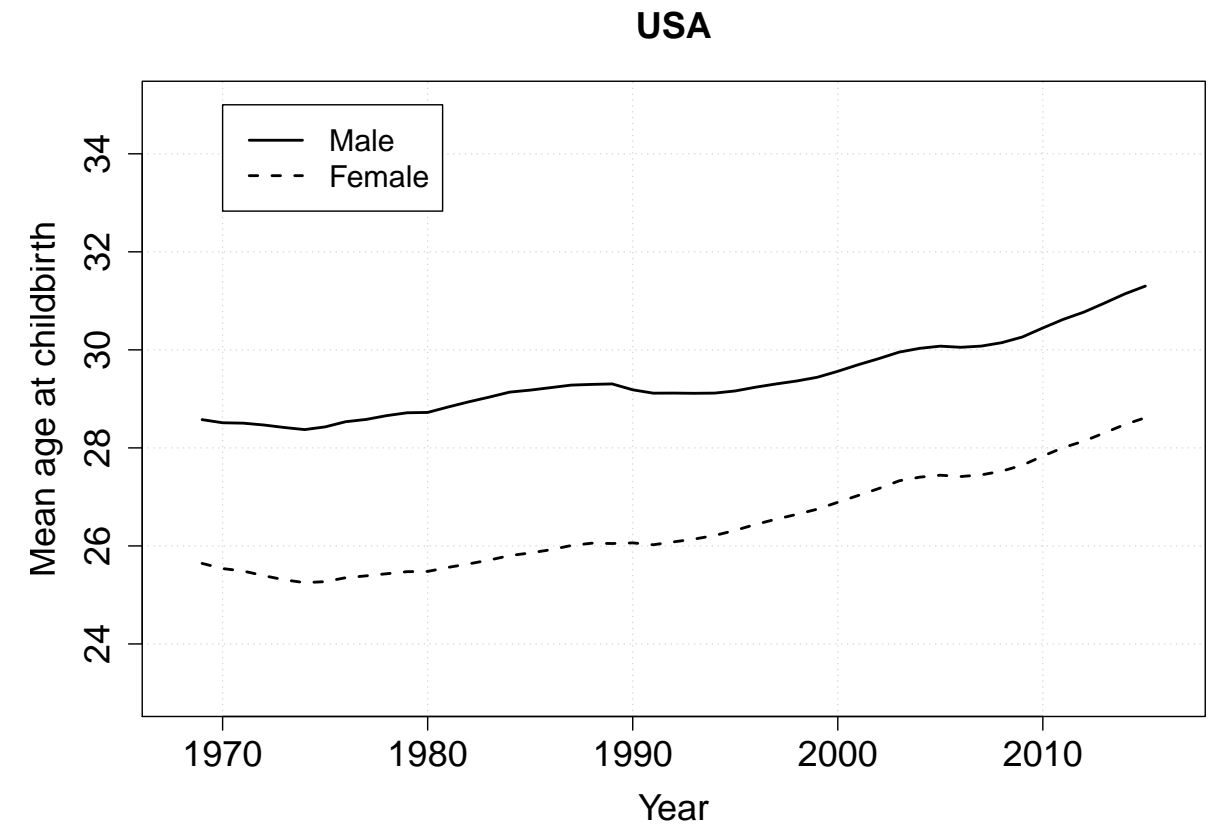

Figure C19: Mean age at childbirth by gender, USA. 